Florida International University

FIU Digital Commons

6-3-2019

\title{
How Organizational Cultures Moderate the Relationship between Demographic Diversity and Intragroup Conflict: A Meta-analysis
}

Ryan K. Jacobson

Florida International University, rjaco033@fiu.edu

Follow this and additional works at: https://digitalcommons.fiu.edu/etd

Part of the Psychology Commons

\section{Recommended Citation}

Jacobson, Ryan K., "How Organizational Cultures Moderate the Relationship between Demographic Diversity and Intragroup Conflict: A Meta-analysis" (2019). FIU Electronic Theses and Dissertations. 4266. https://digitalcommons.fiu.edu/etd/4266

This work is brought to you for free and open access by the University Graduate School at FIU Digital Commons. It has been accepted for inclusion in FIU Electronic Theses and Dissertations by an authorized administrator of FIU Digital Commons. For more information, please contact dcc@fiu.edu. 


\section{FLORIDA INTERNATIONAL UNIVERSITY}

Miami, Florida

\section{HOW ORGANIZATIONAL CULTURES MODERATE THE RELATIONSHIP BETWEEN DEMOGRAPHIC DIVERSITY AND INTRAGROUP CONFLICT: A META-ANALYSIS}

A dissertation submitted in partial fulfillment of the requirements for the degree of DOCTOR OF PHILOSOPHY

in

PSYCHOLOGY

by

Ryan Jacobson

2019 
To: $\quad$ Dean Michael R. Heithaus

College of Arts, Sciences and Education

This dissertation, written by Ryan Jacobson, and entitled How Organizational Cultures Moderate the Relationship Between Demographic Diversity and Intragroup Conflict: A Meta-Analysis, having been approved in respect to style and intellectual content, is referred to you for judgment.

We have read this thesis and recommend that it be approved.

Chockalingam Viswesvaran

Samantha Paustian-Underdahl

Valentina Bruk-Lee

Asia Eaton, Major Professor

Date of Defense: June 3, 2019

The dissertation of Ryan Jacobson is approved.

Dean Michael R. Heithaus College of Arts, Sciences and Education

Andrés G. Gil Vice President for Research and Economic Development and Dean of the University Graduate School

Florida International University, 2019 


\section{DEDICATION}

I dedicate this dissertation to my Father and Dr. Michael Stachiw. Without their encouragement, inspiration, and commitment the completion of this work would not have been possible. 


\begin{abstract}
OF THE DISSERTATION
HOW ORGANIZATIONAL CULTURES MODERATE THE RELATIONSHIP BETWEEN DEMOGRAPHIC DIVERSITY AND INTRAGROUP CONFLICT: A META-ANALYSIS

by

Ryan Jacobson
\end{abstract}

Florida International University, 2019

Miami, Florida

Professor Asia Eaton, Major Professor

Research suggests that as work groups become more demographically diverse, they are more likely to experience relationship and task conflict (Barak, 2016; $\underline{\text { Holck, }}$ Muhr, \& Villeseche, 2016; Mohammed \& Angell, 2004). In an increasingly diverse, global workforce, one way to mitigate this conflict might be to promote organizational cultures that support group harmony and respect, such as team-oriented culture (Galinsky et al., 2015; Lambert, 2016; Nielsen, 2017; Williams \& O’Reilly, 1998). In this paper, we sought to test the moderating potential of organizational culture on the relationship between worker diversity and conflict using a meta-analysis. Using 40 samples, we examined the effect of culture (team oriented and outcome-oriented cultures) on the relationship between sample diversity (in terms of gender, race, age, and organizational tenure) and group conflict (task and relationship conflict). The results indicated that team-oriented culture significantly moderated the association between demographic diversity and relationship conflict, with greater levels of team-oriented culture associated 
with weaker associations between demographic diversity and relationship conflict. Thus, the current findings illustrate that team-oriented culture may serve as a substantial contextual moderator that may mitigate the amount of relationship conflict occurring within diverse groups. Outcome-oriented culture, meanwhile, appeared to enhance the detrimental positive association between sample demographic heterogeneity and relationship conflict. The current meta-analysis suggests that different types of organizational cultures may be used to reduce task and relationship intragroup conflict in demographically diverse groups. 


\section{TABLE OF CONTENTS}

\section{CHAPTER}

PAGE

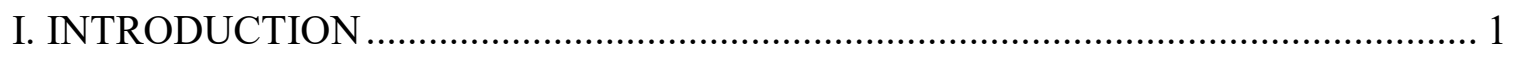

II. LITERATURE REVIEW.............................................................................. 5

Social Identify Theories and the Pitfalls of Diversity................................................ 5

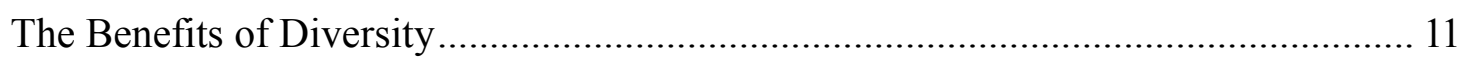

Optimizing the Benefits and Reducing the Pitfalls of Diversity............................... 17

The Impact of Culture on the Relationship between Diversity and Conflict............... 26

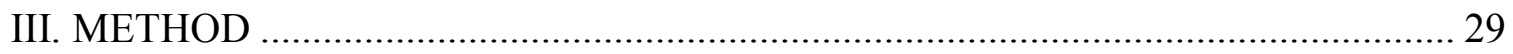

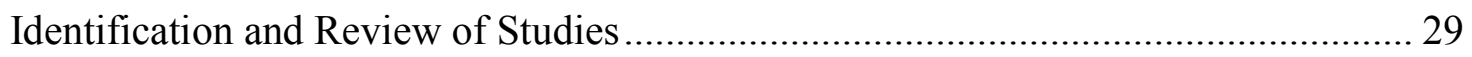

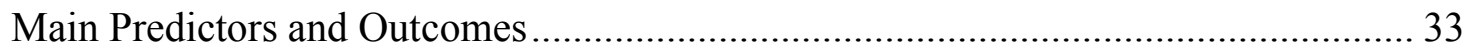

Development of Coding Categories..............................Error! Bookmark not defined.

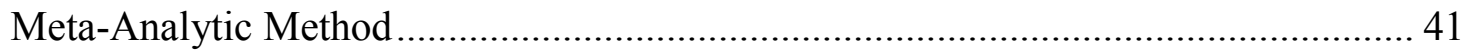

IV. RESULTS ...........................................................44

Team-Oriented Culture, Outcome-Oriented Culture, and Intragroup Conflict Types...44

Moderator Analyses.....................................................49

The impact of Team-Oriented Culture and Outcome-Oriented Culture on Intragroup

Conflict Co-Occurrence................................................54

Culture Moderator Analyses Between Sample Diversity and Task Conflict.............57

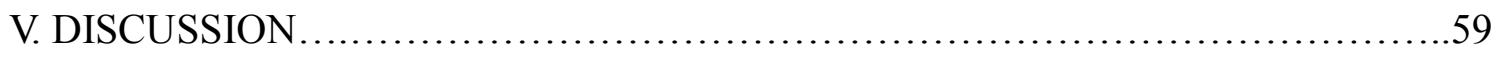

Team-Oriented Culture, Outcome-Oriented Culture, Diversity, and Intragroup

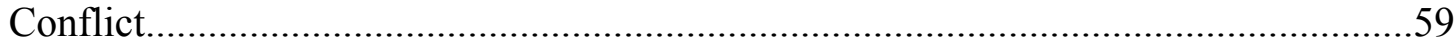

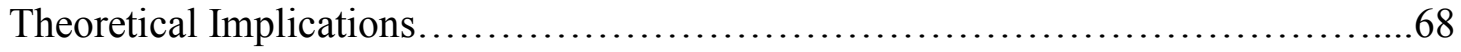

Limitations and Future Research............................................ 73

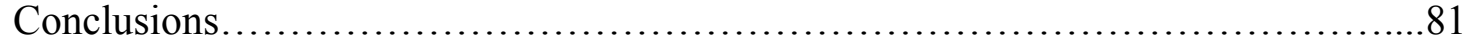

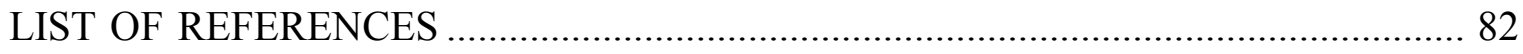

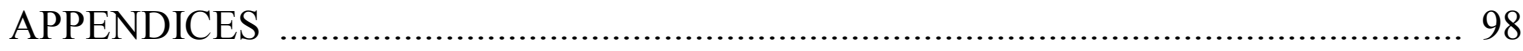

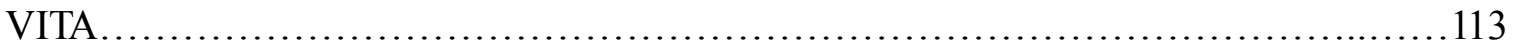




\section{LIST OF TABLES}

TABLE

PAGE

1. Study, Sample Characteristics, and Effect Size Information......................98

2. Meta-Analysis Results for Culture and Intragroup Conflict Outcomes...............100

3. Results for Culture Moderators, Sample Diversity, and Relationship Conflict........ 101

4. Results for Culture Moderators, Sample Diversity, and Task Conflict.................102

5. Results of the Associations Between Culture and Conflict Co-Occurrence.............. 103

6. Categorical Moderation Results Between Culture and Conflict Co-Occurrence...... 104

7. Cumulative Meta-Analysis Team-Oriented Culture and Relationship Conflict.........105

8. Cumulative Meta-Analysis Team-Oriented Culture and Task Conflict.................. 106

9. Cumulative Meta-Analysis Outcome-Oriented Culture and Relationship Conflict..... 107

10. Cumulative Meta-Analysis Outcome-Oriented Culture and Task Conflict............. 108 


\section{INTRODUCTION}

As a result of globalization, immigration, and age shifts occurring nationally and internationally, the demographic composition of the workforce has become more heterogeneous over the past several decades, especially in the United States (U.S. Bureau of Labor Statistics, 2017). In response, diversity has increasingly become a topic of interest in industrial-organizational psychology and organizational behavior research (Dayan, Ozer, \& Almazrouei, 2017; Gould \& Sardeshmukh, 2017; Lambert, 2016) as well as in the popular press (Fortune, 2017; Thakrar, 2017). Research in recent years has sought to examine the benefits and challenges associated with demographically diverse workforces, as well as potential organizational factors that may impact the relationship between demographic heterogeneity within work groups and various group processes and outcomes. Specifically, organizational researchers have increasingly called for investigations to examine how different contextual factors may both optimize the benefits and minimize the potential pitfalls of employing highly demographically diverse work units (Chuang, Church, \& Zikic, 2004).

Diversity can be broadly defined as any employee differences that may impact individual or organizational perspectives and strategies (Chrobot-Mason \& Thomas, 2002; Shore et al., 2011). Diversity has also been referred to in organizational behavior research as variations between individuals at work on any attribute that may evoke the perception that the other person is different from the self (Guillaume, Dawson, Woods, Sacramento, \& West, 2017; Tekleab \& Quigley, 2013; van Knippenberg, De Dreu, \& Homan, 2004; van Knippenberg \& Schippers, 2007; Williams \& O’Reilly, 1998). Most of the research examining workplace diversity has focused on the demographic attributes of gender, age, 
ethnicity, tenure, and functional background (Guillaume et al., 2017; Milliken \& Martins, 1996; Williams \& O’Reilly, 1998). Although previous research on workplace diversity has primarily focused on these five main demographic attributes, there are many other attributes that may constitute diversity within organizations (Guillaume et al., 2017), such as sexual orientation (e.g., Ragins, Singh \& Cornwell, 2007), marital status (e.g., Price, Harrison \& Gavin, 2006), disability (e.g., Olkin, 2002), professional skills, expertise, and experience (e.g., Van der Vegt, Bunderson \& Oosterhof, 2006), religion (e.g., Hicks, 2002), and differences in values, attitudes, and personality (e.g., Harrison, Price, Gavin, \& Florey, 2002; Kozhevnikov, Evans, \& Kosslyn, 2014; Liao, Chuang, \& Joshi, 2008).

Differences in demographic attributes in organizational research typically reference the commonly used categories identified by Milliken and Martins (1996), which classify attributes as visible or "surface-level" attributes or underlying "deep-level" attributes (Christian, Porter, \& Moffitt, 2006; Guillaume et al., 2017; Harrison et al., 2002; Pelled, 1996; Williams \& O’Reilly, 1998). Surface-level attributes are highly salient demographic attributes that can be determined quickly and with a high degree of consistency by others; such attributes include age, ethnicity, and gender (Galinsky et al., 2015; Harrison et al., 2002; Milliken \& Martins, 1996; Pelled, 1996; Shaw, 2004). Deep-level demographic attributes are generally thought to be less obvious as individuals often do not notice these attributes until they have interacted on several occasions with the person in question (Ragins et al., 2007; Tekleab \& Quigley, 2013). Deep-level attributes often include functional individual differences, such as differences in knowledge, skills, education, and perspectives that members bring to the work group (Homan, van Knippenber, Van Kleef, \& De Dreu, 2007; Williams \& O'Reilly, 1998). There are also some attributes that can either be classified as 
either surface-level or deep-level attributes, depending on the exact manifestation of this attribute and the disclosure status of individuals, such as disabilities, pregnancy, and sexual orientation (e.g., Kim \& Von Glinow, 2017; Olkin, 2002; Shore et al., 2011). Heterogeneity in surface-level demographic attributes and deep-level demographic attributes have each been found to have unique potential benefits and challenges that impact work unit functioning and effectiveness.

Previous research indicates that high levels of surface-level demographic diversity among members within work groups can increase relationship conflict and reduce the quality of interpersonal interactions (Homan et al., 2007; Pelled, 1996; Tekleab \& Quigley, 2013; Thatcher \& Patel, 2011; van Knippenberg, Dawson, West, \& Homan, 2011; Williams \& O’Reilly, 1998). For example, heterogeneity in surface-level demographic attributes may undermine group performance through social categorization processes (e.g., Galinsky et al., 2015; Homan et al., 2007; Jehn \& Chatman 2000; Pelled, 1996; Tajfel, 1978; Tajfel \& Turner, 1986; Williams \& O'Reilly, 1998). When subgroup categorizations are utilized to create an "us-them" distinction, interpersonal tensions and conflict can be expected to increase, and task communication effectiveness and knowledge-sharing should decrease (Chuang, Church, \& Zikic, 2004; Galinsky et al., 2015; Homan et al., 2007; Jehn \& Chatman, 2000; Williams \& O’Reilly, 1998). However, high surface-level demographic diversity within work units has also been associated with positive work outcomes, such as increased group problem-solving effectiveness, increased production of creative solutions, and increased task conflict (Chatman, Polzer, Barsade \& Neale, 1998; Horwitz \& Horwitz, 2007; Jackson, 1992; Nielsen, 2017; Thatcher \& Patel, 2011; Wooley, Aggar, \& Malone, 2015). 
Deep-level diversity attributes, such as education background, organizational tenure, or primary career industry, may enhance beneficial group performance outcomes through the elaboration of shared perspectives and task-relevant knowledge during group interactions (Bunderson \& Sutcliffe, 2002; Galinsky et al., 2015; Homan et al., 2007; Williams \& O’Reilly, 1998). For example, heterogeneous diverse work groups with a greater range of informational diversity have been found to outperform more homogeneous groups on complex tasks that have a high degree of cognitive information processing and decisionmaking requirements (Homan et al., 2007). However, research has also indicated that greater diversity in many deep-level attributes including education, functional background, and values, can also have detrimental effects on work groups; findings have found that increased heterogeneity in these attributes is also associated with decreased group viability and increased relationship conflict (Homan et al., 2007; Williams \& O’Reilly, 1998).

Given the potential benefits of both surface-level and deep-level diversity for team effectiveness, innovation, and problem-solving, ensuring the successful integration of individuals from different demographic backgrounds in work groups is crucial to organizational success, especially in an increasingly diverse and international workforce (Galinsky et al., 2015; Nielsen, 2017). Thus, researchers have suggested examining how contextual factors in organizations may influence the functioning and productivity of interactions between employees in highly diverse workforces (Chuang et al., 2004; Galinsky et al., 2015). Uncovering theoretical moderators that may prevent adverse relationship conflict within diverse work groups, while simultaneously retaining and promoting task conflict and work group performance, is vital to improving the functioning of groups in these organizations and the well-being of employees within them, filling a critical need in the 
organizational diversity literature. In this paper, team-oriented and outcome-oriented organizational cultures are proposed as potential theoretical moderators that may each affect the relationship between the amount of heterogeneity in demographic diversity attributes within organizational units and the levels of task conflict and relationship conflict.

\section{LITERATURE REVIEW}

\section{Social Identify Theories and the Pitfalls of Diversity}

Organizational diversity research has largely been grounded in three theoretical backgrounds which inform how social categorization processes may impact work unit functioning in diverse work groups: social identity theory (SIT) (Tajfel, 1978), selfcategorization theory (SCT) (Tajfel \& Turner, 1986), and the similarity/attraction paradigm (Byrne, 1971). According to the social identity theory, as well as self-categorization theory, individuals tend to classify and differentiate themselves from others on the basis of surfacelevel demographic differences such as differences in age, race, and gender (Ashforth \& Mael, 1989; Tajfel, 1978; Tajfel \& Turner, 1986). Doing so enables the pursuit of a positive selfidentity by making comparisons between the in-group and relevant out-groups in a way that reflects positively on in-group members (Ashforth \& Mael, 1989; Pelled, 1996). SIT and SCT each indicate that these between-group comparisons may result in the stereotyping of targeted out-group members, as well as in the development of hostile attitudes toward members of outgroups (Ashforth \& Mael, 1989; Tajfel, 1978; Tajfel \& Turner, 1986; Tekleab \& Quigley, 2013).

Similar to SIT and SCT, the similarity/attraction paradigm holds that individuals who possess similar characteristics and attitudes will typically perceive one another as similar, and, as a result, be attracted to each other (Byrne, 1971). SIT and SCT provide support for 
the similarity/attraction paradigm, as the reinforcement of an individual's particular attitudes and beliefs generally helps affirmed individuals maintain a positive self-identity (Ashforth \& Mael, 1989; Byrne, 1971; Chatman et al., 1998; Tajfel, 1978; Tajfel \& Turner, 1986). In order to reinforce preexisting attitudes and beliefs, individuals may prefer to interact only with organizational members from the same demographic group and may engage in comparison processes that promote hostility and relationship conflict (Pelled, 1996; Tajfel \& Turner, 1986; Tekleab, \& Quigley, 2013). Thus, the theoretical frameworks of SIT, SCT, and the similarity/attraction paradigm each suggest that a wide variability of surface-level demographic differences in highly heterogeneous workplaces may negatively affect work group functioning.

Supporting this claim, previous meta-analytic investigations measuring diversity using the surface-level demographic attributes of age, gender, and race/ethnicity indicated that nearly all these variables had negative impacts on one or more organizational outcome variables, including group satisfaction, low group commitment, and low social integration (e.g., Tekleab \& Quigley, 2013; Williams \& O’Reilly, 1998). Previous findings in the organizational behavior literature have suggested that heterogeneous work units are associated with decreased levels of trust and increased levels of relationship conflict (Williams \& O'Reilly, 1998). The potential negative effects often associated with highly diverse organizations highlight the importance for adjusting contextual factors in the environment that may help mitigate relationship conflict outcomes prone to occur in demographically diverse workplaces and organizations (Chuang et al., 2004; Horwitz \& Horwitz, 2007; Tekleab \& Quigley, 2013). 
Conflict. It is widely accepted that organizations rely on individual members to cooperate with one another in accomplishing goals and tasks to enhance effectiveness (Galinsky et al., 2015; Simon, 1976). Generally, conflict occurs when organizational members perceive discrepancies or incompatible wishes regarding beliefs and attitudes with other members (Tekleab, Karaca, Quigley, \& Tsang, 2016). Conflicts can have detrimental or beneficial effects on group and organizational processes and outcomes, depending on how the nature of the conflict being experienced is categorized (Chuang et al., 2004; Jehn, 1997, 1995; Liao et al., 2008; Pelled, 1996).

Researchers have widely accepted that conflict is a multidimensional construct with two principal types (Flink, 2015). The first type of conflict is categorized as task-related, also described as cognitive, informational, substantive, functional, or beneficial. Task conflict has generally been found to improve team effectiveness in complex, non-routine tasks and decision-making when occurring in non-excessive amounts, especially in somewhat diverse work groups (Amason, 1996, 1998; Loughry \& Amason, 2014). The second type of conflict is typically classified as relationship conflict, also known as affective, socio-emotional, or dysfunctional conflict, and is widely thought to only have detrimental effects on team and individual performance outcomes (Amason, 1998; Amason \& Schweiger, 1994; Jehn, 1995; Loughry \& Amason, 2014). Following the most common classifications, the current study utilizes the terms "task conflict" and "relationship conflict" to refer to the two conflict types.

Relationship conflict. Relationship conflict refers to interpersonal incompatibilities among organizational or group members, often resulting in tension, animosity, and annoyance (Jehn, 1995). There is a general agreement among researchers that relationship conflict among organizational members leads to negative effects on organizational outcomes 
(Chuang et al., 2004; Jehn, 1995; Jehn \& Chatman, 2000) as well as large negative effects on both proximal and distal group outcomes (e.g., De Wit, Greer, \& Jehn, 2012; Jehn, 1995). Disagreements about personal issues heighten member anxiety (Dijkstra et al., 2005) and often represent ego threats because the issues central to these conflicts are strongly intertwined with the self-concept. For example, the results of a previous study examining the effects of varying levels of task and relationship conflict on group outcomes indicated that groups with a high proportion of task conflict and a low proportion of relationship conflict tended to have higher organizational performance, group performance, and group satisfaction compared to groups with a high proportion of task conflict and a high proportion of relationship conflict (Jehn \& Chatman, 2000).

Researchers have investigated the specific ways that relationship conflict leads to detrimental outcomes (e.g., De Dreu \& Weingart, 2003; Jehn, 1995; Pelled, 1996). Specifically, it has been hypothesized that relationship conflict among organizational members subsequently leads to aversive task-related and interpersonal outcomes in the workplace. When members' attention and cognitive resources are fixated on other employees embroiled in the conflict rather than on task-related issues, this can negatively impact cognitive functioning when employees are performing critical job tasks, as well as lead to employees experiencing stress and anxiety (Chuang et al., 2004; Jehn, 1995). Indeed, relationship conflict is likely to engender decreases in satisfaction, decreased levels of trust with other group members, decreased creativity, reduced team problem solving decision quality, decreased perceived organizational support, increased perceptions of stress, and a variety of other detrimental organizational outcomes that impede organizational functioning 
(e.g., Chuang et al., 2004; De Dreu, 2006; De Dreu \& Weingart, 2003; DeChurch, MesmerMagnus, \& Doty, 2013; O’Neill, Allen, \& Hastings, 2013; Thatcher \& Patel, 2011).

Relationship conflict has been found to be higher in groups with high levels of surface-level demographic diversity, exacerbating the negative outcomes that result from this type of conflict. For example, Amason and colleagues (2010) used a sample of heterogeneous management teams from China and the United States to examine the impact of national origin diversity on relationship conflict and work group performance. This study found that higher levels of national origin heterogeneity in work groups was associated with increased relationship conflict and decreased decision-making effectiveness compared to management teams with more homogeneous national origins. Similarly, when assessing the impact of gender heterogeneity on work team outcomes, Pelled (1996) found that increased gender diversity resulted in lower overall team performance ratings and greater intragroup relationship conflict in electronic manufacturing work teams. Likewise, findings from previous studies assessing within-group diversity in race/ethnicity have indicated that highly heterogeneous teams exhibited greater relationship conflict and lower team member satisfaction than more racially homogenous teams (e.g., Hinds, Carly, Krackhardt, \& Wholey, 2000; Sessa, 1993). Another study conducted by Thatcher and Patel (2011) examined the impact of surface-level demographic diversity and deep-level demographic diversity on overall team dynamics and team process outcomes using data from 24,388 individuals in 4,366 teams across 39 independent studies. In this analysis, the authors found that increased work group heterogeneity in the surface-level demographic variables of gender and race was associated with a modest increase in relationship conflict (Thatcher \& Patel, 2011). 
However, not all studies find a clear relationship between surface-level demographic diversity among employees and relationships conflict and its negative downstream consequences. A meta-analysis conducted by Horwitz and Horwitz (2007) found that heterogeneity in both surface-level demographic variables (e.g., race and gender) and deeplevel demographic variables (e.g., education, organizational tenure, and occupation) were not significantly related to relationship conflict or social integration. Specifically, more heterogeneity in surface-level demographic characteristics was not associated with any beneficial outcomes in task/relationship conflict or work group performance across studies (Horwitz \& Horwitz, 2007).

Similarly, Smith and colleagues (1994) and Jehn (1995) did not find a direct relationship between surface-level diversity and relationship conflict or cohesion. Jehn (1995) examined the impact of demographic diversity on work team relationship conflict and team performance found neither individual nor group performance was significantly negatively associated by relational conflict that arose due to individual differences within work groups. Thus, findings have been largely inconsistent regarding the relationship between work group heterogeneity in both surface-level (e.g., gender, age, and race/ethnicity) and deep-level (e.g., organizational tenure, education) diversity attributes and work unit relationship conflict, work unit task conflict, and work unit performance outcomes. These findings underscore the importance of understanding contexts that can reduce the negative effects of relationship conflict that so often accompany groups with high surface-level demographic diversity (Amason et al., 2010). 


\section{The Benefits of Diversity}

While there are potential pitfalls to workplace diversity that include relationship conflict (e.g., Jehn, Northcraft, \& Neale, 1999) and weaker employee attachment (e.g., Tsui, Egan \& O'Reilly, 1992), there are also several benefits to diversity that can increase organizational effectiveness (e.g., Cox \& Blake, 1991; Guillaume et al., 2017; Horwitz \& Horwitz, 2007). Having highly demographically diverse work units enables organizations to draw from a larger assortment of talent, increases their capacity to innovate and make better decisions, allows them to access a more extensive customer base, and enables them to better satisfy customer needs (Cox \& Blake, 1991; Guillaume et al., 2017). Another benefit of workplace diversity occurs when task conflict occurs independently of relationship conflict

(e.g., De Wit et al., 2012). Previous research has found that the presence of moderate to high task conflict in heterogeneous work groups, without the presence of relationship conflict, is associated with increased levels of work group performance compared to more demographically homogenous work groups (Horwitz \& Horwitz, 2007).

\section{Task Conflict}

Task conflict, the second major form of workplace conflict, refers to disagreements among group members about issues related to their tasks, including task goals, procedures, and key decision-making areas (Chuang et al., 2004). Such conflict often arises from differences in members' perspectives about task-related information and/or opposing interpretations and applications of facts, data, or evidence (Amason, 1996, 1998; Jehn, 1995; Loughry \& Amason, 2014). As opposed to relationship conflict, task conflict can have positive effects on organizational functioning outcomes when groups are performing nonroutine and challenging tasks (Chatman et al., 1998; Jehn, 1995; 1997). However, previous 
research has also found that task conflict in work groups can have detrimental effects on routine, simple tasks (Chuang et al., 2004; Jehn, 1997). Therefore, task conflict can be productive or detrimental, depending the tasks involved and other contextual factors, such as climate (e.g., Bradley, Postlethwaite, Klotz, Hamdani, \& Brown, 2012).

Another critical moderating variable in the relationship between conflict and group outcomes is the co-occurrence of conflict types (Amason \& Sapienza, 1997; De Dreu \& Weingart, 2003; De Wit et al., 2012; DeChurch et al., 2013). Task conflict, for example, has been found to be more positively related to group outcomes and performance when it does not co-occur with relationship conflict (De Wit et al., 2012; Eisenhardt, Kahwajy, \& Bourgeois, 1997; Mooney, Holahan, \& Amason, 2007). In contrast, when intragroup task conflict is highly associated with relationship conflict, the detrimental hostile behaviors that characterizes relationship conflict may occlude and inhibit any beneficial effects of task conflict from occurring within work groups (e.g., De Wit et al., 2012; Pelled, 1996; Simons $\&$ Peterson, 2000). Previous research examining intragroup conflict within top management teams has found that teams that that had high task conflict with low relationship conflict and interpersonal tension had greater team performance than similar teams that lacked both task conflict and relationship conflict as well as teams that exhibited high levels of relationship conflict (Eisenhardt et al., 1997). Relatedly, De Dreu and Weingart (2003) found that the association between intragroup task conflict and group performance was less negative in studies that task and relationship conflict were weakly associated compared to studies that task and relationship conflict were strongly correlated.

The contextual moderating variable of work unit culture, specifically, team-oriented and outcome-oriented cultures, have been found to influence and modify cultural beliefs, 
norms, and expectations toward conflict which may augment or mitigate the co-occurrence of task and relationship conflict (Fu et al., 2007; Gelfand, Leslie, \& Keller, 2008). Specifically, work groups with high collectivistic team-oriented cultures and low outcome-oriented cultures have been found to have lower associations between task and relationship conflict and a lower preference for addressing conflict with a competing style compared to work groups with low team-oriented cultures and high outcome-oriented cultures (Fu et al., 2007; Gelfand, Leslie, \& Keller, 2008). Therefore, greater levels of team-oriented culture may likely mitigate the co-occurrence of task conflict and relationship conflict occurring within work groups while greater levels of outcome-oriented culture may likely increase the association between task conflict and relationship conflict occurring within work groups.

In general, previous findings have suggested that high levels of heterogeneity in taskrelevant, deep-level diversity variables (such as education, occupation type, organizational tenure, and functional background) are associated with increased levels of task conflict and increased group performance outcomes, such as the production of effective and innovative solutions, and increased decision quality (e.g., Chatman et al., 1998; Chuang et al., 2004; Jehn, 1995; Jehn, Northcraft, \& Neale, 1999; Nielsen, 2017; Thatcher \& Patel, 2011; Webber \& Donahue, 2001). A meta-analytic review conducted by Horwitz and Horwitz (2007) on the effects of team demographic diversity on team outcomes found that high task-relevant, deeplevel diversity variables (e.g., differences in education and job type) are positively related task conflict, work group decision-making quality, and the production of original, creative solutions. Another meta-analysis examining team diversity found that high work group heterogeneity in deep-level diversity variables (e.g., education level) positively predicted 
work group team performance outcomes, task conflict, and group decision-making quality for highly complex team tasks and projects (Thatcher \& Patel, 2011).

While heterogeneity in task-related, deep-level diversity variables, such as education and employee tenure, can positively impact task conflict and group performance, research has also indicated a significant relationship among surface-level demographic diversity and task conflict and group performance (Horwitz \& Horwitz, 2007; Thatcher \& Patel, 2011; Webber \& Donahue, 2001). The positive linkage between task-conflict and work group heterogeneity in demographic diversity across studies supports the implication that high work group heterogeneity may help facilitate effective team problem solving outcomes (Horwitz \& Horwitz, 2007; Thatcher \& Patel, 2011).

Additional research highlights the strength of demographically diverse work units across multiple dimensions of performance that contribute to the overall effectiveness and revenue growth of organizations (Galinsky et al., 2015; Guillaume et al., 2013; Horwitz \& Horwitz, 2007). For example, having a diverse workforce of talent in both surface-level and deep-level attributes has been associated with increased organizational flexibility, increased task conflict and decision quality, improved work group problem solving performance (Cox \& Blake, 1991; Horwitz \& Horwitz, 2007). Additionally, findings of previous research have also found that greater diversity in demographic deep-level and surface-level attributes is also associated with increased innovativeness, increased production of creative and highlyeffective solutions to address key organizational challenges, increased quality of talent sourcing and acquisition, enhanced strategic financial and marketing advantages, and reduced risk of potential organizational costs (Cox \& Blake, 1991; Horwitz \& Horwitz, 2007). Studies examining the impact of diversity in surface-level demographic diversity variables 
(e.g., gender and race) found that moderately diverse work groups had better problem solving, more task conflict, and were more innovative than highly homogenous work groups (Kozhevnikov et al., 2014; Nielsen, 2017; Wooley et al., 2015). These findings suggest that groups whose members are too similar to each other may lack the variety of perspectives and skills needed to perform well on a variety of tasks and may have lower creativeness, innovation, less task conflict, and poorer decision-making than more heterogeneous work groups (Kozhevnikov et al., 2014; Wooley et al., 2015).

Creativity and innovation. Previous organizational diversity research has generally indicated that more demographically heterogeneous groups in surface-level and deep-level attributes may perform at a higher level on tasks requiring creativity or in producing creative solutions than demographically homogeneous groups (e.g., Horwitz \& Horwitz, 2007; Koch, Koch, Menon, \& Shenkar, 2016; Richard, McMillan, Chadwick, \& Dwyer, 2003). This is potentially due to the increased scope and variety of ideas, perspectives, and potential solutions to solve complex problems (Chatman et al., 1998; Koch et al., 2016; Nemeth, 1992). Organizational diversity research has consistently found that workplace heterogeneity engenders increased creativity and innovative effective solutions within organizations (e.g., Chatman et al., 1998; Horwitz \& Horwitz, 2007; Koch et al., 2016; Richard et al., 2013). For example, previous research on work group and team problem-solving using small groups and dyad teams found that groups composed of members highly diverse in deep-level task-related diversity attributes, such as in attitudes and knowledge areas, were found to have higher problem-solving performance and higher quality decision-making compared to more homogenous dyads and work groups (Martins, Milliken, Wiesenfeld, \& Salgado, 2003; Lambert, 2016). 
Demographic diversity may also improve the quality of innovative strategic decisionmaking within organizations and positively impact the attainment of organizational level strategic objectives (Horwitz \& Horwitz, 2007; Richard et al., 2013). For example, previous research examining the impact of different types of surface-level demographic attributes (e.g., age, gender) on organizational-level outcomes found that high levels of racial diversity were related to increased overall financial performance within organizations that implemented innovation and creative solution strategies (Richard et al., 2013). Thus, under the right culture and strategic initiatives, increased demographic diversity in surface-level diversity may likely improve the innovative solutions and the overall quality of strategic decision-making within organizations and, as a result, increase the financial performance of organizations (Horwitz \& Horwitz, 2007; Martins et al., 2003; Richard et al., 2013).

However, in order for the benefits of innovativeness and creativity resulting from demographic diversity to be realized, diverse organizational members must be willing to openly share relevant important task-related information, as well as their novel and unique ideas and solutions with other members of the organization. Information-sharing studies have shown that individuals may be reluctant to share novel ideas with others, especially with others perceived to be different from them (Bunderson \& Suttcliffe, 2002; Chatman et al., 1998; Gilson, Lim, Luciano, \& Choi, 2013; Pinjani \& Palvia, 2013). Thus, a lack of cohesion and trust between demographically diverse individuals may impede sharing creative knowledge and ideas to others due to fears of being ridiculed or ostracized by other members (Gilson et al., 2013; Nemeth, 1986; Pinjani \& Palvia, 2013). Previous organizational conflict research has also found that a lack of trust and cohesion between members may lead to members perceiving task conflict as relationship conflict, highlighting the importance of first 
establishing trust and cohesion within work groups to maximize the benefits of task conflicts and avoid the misattribution of task conflict as relationship conflict (De Wit et al., 2012; Mooney et al., 2007). Thus, in order to maximize the benefits associated with diversity, demographically diverse work units should establish an environment of mutual trust, cohesion, learning, team work, and open collaboration between work group members (Gilson et al., 2013; Pinjani \& Palvia, 2013; Schaeffner, Huettermann, Gebert, Boerner, Kearney, \& Song, 2015).

\section{Optimizing the Benefits and Reducing the Pitfalls of Diversity}

Determining the role of contextual moderators that may reduce relationship conflict in demographically diverse groups and organizations represents a critical gap in the organizational literature. Bridging this gap has both applied and theoretical value by helping to shed light on explanations and strategies for optimizing functioning in diverse workforces. In this paper, we examine organizational culture and climate as potential contextual variables that may impact the relationship between organizational diversity and conflict, especially relationship conflict. When highly demographically diverse people are working together in a team-oriented or collectivistic culture, we argue that it could be particularly effective in maximizing creative results (e.g., Chatman et al., 1998; Pinijani \& Palvia, 2013; Martins et al., 2003) and minimizing relationship conflict (e.g., Chuang et al., 2004; Galinsky et al., 2015; Schaeffner et al., 2015).

Organizational culture. Organizational culture is generally defined as the perceived pattern of shared underlying assumptions, espoused values, and visible artifacts that define appropriate attitudes and behaviors for organizational members (Hofstede, 1998; Schein, 1985). A strong sense of similar, shared values in the organizational culture indicates the 
organization is a bounded unit, and provides it with a distinct identity that influences the behavior of all members (Schein, 1985). Thus, a strong organizational culture that represents a shared set of value congruence among members may reduce the likelihood of relationship conflict between demographically diverse organizational members. A strong team-oriented organizational culture, specifically, may also moderate the relationship between diversity and relationship conflict by increasing the degree to which members identify with each other.

O'Reilly, Chatman, and Caldwell (1991) developed the organizational culture profile (OCP) measure, which assesses seven organizational culture dimensions across 54 value statements. The seven organizational culture dimensions included in the OCP measure are: 1) innovativeness, 2) stability, 3) respect for people, 4) outcome orientation, 5) attention to detail, 6) team orientation, and 7) aggressiveness (O’Reilly et al., 1991). The OCP assumes that every organization's cultural values can be profiled through these seven dimensions (Baird, Harrison, \& Reeve, 2007; O’Reilly et al., 1991). The measure utilizes a single aggregated mean composite score of members' responses to their organization's or work group's standing in each of the seven OCP cultural dimensions (Baird et al., 2007; O’Reilly et al., 1991).

Baird and colleagues (2007) created a modified version of the OCP, which consists of four of the seven original OCP cultural dimensions. The modified OCP measures outcome orientation, innovation, team orientation, and attention to detail (Baird et al., 2007). These different dimensions of the modified version of the OCP each represent independent and distinct underlying constructs, although there are small correlations between some of the dimensions (Baird et al., 2007). These four dimensions are the most frequently implemented dimensions of the OCP in existing organizational culture research (e.g., Baird et al., 
2007; Charaf \& Bescos, 2013; Rababah, 2015). Therefore, using this version of the OCP to measure organizational culture should allow for wide-ranging comparisons and inferences among studies assessing the impact of organizational culture on task conflict and relationship conflict outcomes.

Given that the four cultural dimensions in the modified OCP are among the most frequently implemented measures of organizational culture in the organizational behavior and workplace diversity literature, studies assessing how different types of culture distinctly impact the relationship among demographic diversity, relationship conflict, and task conflict are likely to utilize at least one of the four modified OCP cultural dimensions (Baird et al., 2007). Thus, two of the four cultural dimensions in the modified OCP, team orientation and outcome orientation, were included in the current analysis as the two primary culture dimensions since they represent two of the most commonly assessed dimensions of organizational culture and are supported by a relatively substantial body of validation evidence.

In addition to organizations, groups also have specific identifiable cultures that are commonly measured utilizing the four cultural dimensions of the modified OCP (Sackman, 1992; Schein, 1985). Key defining aspects of group culture include the group's work-related values and preferred behavioral decisions relating to the different cultural dimensions (Jehn, 1994; O'Reilly et al., 1991). More specifically, the group cultural dimensions of team orientation and outcome orientation from the modified version of the OCP together represent the only two culture variables included in current analyses.

Organizational culture dimensions and conflict. The organizational culture dimension of team orientation is defined as the degree to which collaborative or 
interdependent behavior between individuals is valued or prioritized (Erdogan, Liden, \& Kraimer, 2006; O'Reilly et al., 1991). Team-oriented cultures have been characterized as prioritizing the interdependence of organizational members over individual preferences, as well as the importance of individuals making personal contributions to group processes and outcomes (Erdogan et al., 2006; O’Reilly et al., 1991). Team-oriented organizational cultures are described as emphasizing the importance of getting along with other organizational members, as well as developing strong, lasting interpersonal relationships and friendships to help encourage behaviors that promote positive and effective social interactions (Erdogan et al., 2006). Although many names have been used to signify team-orientation culture (e.g., collectivistic and clan) there is a general consensus among researchers that these various terms tap into a similar underlying construct (Erdogan et al., 2006; Schaeffner et al., 2015).

Since team-oriented cultures typically emphasize working with others in teams, employees and organizational leaders may be highly motivated and incentivized to participate in high-quality member social interactions and exchanges with other organizational members (Erdogan et al., 2006; Sparrowe \& Liden, 1997). When an organizational culture emphasizes a team-oriented atmosphere, social exchanges may become more frequent and may progress from more balanced exchanges between individuals to more generalized, positive, and detailed exchanges in which people assist each other without expecting direct benefits from the other person in return (Erdogan et al., 2006; Sparrowe \& Liden, 1997). Since continuous, high-quality social exchanges between organizational members often facilitates the exchange of task-relevant information and the coordination of relevant activities, the development and sustainability of strong, lasting, and 
harmonious interpersonal relationships is generally highly valued (Erdogan et al., 2006; Schaeffner et al., 2015).

Cultures high in outcome-orientation are characterized as those that value and prioritize the achievement of competitive outcomes and place the responsibility on individuals to produce attractive results (O'Reilly et al., 1991; Williams \& Durray, 2006). Outcome-oriented cultures generally prioritize encouraging employees to focus on producing specific, tangible, and individual outcomes that benefit the organization; this approach is often reinforced at the individual level by using merit-based incentive systems to recognize and reward the individual input of employees with tangible resources (Erdogan et al., 2006). Although many names have been used to signify outcome-orientation culture (e.g., individualistic, aggressive, growth) there is a general consensus among researchers that these various terms tap into a similar underlying construct (Erdogan et al., 2006; Schaeffner et al., 2015).

Outcome-oriented cultures are also typically characterized as valuing and prioritizing the completion of tangible outcomes by individual group members over harmonious interactions and relationships between group members (Erdogan et al., 2006; O'Reilly et al., 1991; Williams \& Durray, 2006). Thus, such cultures are purported to increase the focus on the generation of outcomes and the exchange of tangible resources in relationships, rather than attending to the quality of interpersonal interactions and the degree of tranquility between group members. This may result in employees being less interpersonally sensitive, and more concerned about the completion of outcomes than amount of relationship conflict between organizational members (Erdogan et al., 2006). 
Due to their differences in values, team-oriented cultures and outcome-oriented cultures predict distinct organizational effectiveness outcomes (Hartnell, Ou, \& Kinicki, 2011; Williams \& Durray, 2006). For example, the "clan" organizational culture type of the Competing Values Framework (CVF), which largely overlaps with the team-oriented culture dimension of the OCP, was found to be more strongly associated with positive employee attitudes and service quality organizational outcomes than any other CVF organizational culture type. In contrast, the "market" culture type of the CVF, which largely overlaps with the outcome-oriented culture dimension of the OCP, was more strongly related to the outcomes of innovation and financial effectiveness than the other culture types (Hartnell et al., 2011). Team-oriented cultures have also previously been found to be significantly related to a variety of interpersonal and conflict-related outcomes and processes, including decreased relationship conflict, increased individual team-source learning, beneficial social interaction processes, positive team-level attitudes favoring cooperation, and more positive experiences and attitudes towards using teams in demographically diverse organizations (Chen et al., 1995; Kleinman et al., 2002; Schaeffner et al., 2015; Williams \& Durray, 2006).

Diverging from the interpersonal benefits associated with team-oriented cultures, outcome-oriented organizational cultures have been shown to be more closely associated with team and organizational effectiveness, such as work group decision-making effectiveness, program implementation, and various team and organizational performance outcomes (Kleinman et al., 2002; Williams \& Durray, 2006). However, previous research has also found some similar organizational benefits associated with both team-oriented and outcome-oriented cultures. For example, the organizational culture dimensions of team orientation and outcome orientation have both previously been found to be positively related 
performance management effectiveness (e.g., the level of support employees provided for a newly implemented performance management system) (Baird et al., 2007; Charaf \& Bescos, 2013; Rababah, 2015). Overall, the two culture dimensions of team orientation and outcome orientation are generally related to distinct group processes and outcomes; when both are used to assess work unit culture, researchers and practitioners are able to make a broader range of meaningful inferences regarding group processes and outcomes (Hartnell et al., 2011; Kleinman et al., 2002).

Organizational culture dimensions, conflict, and diversity. Some research has already found that organization culture appears to influence the functioning and outcomes of diverse work groups (e.g., Chatman et al., 1998; Chuang et al., 2004; O'Reilly et al., 1991). For example, Chatman and colleagues (1998) found that employees working in more collective organizations who were dissimilar to other employees in terms of surface-level demographic attributes (i.e., race and gender) had fewer and more beneficial interpersonal conflicts than diverse individuals working in individualistic organizations. One potential reason for the decreased interpersonal conflict in heterogeneous collectivistic work units was through the role self-categorization processes may have played in the reduced conflict in the collectivist-oriented organizations (Chatman et al., 1998; Chuang et al., 2004). More specifically, interpersonal conflict may have been reduced in heterogeneous collectivistic work units since collectivist-oriented organizational cultures tend to make organizational membership more salient than demographic attributes and encourage employees to categorize themselves with others they work with as a unit (Chatman et al., 1998; Chuang et al., 2004).

Trust between diverse individuals may be increased through the implementation and promotion of team-oriented and collectivistic organizational cultures (Schaeffner et al., 
2015). These types of cultures may create a larger organizational in-group that results in increased trust and perceived similarity of actions and attitudes for all members of the organization (Brewer, 1981; Chatman et al., 1998; Hofestead, 2001). This increase in perceived similarity of actions and in-group categorization may facilitate the willingness and likelihood of individuals working in demographically diverse organizations to share their ideas, knowledge, and solutions with other members of the organization (Chatman et al., 1998; Gilson et al., 2013; Schaeffner et al., 2015).

In-group membership can be based on belonging to the same demographic categories or to the same organization, and, for people who are demographically different, trust in other members may arise from the culture of the organization (Chatman, 1989; Chatman et al., 1998; Chuang et al., 2004). High levels of creativity may require demographic diversity within organization units for the best range of novel ideas and a basis for in-group organizational categorization through team-oriented or collectivistic organizational cultures that allow demographically diverse individuals to increase trust and data sharing (Chatman et al., 1998). Thus, demographically diverse individuals may have the requisite variety of ideas to achieve high levels of creativity, but, in outcome-oriented or individualistic cultures, they may be obstructed from sharing these ideas openly due to a lack of trust in each other and the perceived risk that sharing information may lead to social ostracism or not receiving credit for presenting the ideas or information (Chatman et al., 1998; Chuang et al., 2004).

For firms to optimize benefits from diversity, organizational research has emphasized that firms must emphasize inclusiveness within the organization (Dwyer \& Chadwick, 2003; Richard et al., 2013). When members of an organizational unit are demographically diverse, research has found that specific organizational cultures may influence productivity and 
effectiveness in competing tasks (Chatman et al., 1998; Schaeffner et al., 2015). Generally, interacting with diverse others in organizations with outcome-oriented and individualistic cultures may involve little information sharing and idea modification based on input from others due to a belief in individual responsibility and individual reward systems (Chatman et al., 1998; Dwyer \& Chadwick, 2003; O’Reilly et al., 1991). Members of more individualistic or outcome-oriented cultures often are not required to consider working with other organizational members when performing assigned tasks (Dwyer \& Chadwick, 2003; O'Reilly et al., 1991). Even when demographically diverse individuals interact with each other in the work environment in outcome-oriented and individualistic cultures, they are not likely to spend much time discussing or sharing information related to task performance to allow for individuals to complete more tasks in shorter periods of time (Dwyer \& Chadwick, 2003; Richard et al., 2013).

In team-oriented and collectivistic cultures, however, organizational members may be more compelled to value, consider, and debate each other's ideas for best practices. Since diverse organizational members in team-oriented cultures will be working more in teams and are rewarded more on group performance, they will be more motivated to consider coworkers' perspectives and information (Chatman et al., 1998). Thus, because demographically diverse individuals working in team-oriented and collectivistic cultures consider the perspectives of others when making decisions and completing tasks, they may produce higher quality creative solutions for complex group tasks and problems, but may also take longer to make decisions and complete tasks compared to demographically diverse individuals working in outcome-oriented and individualistic organizational cultures (Chatman et al., 1998). 


\section{The Impact of Culture on the Relationship between Diversity and Conflict}

Previous findings have generally indicated that surface-level demographic diversity is positively associated with relationship conflict, with higher rates of relationship conflict occurring in highly demographically diverse workplaces compared to workplaces that are demographically more homogeneous (Guillaume et al., 2017; O’Reilly et al., 1991; Williams \& O’Reilly, 1998). However, the presence of specific types of organizational cultures may help to mitigate the detrimental effects of increased relationship conflict often associated with demographic diversity (Chuang et al., 2004; Guillaume et al., 2017). Specifically, high levels of a team-oriented organizational culture should reduce the relationship conflict in diverse work units, since team-oriented culture has been found to be negatively related to relationship conflict in diverse organizations and workgroups (Chuang et al., 2004; Jehn \& Chatman, 2000; Williams \& O'Reilly, 1998). An organization perceived to have a strong team-oriented culture may thus reduce the effects of surface-level diversity on relationship conflict by shifting self-categorization to the organization instead of different demographic groups. More specifically, organizations with strong team-oriented organizational cultures should be more likely to reward employees who respect each other and show tolerance for individual differences and reduce individuals' propensity to process social categorization based on surface-level demographic attributes (Chuang et al., 2004; O’Reilly et al., 1991). Another method by which a strong team-oriented culture can improve the quality of organizational functioning and reduce relationship conflict is through increased emotional support for all members in the organization, which leads to reduced interpersonal conflict and increased positive psychological perceptions of the work environment (Chuang et al., 2004; Pelled, 1996). 
Similar to team-oriented organizational cultures, outcome-oriented cultures may also serve a potential moderating effect in the relationship between surface-level demographic diversity variables and relationship conflict. Since strong outcome-oriented organizational cultures tend to emphasize competition and effectiveness, they may also make individual demographic differences more salient due to increased categorization and mental energy focused on comparing groups of other employees in the organization who belong to different demographic groups (Chatman et al., 1998; Chuang et al., 2004; Tajfel \& Turner, 1986). Supporting this notion, previous research has found that the increased levels of outcomeoriented cultures within work units is significantly positively associated with relationship conflict and negatively associated with levels of trust between work unit members (Chatman et al., 1998; Chuang et al., 2004; Pelled, 1996).

Organizations perceived to have strong outcome-oriented cultures may increase interpersonal conflict outcomes in diverse workgroups by fostering competition among group members based on both task and non-task related issues, increasing distrust and interpersonal conflict between members from different demographic groups (Chatman et al., 1998; Chuang et al., 2004). Additionally, organizations with strong outcome-oriented organizational cultures tend to have increased interpersonal conflict due to their fostering of an environment that emphasizes competition and social comparisons with other employees made possible through categorization processes. This thereby increases the likelihood that task conflict issues are misattributed as non-work-related relationship conflict between organizational members (Chuang et al., 2004; Pelled, 1996). Thus, we offer the following hypotheses, to be tested via a meta-analysis of studies assessing organizational culture, sample diversity, and group conflict: 
Hypothesis 1: Increased heterogeneity in surface-level demographic variables within samples (i.e., gender, race, age) will be positively related to relationship conflict (H1a) and task conflict (H1b) across studies.

Hypothesis 2: The culture dimension of team orientation at the group level will be negatively associated with relationship conflict (H2a) and task conflict (H2b) across studies.

Hypothesis 3: The culture dimension of outcome orientation at the group level will be positively related to relationship conflict (H3a) and task conflict (H3b) across studies.

Hypothesis 4: Across studies, the organizational culture dimension of team orientation will significantly attenuate the relationship between surface-level demographic diversity within samples and relationship conflict, such that increases in team-oriented culture within samples will be associated with weaker correlations between diversity and relationship conflict.

Hypothesis 5: Across studies, the organizational culture dimension of outcome orientation will significantly moderate the relationship between surface-level diversity within organizational units and relationship conflict, such that increased perceptions of outcome-oriented cultures within samples will strengthen the correlation between diversity and relationship conflict.

Hypothesis 6: The organizational culture dimension of team orientation at the group level will significantly moderate and attenuate the association between task conflict and relationship conflict across studies. 
Hypothesis 7: The organizational culture dimension of outcome orientation at the group level will significantly moderate and increase the association between task conflict and relationship conflict across studies.

In addition, based on the OCP theoretical framework and previous research findings on how different culture dimensions impact intrapersonal conflict outcomes, we propose the following research questions:

Research Question 1: To what extent will the organizational culture dimension of team orientation moderate the relationship between surface-level demographic diversity and task conflict across studies?

Research Question 2: To what extent will the organizational culture dimension of outcome orientation moderate the relationship between surface-level demographic diversity and task conflict across studies?

While we did not include any priori hypotheses about the relationship between deeplevel diversity variables, culture, and conflict, we also collected and analyzed the deep-level diversity variable of "organizational tenure" in an exploratory fashion.

\section{METHOD}

\section{Identification and Review of Studies}

To examine the effect of organizational cultures on the relationship between demographic diversity in organizational units and conflict outcomes, a meta-analysis was conducted of existing studies. First, a database of potential studies was assembled. To locate studies, the keywords "organizational culture," "Organizational Culture Profile," "Organizational Culture Inventory," "team-oriented culture," "outcome-oriented culture," "task conflict," "relationship conflict," "emotional conflict," "dysfunctional conflict," 
"interpersonal conflict," "process conflict," "cognitive conflict," and "intragroup conflict," were entered into a computer-based literature review search of articles in PsycINFO, PsycARTICLES, ProQuest, JSTOR, and Business Source Complete electronic databases. Different combinations and truncations of keywords were utilized in the search to broaden the literature base relevant to the topic.

Following the protocol of previous meta-analytic studies examining the relationship of various organizational culture dimensions with different effectiveness outcomes, the search procedure utilized allowed for the inclusion of studies that examined related organizational culture dimensions with taxonomies other than the OCP (Hartnell et al., 2011). To help address publication bias, (e.g., Rothstein, Sutton, \& Borenstein, 2005), inquiries for unpublished and working papers and publications examining team-oriented or outcome-oriented culture with task or relationship conflict were sent via professional listserves to active members of the Academy of Management, Occupational Health Psychology, the International Academy of Conflict Management, and the Society for the Psychological Study of Social Issues.

Upon the initial searches, there were 278 original "hits" of journal articles that appeared for consideration to be included in the current analysis. Of the 278 articles that were considered, studies were only included if they met eight different criteria. The first criteria for inclusion was that the study administered a measure of team-oriented or outcome-oriented organizational culture operationalized to represent a higher-level unit of analysis as organizational culture is defined as an organizational-level construct (Chan, 1998; Hartnell et al., 2011). Theoretical articles, qualitative studies, papers merely mentioning organizational culture without measuring it, and studies with measures of organizational culture that utilized 
individual level perceptions of culture instead of higher-level units of analysis were removed from consideration, resulting in the removal of 48 potential studies. Secondly, studies had to include at least one measure assessing group conflict: either task conflict, relationship conflict, or a measure of a construct that widely overlapped with task or relationship conflict. The second criteria resulted in the removal of 78 studies, leaving 152 remaining potential studies to be considered for inclusion. Thirdly, studies had to be published in peer-reviewed journals, rather than in non-peer review journals, unpublished dissertations, or textbook chapters. The third criteria resulted in the removal of 13 studies, leaving 139 studies to be considered for possible inclusion.

The fourth criteria for inclusion in the current meta-analysis was that the study be available in English. Of all of the studies in the original search lists, two studies were only available in languages other than English. Since no translated version of these studies could be found, they were left out of the analysis to include only the 137 remaining studies that were available in English. The fifth criteria for inclusion was that studies provided one or more correlations and/or one or more relevant statistics that could be converted into correlation coefficients (e.g., t, F, or chi-square statistics) between measures of team-oriented or outcome-oriented organizational culture and task conflict or relationship conflict outcomes following previous meta-analytic reviews of organizational culture with different outcomes (Hartnell et al., 2011). The fifth criteria resulted in the removal of 81 studies, leaving 56 remaining studies for consideration.

Next, the sixth criteria for inclusion in the current meta-analysis was that the organizational culture measure used in the study did not utilize a forced-choice ipastive scale to measure organizational culture dimensions, since the use of ipastive force-choice scales 
may result in non-independent ratings of culture and potentially spurious and overestimated correlations (Hartnell et al., 2011; Johnson, Wood, \& Blinkhorn, 1988). Three of the remaining potential studies were removed from inclusion in the current meta-analysis, as they included measures of organizational culture dimensions that utilized ipastive forcedchoice response scales. The seventh criteria for inclusion was that studies must assess either team-oriented culture or outcome-oriented culture at the group level of analysis and also must assess either task conflict and relationship conflict outcomes at the group level of analysis so as to ensure that team-oriented culture, outcome-oriented culture, relationship conflict, and task conflict were correctly operationalized to represent the group level of analyses. The seventh criteria resulted in the removal of 21 of the remaining potential studies that operationalized the included culture measures at an incorrect level of analysis or operationalized task conflict or relationship conflict outcomes at an incorrect level of analysis. Lastly, the eighth criteria for inclusion was that studies must have reported the sample demographic information of at least one of the four demographic diversity attributes that made up the demographic diversity variables in the current study, namely age, race/ethnicity, gender, and/or organizational tenure. The eighth criteria resulted in the removal of 12 studies.

After removing all studies that did not meet all eight of the above criteria, our final data set for the current meta-analysis consisted of 39 studies. Among these 39 studies, there were 40 independent samples that qualified for inclusion in the final data set, resulting in a total of 40 independent samples that were included in our final data analysis. Sample means and standard deviations of culture and conflict, culture and conflict reliability information, sample demographic information of the four diversity variables, and correlation measures 
between culture dimensions, demographic diversity attributes, and task conflict and relationship conflict variables were included in the final data set from these samples.

\section{Primary Variables}

Demographic diversity variables. Age, gender, race, and organizational tenure were included as demographic diversity variables in the current analysis. These four demographic attributes were used because previous research indicates they are commonly used when assessing forms of diversity that may potentially influence group processes and functioning at work (Chatman et al., 1998; Chuang et al., 2004; Williams, \& O’Reilly, 1998). Age, gender, and race heterogeneity within samples were included as surface-level demographic diversity attributes, while organizational tenure heterogeneity was included as a deep-level demographic diversity attribute.

Age heterogeneity was represented as the standard deviation of participant age in years (coded as a continuous variable). Organizational tenure diversity was assessed in each study as the standard deviation of the number of years participants spent working for their current organization (coded as a continuous variable). Simpson's index of diversity (D) was computed and included for sample gender diversity and sample racial diversity in each respective sample as continuous measures. The $\mathrm{D}$ values for race and gender diversity represented the probability that two randomly selected individuals from a sample would differ in race or gender based on the equation: $\mathrm{D}=1-\sum S i^{2}$ where $S i$ represents the proportion of each category $i$ (Leonard, Levine, \& Aparna, 2004; Roberson \& Park, 2007; Simpson, 1949). For example, for a sample that consisted of $70 \%$ women and $30 \%$ men, the D value for gender diversity in the sample would be calculated as $\mathrm{D}=1-\left(.70^{2}+.30^{2}\right)$ with a $\mathrm{D}$ value 
for gender diversity of .42 for the sample indicating the probability that two randomly selected individuals from the sample would differ in gender.

Relationship conflict. Relationship conflict was typically measured in the samples using employees' self-report responses to statements about their immediate work group in the organization. Participant responses to the statements for relationship conflict were typically assessed using a five or seven response option Likert-type scale ranging from 1 (strongly disagree) to 5 or 7 (strongly agree); higher mean composite values for the scale indicated higher levels of relationship conflict. Example statements from Jehn's (1997) measure of relationship conflict include: "narrow-mindedness or envy usually drives the conflict in our workgroup," "when differences occur, some group members tries to put themselves forward at the expense of others," "the conflict is also caused by personal clashes in our group," "there are tendencies of anger and aggression between some persons in our group," and "there is a high degree of emotional conflict in our workgroup." Higher scores indicate higher perceived relationship conflict within the organizational unit.

Task conflict. Task conflict was typically measured using employees' self-report responses to statements about their immediate work group in the organization. Responses to the statements for task conflict were typically assessed using a five or seven response option Likert-type scale ranging from 1 (strongly disagree) to 5 or 7 (strongly agree) with higher mean composite values for the scale indicating higher levels of task conflict. Example statements from Jehn's (1997) measure of task conflict include: “during the conflict, our group is concerned about solving problems by using a sensible and rational procedure," "our disagreements are tasks oriented and put reasons before emotions," "while disagreeing on the subject matter, feelings are kept under control and argued in a logical and analytical manner," 
"conflict of ideas occur in our work group," and "there are frequent disagreements within our workgroup about the tasks we are working on." Higher scores indicate higher perceived task conflict within the organizational unit.

Organizational culture. The dimensions of organizational culture we examined in this study as moderators of the relationship between diversity and conflict were outcome orientation and team orientation. These are two of the most commonly utilized culture dimensions in the Organizational Culture Profile (Baird et al., 2007; O'Reilly et al., 1991) and constitute two of the seven cultural dimensions developed from the original O'Reilly et al. (1991) OCP measure. Similar variations of these dimensions that were agreed upon by coders were grouped together, as will be later described in the coding section of this paper. Team orientation and outcome orientation were included as predictor variables, and task conflict and relationship conflict were included as two distinct criterion variables.

Measures for both cultural dimensions are typically calculated as the composite average of all of the rated statements that individual group members gave for their group. Specifically, the composite average of all team orientation statements that participants responded to often representing the team orientation organizational culture dimension for each group and the composite average to the orientation culture statements often representing the outcome orientation culture dimension for each group. Most of the measures assessing outcome orientation and team orientation typically resulted from employees' summed responses to a series of statements for team-oriented culture dimension and outcome-oriented that they rated using five- or seven-point Likert-type scales, with participants assessing the extent to which each statement was valued by their group from 1 (not valued at all) to 5 or 7 (valued to a very great extent). 


\section{Development of Categories for Coding the Primary Variables}

Two independent coders examined and recorded the information for the primary variables in the 40 independent samples included in the current meta-analysis. The coding process began with each coder independently coding the effect size data of the correlations between each of the four demographic diversity variables and relationship conflict, each of the four demographic diversity variables and task conflict, team-oriented culture and relationship conflict, team-oriented culture and task conflict, outcome-oriented culture and relationship conflict, and outcome-oriented culture and task conflict. The internalconsistency reliability information was coded for the task conflict and relationship conflict measures as well as the team-oriented culture and outcome-oriented culture measures. Additionally coded was the sample demographic diversity information for sample gender, sample race/ethnicity, sample age, and sample tenure; and the correlation between task conflict and relationship conflict. Finally, we recorded the sample size, the number of teams in the sample, group task complexity, the average number of individuals in a team, the sample population type, the industry type, geographic location, and other sample characteristics from each study to potentially test for further moderation of the expected effects. The interrater agreement between the two coders was high across all of the studies, with percentage agreement at $93.10 \%$ across all of the coded effect sizes and moderating variables. This was an agreement rate similar to those reported in previous similar metaanalyses (e.g., De Dreu \& Weingart, 2003; De Wit, Greer, Jehn 2013). Any disagreements were resolved by reaching a consensus through discussion addressing the original article. 
Due to the variability in how organizational culture, task conflict, and relationship conflict were measured across studies, we applied a procedure used in previous meta-analytic research to categorize similar measures of organizational culture, relationship conflict, and task conflict together (Hartnell et al., 2011; Kinicki, McKee-Ryan, Schriesheim, \& Carson, 2002). Indeed, one of the first objectives in locating studies for inclusion was for both of the coders to identify studies that used measures of organizational cultures consistent with the OCP taxonomy of team-oriented and outcome-oriented cultures (Hartnell et al., 2011). Using the database of potential articles, the coders obtained and recorded the definitions of the measured culture variables, as well as the actual items that were used to measure the culture types (Hartnell et al., 2011). Each coder then independently compared the recorded definition and item information for the cultural dimensions in each study against the revised, fourdimension OCP descriptions of outcome orientation, innovation, team orientation, and attention to detail (Baird et al., 2007; O'Reilly et al., 1991).

The two coders then each made independent judgments about whether the dimensions of culture assessed in each article were congruent with the theoretical framework and definitions of one of the four culture types underlying the OCP. To ensure that the measures included in each culture category were homogeneous, the dimensions were classified as team-oriented culture or outcome-oriented culture only when both coders agreed that the definitions and item content of the organizational culture dimension in the study demonstrated a large degree of overlap with the definition and item content of either teamoriented culture or outcome-oriented culture. This approach is consistent with the protocol outlined in other meta-analytic research on the effects of organizational culture types on various organizational outcomes (Hartnell et al., 2011). 
Following the classification protocol of similar previous meta-analyses assessing organizational culture (Hartnell et al., 2011), coders then discussed the inclusion of each culture measure as a potential measure of one of the OCP culture dimensions. The criterion was $100 \%$ agreement between the coders to finalize each classification decision regarding whether to classify specific measures of culture utilized in the studies as one of the OCP culture dimensions or as a different cultural dimension found in other frequently utilized organizational culture theoretical frameworks. These included the Organizational Culture Inventory (OCI) or the competing values framework (CVF) that assessed similar and overlapping culture dimensions with a high degree of content and theoretical similarity to the culture dimensions included in the OCP framework.

The raters did not record the correlations of studies that included measures of culture dimensions that were determined by both coders to be theoretically and conceptually ambiguous, or to have meanings that overlap with more than one of the OCP culture dimensions (e.g., the decisiveness dimension in the OCP). Thus, the coding procedure excluded correlations from studies that included measures of culture types that were unclear or related to more than one of the dimensions of the OCP. Additionally, the correlations that were included in the current meta-analysis were only those that were determined by both of the raters to sufficiently assess one of the OCP dimensions of culture.

Similarly, attempts were made to allow for comprehensive and clear classifications of relationship conflict and task conflict measures included in the final data analysis. Using a similar process to that used to code measures of organizational culture, coders each independently evaluated and recorded the definitions and items used to measure relationship conflict and task conflict. They then decided whether to code the conflict measure as task 
conflict (coded as 0 ), relationship conflict (coded as 1 ), or a separate outcome with a unique code value assigned to each of the distinct outcomes measured (Hartnell et al., 2011). New independent codes were assigned to outcome variables when they were determined not to include similar content as the existing outcome variables. Consistent with the inclusion criteria used for coding measures of culture, both coders were required to agree $100 \%$ on whether a given conflict variable represented relationship conflict, task conflict, or another variable (Hartnell et al., 2011).

Data from each of the qualified 40 studies was also coded for the following: the reported correlation between task conflict and relationship conflict in the sample (coded as a continuous variable); gender composition of the sample; racial/ethnic demographic composition of the sample; standard deviation age of the participants in the sample representing the demographic diversity variable of age; and standard deviation of the organizational tenure of the participants included in the sample representing the demographic diversity variable of tenure. Primary study effect size information, reliability information, and demographic information can be found in Table 1.

In addition to these variables, we also collected information about methodological and organizational aspects of the qualified studies, including study sample size, size of the organization, size of the work unit(s) (in the instances when two or more work units were included in a study, the average group size across the work units was recorded), and type of organizational culture measure administered (OCP measures of culture coded as 0 and other non-OCP measures coded as 1). We also collected information about aspects that may have had an influence on whether team-oriented culture and outcome-oriented culture were positively or negatively related to group conflict. Specifically, one of the methodological 
variables that was coded and included in the final data set as a potential categorical moderator was study setting (field vs. nonfeild) in order to assess whether the results differ for studies conducted within organizations (coded as 0 ) between studies within laboratory or classroom settings (coded as 1). Sample population was also coded as consisting of professionals (coded as 0 ) or of undergraduates and post-graduates (coded as 1 ) to examine if and to what extent the true estimated effect sizes vary between samples with professional subjects compared to samples with student subjects. Additionally, industry type was also coded as a potential moderator variable whenever sample industry information or composition was reported within a study to determine if effect sizes varied by the industry type (financial-related industries coded as 0 , marketing and sales-related industries coded as 1 , healthcare and education-related industries coded as 2 , technological service-related industries coded as 3, production and other manufacturing-related industries coded as 4).

Group task complexity of the interdependent tasks primarily being completed by work group members was also coded and included as a methodological moderator variable to determine if effect sizes varied by group task complexity (highly complex tasks involving high levels of information processing and novel decision-making tasks requiring a high degree of consideration from a number of different criteria coded as 0 , moderately complex tasks with a moderate degree of novelty and existing task structure and protocols being coded as 1 , and simple routine tasks with a high degree of task structure coded as 2) with task complexity broadly defined as a function of the degree of formal task structures involved in a task, the degree of the non-routineness, and the degree to which different criteria need to be considered to successfully perform a task (e.g., Campbell, 1988; Fisher, et al., 2003). The geographic location where the studies were conducted for each sample was also coded to 
determine if and to what extent the estimated effect sizes varied between samples depending on geographic location (studies conducted in the United States coded as 0, studies conducted in European countries coded as 1, studies conducted in Asian countries coded as 2, and studies conducted in other geographic locations coded as 3). Additionally, organizational level was also included and coded in order to assess potential differences between samples with top management teams (coded as 0 ) at the top of the organizational hierarchy compared to samples with teams at lower levels of the organization (coded as 1).

\section{Meta-Analytic Method}

Following the approach developed by Hunter and Schmidt (1990, 2004), we first corrected all the study effect sizes for sampling error. We corrected for measurement error in the conflict criterion variables by using the square root of the reliability estimate of the conflict measure included in the study. We also corrected for measurement error in the teamoriented culture and outcome-oriented culture predictor variables using the internal consistency coefficients of the culture and conflict measures included in the study when computing the estimated true-score correlations between culture and conflict. Reliability estimates for the relationship conflict and task conflict criterion variables were reported in each study using the reported internal consistency coefficient estimates for each of the conflict measures it included. The overall internal consistency coefficient across all studies for task conflict and relationship conflict were included in the case that an individual study did not report the internal consistency coefficient information for one or both of the conflict measures. Similarly, for studies that included correlations between culture and conflict used to compute the estimated true-score correlations between culture and conflict, the average overall reliability estimate across all studies for team-oriented culture and outcome-oriented 
culture were included in the case that a study did not report the internal consistency coefficients for one or both of the culture predictor measures.

Additionally, in cases that studies reported more than one estimate of a correlation between a culture predictor variable $(\mathrm{X})$ and a conflict criterion variable $(\mathrm{Y})$, the formula for composites (Hunter \& Schmidt, 2004) was utilized to compute and include composite correlations of the effect using the intercorrelations across the measures reported in the individual studies. The linear composite correlation provides a better estimate of the relationship than either the component or the average correlation as linear composites computed as unit weights have been found to be comparable to regression-derived weights (Hunter \& Schmidt, 1990; Nunnally, 1978).

Next, the sampling error variance of corrected effect sizes, $\operatorname{Var}(e i)$ was computed along with the correction factor $a$ (Hunter \& Schmidt, 1990, 2004). $\operatorname{Var}(e i)$ was then multiplied by $a^{2}$ to obtain $v e$ as superior estimate of the sampling error variance of corrected effect sizes (Hunter \& Schmidt, 2004). The weight for each individual sample (wi) was then computed as the product of each respective study's sample size and the artifact correction (Hunter \& Schmidt, 1990, 2004). Subsequently, the estimated true-score correlation ( $\rho$ ), the variance of the estimated true-score correlation $\left(S^{2} \rho\right)$, the estimated standard deviation of the true-score correlation $(S D \rho)$, and the estimated percentage of variance in $\rho$ due to sampling error and unreliability (\%SEV) were computed and utilized to determine whether or not more than $75 \%$ of the total estimated variance was accounted for by artifactual variance (Hunter \& Schmidt, 1990, 2004). Following the protocol outlined by Hunter and Schmidt (2004), a search for moderators was considered warranted and conducted in the case that less than $75 \%$ 
of the observed variance was accounted for by study artifacts (i.e., sampling error and measurement unreliability).

All of the analyses were conducted using the Schmidt-Le program (Version 1.1;

Schmidt \& Le, 2004). The overall precision of the mean estimates of the corrected population coefficients was examined by calculating the $95 \%$ confidence interval (CI) around the effect size. The disparity and heterogeneity of the effect sizes were analyzed by calculating $80 \%$ credibility intervals (Hunter \& Schmidt, 2004).

Both the fixed-effects and random-effects meta-analysis models have been widely utilized in published meta-analyses (Borenstein, Hedges, Higgins, \& Rothstein, 2011; Hartnell et al., 2011; Hedges \& Olkin, 1985; Hunter \& Schmidt, 2000; Hunter \& Schmidt, 2004). Although both of the models often utilize similar sets of formulas, and may afford similar estimates of effect-size parameters in some instances, the fixed-effects model and the random-effects model represent fundamentally different assumptions about the data. Fixedeffects models make the assumption that all of the studies being analyzed are homogenous at the population level effect-size, and any between-studies differences that are found in the effect-sizes can be attributed to study sampling error and other study artifacts. Randomeffects models do not make the same assumption and allow for the possibility that differences in the effect-sizes may be attributed to different population effect-size parameters between studies (Borenstein et al., 2011; Hunter \& Schmidt, 2000).

When comparing the accuracy of fixed-effects and random-effects models, fixedeffects models can often result in a considerable Type 1 error in significance tests for mean effect sizes and for moderator variable interactions, while random-effects models do not (Hunter \& Schmidt, 2000). Similarly, fixed-effects meta-analysis models can also generate 
confidence interval estimates of mean effects sizes that are more restrictive than their nominal width, resulting in an overly precise range of confidence interval estimates and an overstated precision of meta-analysis findings, while random-effects models are more conservative (Hunter \& Schmidt, 2000). Thus, given the purpose scope of the current metaanalytic study — following the recommendation of Hunter and Schmidt (2000) to employ and prioritize random-effects meta-analysis models in preference to fixed-effects meta-analysis models - the current study utilized and reports only the results of the more conservative random-effects model. Using random-effects meta-analytical methods is also in line with the recommendations of the consensus of meta-analytic research that has indicated that randomeffects methods are the best initial strategy for conducting similar types of meta-analyses (Arthur, Bennett, \& Huffcutt, 2001; Borenstein et al., 2011; Hartnell et al., 2011; Hunter \&

Schmidt, 2004). To test for moderation, studies were assigned a numerical value based on the moderator variables being assessed and grouped accordingly. Although statistical significance testing is not advocated by the Hunter and Schmidt approach (Hunter \& Schmidt, 1990), the mean effect sizes can be compared across groups using a $t$ statistic.

\section{RESULTS}

\section{Team-Oriented Culture, Outcome-Oriented Culture, and Intragroup Conflict Types}

The current meta-analysis used a total of 40 independent samples and had a total sample size of 3,154 groups, with the individual study sample sizes ranging from 44 to 200 groups. Together, the 40 independent samples represented a total of 156 effect sizes.

H1a proposed that increased heterogeneity in surface-level demographic variables within samples (i.e., gender, race, and age) would be positively related to relationship 
conflict across studies. With respect to gender diversity, the results indicated that there was a significant positive corrected correlation between sample gender heterogeneity and relationship conflict across studies, $r=.25, p=.01, k=26$; increased gender diversity within samples was associated with higher levels of relationship conflict. Similarly, regarding the association between sample racial heterogeneity and relationship conflict, there was a significant and positive corrected correlation between sample racial heterogeneity and relationship conflict across studies, $r=.34, p<.01, k=12$. Higher levels of sample racial heterogeneity were associated with increased levels of intragroup relationship conflict. With respect to the association between sample age diversity and relationship conflict, the corrected correlation results indicated that there was a positive significant relationship between sample age heterogeneity and relationship conflict across studies, $r=.19, p=.03, k$ $=16$, with greater sample age heterogeneity associated with higher levels of relationship conflict. For organizational tenure diversity, the results similarly indicated that there was a significant and positive corrected correlation between sample organizational tenure heterogeneity and mean sample intragroup relationship conflict across studies, $r=.21, p<$ $.05, k=12$. The positive corrected correlations found between sample heterogeneity in gender, race, age, and organizational tenure and relationship conflict are in line with previous workgroup diversity research (Shore et al., 2011; Thatcher \& Patel, 2011; Williams \& O'Reilly, 1998). As the corrected correlations between sample heterogeneity in all of the primary demographic diversity attributes were each positively and significantly associated with relationship conflict, H1a was fully supported.

$\mathrm{H} 1 \mathrm{~b}$ proposed that increased heterogeneity in the surface-level demographic variables of race, gender, and age would be positively associated with task conflict across studies. 
With respect to the relationship between sample gender heterogeneity and task conflict, the results revealed a positive and significant corrected correlation between sample gender heterogeneity and task conflict across studies, $r=.26, p<.01, k=25$. Similarly, with respect to the association between sample racial heterogeneity and task conflict, the results indicated there was a significantly positive corrected correlation between sample racial heterogeneity and task conflict across studies, $r=.22, p<.01, k=12$. Regarding the relationship between sample organizational tenure heterogeneity and task conflict, the results indicated that there was a significant positive corrected correlation between sample organizational tenure heterogeneity and task conflict across studies, $r=.37, p<.01, k=12$. However, with respect to sample age heterogeneity, the results indicated that there was not a significant corrected correlation between sample age heterogeneity and task conflict across studies, $r=.07, p>$ $.05, k=15$. Thus, $\mathrm{H} 1 \mathrm{~b}$ was partially supported.

Table 2 reports the number of independent samples included in the meta-analysis $(k)$, the total group sample size across the samples $(N)$, the sample size weighted mean observed correlation $(r)$, the sample size weighted mean observed correlation corrected for unreliability in both measures $(\rho)$, the standard deviation associated with $\rho(\mathrm{SD} \rho)$, the $80 \%$ credibility interval around $\rho$, the $95 \%$ confidence interval around $\rho$, and the percent variance due to sampling error (\%SEV). Additionally, cumulative meta-analyses are utilized as a test of publication bias with alternative effect estimates of $\rho$ reported for the five largest samples (CMA 5) and the samples with the 10\% largest sample sizes (CMA 10\%). The percentage difference between overall estimates of $\rho$ and the cumulative meta-analyses estimates are reported as additional indicators to aid in interpretation in each of the instances when five or more independent studies were included in a distribution. 
The cumulative meta-analysis iterations for the associations between team-oriented culture and relationship conflict, team-oriented culture and task conflict, outcome-oriented culture and relationship conflict, team-oriented culture and task conflict, and the cooccurrence of task conflict and relationship conflict—including the estimates of $r$ and $\rho$ for each iteration-are reported in Tables 7-10 to allow for the analysis of potential positive drift, and aid in visual interpretation of the dispersion of the effects. Lastly, all outliers excluded from the data are reported and assessed using the calculated Sample-Adjusted Meta-Analytic Deviancy (SAMD; Huffcutt \& Arthur, 1995) statistic for each individual study effect using $r$ estimates of Fischer's z score transformation of $r$ (as suggested by Beal, Corey, \& Dunlap, 2002) to create individual SAMD values for each individual effect size. Individual effect estimates across the 40 independent samples with a computed SAMD statistic that had a value greater than 2.58 met the criteria for consideration to be excluded from the data (Huffcutt \& Arthur, 1995; Leys, Ley, Klein, Bernard, \& Licata, 2013). However, no positive or negative outliers were identified that met the criteria to be excluded from the data across the 40 independent samples in any of the analyses.

H2a proposed that team-oriented culture would be significantly and negatively associated with relationship conflict. Table 2 summarizes overall mean-corrected correlations between all the culture and intragroup conflict variables in our samples. The results indicated that team-oriented culture was significantly negatively related to relationship conflict ( $\rho=$ $.29, \mathrm{CI}[-.38,-.21]$, respectively). $\mathrm{H} 2 \mathrm{~b}$ proposed that team-oriented culture would be significantly and negatively associated with task conflict. Similarly, the results indicated that team-oriented culture was significantly negatively related to task conflict $(\rho=-.13, \mathrm{CI}[-.26,-$ $.01])$. The $95 \%$ confidence intervals reported for both the association between team-oriented 
culture and relationship conflict, and between team-oriented culture and task conflict, did not overlap with 0 , suggesting that the negative relationships were reliable (Borenstein et al., 2011; Whitener, 1990). Thus, the results reported a significant negative relationship between team-oriented culture and relationship conflict as well as a significant negative relationship between team-oriented culture and task conflict, providing support for both $\mathrm{H} 2 \mathrm{a}$ and $\mathrm{H} 2 \mathrm{~b}$. Moreover, the $80 \%$ credibility intervals for the associations between team-oriented culture and relationship conflict as well as team-oriented culture and task conflict were both relatively broad, indicating that effect sizes likely differ between studies depending on contextual settings and a high likelihood for the presence of subpopulation moderators between studies (De Wit, Greer, \& Jehn, 2012; Hunter \& Schmidt 2004; Hunter \& Schmidt 2000). Thus, the results indicate that there are relative restrictions to the generalizability of the estimated corrected unattenuated correlations across studies between team-oriented culture and relationship conflict and team-oriented culture and task conflict and that there is sufficient heterogeneity between the study results to justify an investigation of potential moderators of these effects.

H3a proposed that outcome-oriented culture would be significantly and positively associated with relationship conflict. As expected, the results indicated that outcome-oriented culture was reliably positively related to relationship conflict across studies $(\rho=.18, \mathrm{CI}[.03$, .33], respectively), supporting H3a. Similarly, H3b proposed that outcome-oriented culture would be significantly and positively associated with task conflict. Indeed, outcome-oriented culture was reliably positively related to task conflict across studies $(\rho=.18$, CI $[.04, .32]$, respectively). The results also indicate these relationships were both reliable. The $95 \%$ confidence intervals for both associations did not overlap with zero, suggesting that the 
positive relationship between outcome-oriented culture and relationship conflict and the positive relationship between outcome-oriented culture and task conflict were reliable, supporting $\mathrm{H} 3 \mathrm{a}$ and $\mathrm{H} 3 \mathrm{~b}$. The meta-analysis results of the association between outcomeoriented culture and relationship conflict and outcome-oriented culture and task conflict are reported in Table 2 .

With respect to the co-occurrence between task conflict and relationship conflict, the results indicate that there is a significant and reliable positive association between task conflict and relationship conflict $(\rho=.61, \mathrm{CI}=[.50, .73]$, respectively), similar to the findings of previous meta-analyses examining the co-occurrence of intragroup task and relationship conflict (e.g., DeDreu \& Weingart, 2003; DeWitt, Greer. \& Jehn, 2012). Additionally, the credibility intervals for the association between task conflict and relationship conflict did not contain zero, indicating that the positive relationship is generalizable across various contextual settings. These findings are also consistent with and replicate those of DeWitt, Greer, and Jehn (2012) and with the findings of other previous meta-analyses examining intragroup conflict and the co-occurrence of conflict (e.g., De Dreu and Weingart, 2003).

\section{Moderation Analyses}

To test $\mathrm{H} 4$ and H5, team-oriented culture and outcome-oriented culture were modeled as continuous moderators of the associations between gender sample diversity and relationship conflict, racial sample diversity and relationship conflict, age sample diversity and relationship conflict, and organizational tenure sample diversity and relationship conflict in separate WLS regression analyses. Results were reported using the more conservative mixed-effects model due to the wide range of variance remaining in the overall effect size 
estimates between sample heterogeneity in each of the four primary diversity variables and relationship conflict as well as task conflict left unaccounted for after controlling for statistical artifacts. H4 proposed that team-oriented culture would significantly moderate the relationship between sample demographic heterogeneity and relationship conflict, with greater levels of team-oriented culture associated with reduced associations between sample demographic diversity and relationship conflict. The results of the WLS regression analysis indicated that the interaction term between sample gender diversity and team-oriented culture was significantly associated with relationship conflict $(B=-.73, p<.01)$; thus, indicating that team-oriented culture significantly moderated the relationship between sample gender diversity and relationship conflict. Specifically, higher levels of team-oriented culture were associated with weaker associations between sample gender diversity and relationship conflict, supporting $\mathrm{H} 4$.

With respect to the moderation of team-oriented culture between the association of sample racial diversity and relationship conflict, the results of the WLS regression analyses similarly indicated that team-oriented culture moderated the association between sample racial diversity and intragroup relationship conflict as the interaction term between racial sample diversity and team-oriented culture was significantly and negatively associated with intragroup relationship conflict $(B=-.58, p<.05)$. Specifically, highly racially diverse samples with higher levels of team-oriented culture were associated with lower levels of relationship conflict compared to highly racially diverse samples with lower levels of teamoriented culture, supporting H4.

Regarding the moderation of team-oriented culture on the association between sample age diversity and relationship conflict, the results of the WLS regression analyses indicated 
that team-oriented culture significantly moderated the relationship between sample age diversity and relationship conflict $(B=-.30, p<.05)$ as the interaction term between sample age heterogeneity with team-oriented culture was significantly and negatively associated with relationship conflict after controlling for team-oriented culture and sample age diversity. Specifically, increased levels of team-oriented culture were associated with decreased associations between sample age diversity and relationship conflict, further supporting $\mathrm{H} 4$.

Similarly, with respect to sample organizational tenure diversity, the results of the WLS regression analyses indicated that team-oriented culture also significantly moderated the relationship between sample organizational tenure diversity and relationship conflict $(B=$ $-.69, p<.01)$ as the interaction term between sample organizational tenure heterogeneity with team-oriented culture was significantly and negatively associated with relationship conflict after controlling for team-oriented culture and sample organizational tenure heterogeneity. Specifically, increased levels of team-oriented culture were associated with decreased associations between sample organizational tenure diversity and relationship conflict. Thus, team-orientated culture significantly moderated and was negatively related with the associations between sample heterogeneity in each four of the primary diversity attributes with relationship conflict. Thus, there was full support for H4. See Table 3 for full WLS regression analyses results of the team-oriented culture and outcome-oriented culture continuous moderators between the associations of demographic diversity and relationship conflict.

Figure 1 illustrates the interaction between gender sample diversity and team-oriented culture on relationship conflict by showing the slopes of the WLS regression lines linking sample gender diversity to relationship conflict under conditions of high and low team- 
oriented culture at one standard deviation above and below the standardized team-oriented culture mean across studies (Aiken \& West, 1991). A simple slope analysis was conducted and indicated that sample gender heterogeneity was significantly positively associated with increases in relationship conflict in samples in which the mean level of work group teamoriented culture was low $(B=0.41, p<0.01)$. However, the relationship between sample gender diversity and relationship conflict was significantly negative in samples in which mean work group team-oriented culture was high $(B=-0.21, p<.05)$. Similarly, Figure 2 shows findings of a simple slope analysis of the association between racial diversity and relationship conflict under the conditions of high and low levels of team-oriented culture. As shown, samples with high levels of team-oriented culture has a weaker association between race sample heterogeneity and relationship conflict $(B=.18, p=.01)$ compared to samples with low levels of mean group team-oriented culture $(B=.59, p<.01)$. Additionally, Figure 3 includes the simple slope analysis for the association between sample age heterogeneity with relationship conflict at high and low levels of team-oriented culture and indicates that greater team-oriented culture among workgroups was associated with decreased associations between sample age heterogeneity and relationship conflict.

Similarly, Figure 4 includes the simple slope analysis for the association between sample organizational tenure heterogeneity and relationship conflict and indicates that greater team-oriented culture among workgroups was also associated with decreased associations between sample organizational tenure heterogeneity and relationship conflict. Thus, the results of the simple slopes analyses for each of the four sample diversity attributes each indicated that when team-oriented culture was higher among groups within samples, the 
detrimental associations between racial, gender, age, and organizational tenure sample heterogeneity and relationship conflict were more negative, further supporting H4.

H5 proposed that outcome-oriented culture would significantly moderate the relationship between sample demographic heterogeneity and relationship conflict, with greater levels of outcome-oriented culture associated with increased positive associations between sample demographic diversity and relationship conflict. Regarding the moderation of outcome-oriented culture on the association between sample gender diversity and relationship conflict, the results of the WLS regression analysis indicated that outcomeoriented culture also moderated the association between sample gender diversity and relationship conflict in the expected direction, $(B=.73, p<.05)$. Specifically, greater levels of outcome-oriented culture were associated with increased positive associations between sample gender diversity and relationship conflict, supporting H5.

The results of the WLS regression analysis for the attribute of racial diversity indicated that outcome-oriented culture significantly moderated the association between sample racial heterogeneity and relationship conflict in the expected direction. Specifically, after controlling for sample race heterogeneity and outcome-oriented culture independently, the interaction between outcome-oriented culture and sample racial heterogeneity accounted for a significant amount of unique variance in relationship conflict $(B=.67, p<.01)$. Higher levels of outcome-oriented culture were associated with increased positive associations between sample racial diversity and relationship conflict, providing further support for H5.

With respect to the attribute of age diversity, the results of the WLS regression analyses indicated that outcome-oriented culture significantly moderated the relationship between sample age diversity and relationship conflict $(B=.39, p<.05)$. Specifically, higher 
levels of outcome-oriented culture were associated with increased positive associations between sample age diversity and relationship conflict, supporting H5.

Similarly, the results of the WLS regression analyses indicated that outcome-oriented culture also significantly moderated the association between sample organizational tenure diversity and relationship conflict $(B=.43, p<.05)$. More specifically, higher levels of outcome-oriented culture were associated with increased positive associations between sample organizational tenure diversity and relationship conflict. Thus, the results of the WLS regression analyses supported H5. See table 3 for full WLS regression analyses results of the team-oriented culture and outcome-oriented culture continuous moderators between the associations of demographic diversity and relationship conflict.

\section{The Impact of Team-Oriented Culture and Outcome-Oriented Culture on Intragroup Conflict Co-Occurrence}

H6 proposed that as team-oriented culture increases, the association between task and relationship conflict would decrease. Similarly, $\mathrm{H} 7$ proposed that outcome-oriented culture was significantly and positively associated with the association between task and relationship conflict, with greater levels of outcome-oriented culture being associated with increased positive associations between task conflict and relationship. The team-oriented culture and outcome-oriented culture continuous moderators were tested independently using WLS regression analyses, and results were reported using the more conservative mixed-effects model. The chi-square test of heterogeneity for the association between task conflict and relationship conflict was significant $(Q=252.82, p<.01)$ and results were reported using the more conservative mixed-effects model. With respect to the impact of team-oriented culture on the association between task and relationship conflict, the WLS regression analysis 
indicated that team-oriented culture significantly moderated the relationship between task conflict and relationship conflict $(B=-.22, S E B=.03$, CI [-0.27, -0.17], $p<.01)$. Specifically, higher levels of team-oriented culture were associated with increased negative associations between task conflict and relationship conflict. Thus, the results of the WLS regression analysis between team-oriented culture and conflict co-occurrence supported H6.

With respect to the moderation of outcome-oriented culture on the association between task and relationship conflict, the WLS regression analysis indicated that outcomeoriented culture significantly moderated the relationship between task conflict and relationship conflict $(B=.63, S E B=.05$, CI [0.55, 0.71], $p<.01)$. Specifically, higher levels of outcome-oriented culture were associated with increased positive relationships between task conflict and relationship conflict. Thus, the results of the WLS regression analysis between outcome-oriented culture and conflict co-occurrence supported $\mathrm{H} 7$ (for all statistics, see Table 4).

In addition, subsequently, omnibus tests for $\mathrm{H} 6$ and $\mathrm{H} 7$ were conducted to assess the significance, direction, and strength of the association between task conflict and relationship conflict at different levels of team-oriented culture and outcome-oriented culture. They addressed the two culture categorical moderators of team-oriented culture (grouped as one of the two potential team-oriented culture level categories as either high team-oriented culture or low team-oriented culture) and outcome-oriented culture (grouped as one of the two potential outcome-oriented culture level categories as either high outcome-oriented culture or low outcome-oriented culture) between the co-occurrence of task conflict and relationship conflict. The results of the omnibus test for team-oriented culture and conflict co-occurrence 
and the results of the omnibus test for outcome-oriented culture and conflict co-occurrence were both significant $(Q b=8.44, p<.01 ; Q b=4.26, p=.03$, respectively).

With respect to the impact of team-oriented culture on the strength and direction of the association between task conflict and relationship conflict (H6), the results indicated that task conflict was reliably positively associated with relationship conflict when there was high levels of team-oriented culture $(\rho=.58, \mathrm{CI}=[.45, .71]$, respectively) as well as when there was low levels of team-oriented culture $(\rho=.68, \mathrm{CI}=[.55, .81]$, respectively). Specifically, the results indicated that the corrected correlation estimate of the association between task conflict and relationship conflict was visibly more positive for samples with low teamoriented culture compared to samples with high team-oriented culture. However, the $95 \%$ confidence intervals for the samples with low team-oriented culture and the $95 \%$ confidence intervals for the samples with high team-oriented culture overlapped with each other, indicating that the differences in conflict co-occurrence between samples with high levels of team-oriented culture and samples with low levels of team-oriented culture were not reliably significant. Thus, H6 was partially supported.

With respect to the impact of outcome-oriented culture on the strength and direction of the association between task conflict and relationship conflict (H7), the results indicated that task conflict was positively and reliably associated with relationship conflict when there was high levels of outcome-oriented culture and when there was low levels of outcomeoriented culture, $(\rho=.72, \mathrm{CI}=[.59, .85] ; \rho=.61, \mathrm{CI}=[.50, .72]$, respectively $)$. The results illustrate that the corrected correlation between the association of task conflict and relationship conflict was visibly more positive for samples with high levels of outcomeoriented culture compared to samples with low levels of outcome-oriented culture. However, 
the $95 \%$ confidence intervals for the samples with high outcome-oriented culture and the $95 \%$ confidence intervals for the samples with low outcome-oriented culture overlapped with each other, indicating that the difference between samples with high outcome-oriented culture and samples with low outcome-oriented culture was not reliably significant. Thus, H7 was partially supported. The full results of the two categorical culture moderators between the association of task conflict and relationship conflict are reported in Table 5.

\section{Culture Moderator Analyses Between Sample Diversity and Task Conflict}

Subsequently, in order to test RQ1 and RQ2, that team-oriented culture and outcomeoriented culture might moderate the associations between gender sample diversity and task conflict, racial sample diversity and task conflict, age sample diversity and task conflict, and organizational tenure sample diversity and task conflict were tested independently using WLS regression analyses and results were reported using the more conservative mixedeffects model. RQ1 sought to examine if and in what direction team-oriented culture moderated the association between sample demographic heterogeneity and task conflict. The results of the WLS regression analysis indicated that team-oriented culture significantly moderated the relationship between sample gender diversity and task conflict, $B=-.61, p<$ .01 . Higher levels of team-oriented conflict were associated with increased negative associations between sample gender diversity and task conflict. With respect to the moderation of team-oriented culture between the association of sample racial diversity and task conflict, the results of the WLS regression analysis indicated that team-oriented culture did significantly moderate the relationship between sample racial diversity and task conflict, $B=-1.65, p<.01$. Specifically, greater levels of team-oriented culture were associated with reduced correlations between sample racial heterogeneity and task conflict. 
Regarding the moderation of team-oriented culture between the association of sample age diversity and task conflict, the results of the WLS regression analysis indicated that team-oriented culture significantly moderated the relationship between sample age diversity and task conflict, $B=-.29, p<.05$. Higher levels of team-oriented conflict were associated with more negative associations between sample age diversity and task conflict. Lastly, with respect to the moderation of team-oriented culture between the association of sample organizational tenure diversity and task conflict, team-oriented culture significantly moderated the relationship between sample organizational tenure diversity and task conflict, $B=-1.13, p<.01$. Higher levels of team-oriented conflict were associated with more negative associations between sample organizational tenure diversity and task conflict.

RQ2 sought to examine if and in what direction outcome-oriented culture moderated the association between sample demographic heterogeneity and task conflict. With respect to the moderation of outcome-oriented culture between the association of sample gender diversity and task conflict, the results of the WLS regression analysis indicated that outcomeoriented culture significantly moderated the relationship between sample gender diversity and task conflict, $B=.55, p<.05$. As outcome-oriented culture increased, an increased positive relationship between sample gender diversity and task conflict was observed. With respect to the moderation of outcome-oriented culture between the association of sample racial diversity and task conflict, outcome-oriented culture significantly moderated the relationship between sample racial diversity and task conflict, $B=1.45, p<.01$. As outcome-oriented culture increased, the positive relationship between sample racial diversity and task conflict increased. 
Regarding the moderation of outcome-oriented culture between the association of sample age diversity and task conflict, the results of the WLS regression analysis indicated that outcome-oriented culture significantly moderated the relationship between sample age

diversity and task conflict, $B=.71, p<.05$. Higher levels of outcome-oriented conflict were associated with increased positive associations between sample age diversity and task conflict. Lastly, outcome-oriented culture also significantly moderated the relationship between sample organizational tenure diversity and task conflict, $B=.71, p<.01$. Higher levels of outcome-oriented conflict were associated with increased positive associations between sample organizational tenure diversity and task conflict. See Table 6 for the full WLS regression analyses results of the team-oriented culture and outcome-oriented culture continuous moderators between the associations of demographic diversity and task conflict.

\section{Discussion}

\section{Team-Oriented Culture, Outcome-Oriented Culture, Diversity, and Intragroup}

\section{Conflict}

The current meta-analysis used 40 samples to examine how the association between sample demographic diversity and relationship conflict and task conflict were moderated by team-oriented culture and outcome-oriented culture. Additionally, the current meta-analysis also examined the co-occurrence of conflict by assessing the association between task conflict and relationship conflict, as well as the association between task-conflict and relationship conflict at different levels of team-oriented and outcome-oriented culture. The purpose was to examine if and to what extent team-oriented culture and outcome-oriented culture may impact the associations between sample demographic diversity in gender, race, age, and organizational tenure with task conflict and relationship conflict. 
Replicating past work, this meta-analysis indicated that sample gender heterogeneity was significantly positively associated with relationship conflict and task conflict across studies. Similarly, sample racial heterogeneity was significantly and positively associated with relationship conflict and task conflict across studies. With respect to organizational tenure heterogeneity and age heterogeneity, organizational tenure heterogeneity was significantly and positively associated with relationship conflict and task conflict across studies, although sample age heterogeneity was not significantly associated with relationship conflict or task conflict across studies.

The positive associations found between gender heterogeneity and racial heterogeneity with relationship conflict and task conflict are in line with previous workgroup diversity research on intragroup relationship conflict (e.g., Shore et al., 2011; Thatcher \& Patel, 2011; Williams \& O’Reilly, 1998) and task conflict (e.g., Kozhevnikov et al., 2014; Nielsen, 2017; Wooley et al., 2015). The significant positive associations found between the deep-level demographic attribute of organizational tenure heterogeneity with relationship conflict and task conflict support previous work on the effects of deep-level diversity on intragroup relationship conflict (e.g. Williams \& O'Reilly, 1998; Zenger \& Lawrence, 1989) as well as task conflict (e.g. Levine \& Moreland, 1999; Tekleab et al., 2016).

The most novel contribution of the current study was the meta-analytical investigation of team-oriented culture as a moderator of the association of demographic diversity and relationship conflict. As predicted, team-orientation significantly moderated the association between demographic sample diversity and relationship conflict in the expected direction. More specifically, the results indicated that team-oriented culture significantly moderated and mitigated the associations between sample gender heterogeneity and 
relationship conflict and sample racial heterogeneity and relationship conflict. Similarly, the findings also indicated that team-oriented culture significantly moderated and attenuated the associations between sample age heterogeneity and relationship conflict and sample organizational tenure heterogeneity and relationship conflict. Thus, for each of the four diversity attributes, increased levels of team-oriented culture were related to reduced and more negative associations between sample heterogeneity and relationship conflict, indicating that team-oriented culture could potentially serve as a contextual moderator that may help buffer and mitigate the detrimental relationships often associated between demographic diversity and relationship conflict.

With respect to the moderation of outcome-oriented culture on the association of demographic diversity and relationship conflict, the results indicated that outcomeorientation significantly moderated the association between demographic sample diversity and relationship conflict in the expected direction. More specifically, the results indicated that outcome-oriented culture significantly moderated and was related to increased positive associations between sample gender heterogeneity, sample racial heterogeneity, sample age heterogeneity, and sample organizational tenure heterogeneity with relationship conflict, with higher levels of outcome-oriented culture associated with increased positive associations between sample demographic diversity and relationship conflict. Thus, the findings suggest higher levels of outcome-oriented culture within work groups may potentially further exasperate and increase the positive detrimental association often linked between demographic diversity and relationship conflict.

With respect to the association between team-oriented culture and intragroup conflict, the results indicated that team-oriented culture was reliably negatively associated with 
relationship conflict and task conflict. The current findings illustrate that team-oriented culture may serve as a substantial contextual moderator that may mitigate the amount of intragroup conflict occurring within groups for both relationship conflict as well as task conflict. This provides novel insight and sheds light on how a team-oriented culture may be utilized to lessen both task and relationship intragroup conflict.

Our findings add a substantial and novel contribution to organizational diversity and intragroup conflict research by shedding light on whether team-oriented culture may mitigate or act as a buffer to mitigate and assuage the adverse positive associations often linked between gender diversity, racial diversity, age diversity, and organizational tenure diversity with relationship conflict. Team-oriented cultures may indeed reduce the detrimental effects of gender, racial, age and tenure diversity on relationship conflict for groups.

Regarding the particularly strong negative associations of team-oriented culture found on the relationships between gender and racial heterogeneity with relationship conflict, the increased tendency for work group members to use cognitively accessible demographic attributes during social categorization processes to define ingroup others from dissimilar outgroup individuals may likely be an influence of particular importance (Guillaume et al., 2017; Kearney, Gebert, \& Voel, 2009; van Knippenberg et al., 2004). According to social identity theory (Tajfel, 1978; Tajfel \& Turner, 1986), intergroup bias is proposed to be instigated through group members perceiving dissimilar others in different categorizations as a threat or challenge to favorable and positive self-identity and is largely a function of the cognitive accessibility of the categorization as well as the extent of the perceived social importance of the comparative fit between perceptions between-category dissimilarity and within-category similarity. As gender and race are attributes that result in cognitively readily- 
accessible perceptions of different subgroup memberships within organizational work groups implied to have high levels of potential social significance, they may be more likely to result in even greater social category salience and intergroup bias compared to less cognitively readily-accessible demographic attributes (i.e., age) (e.g., Knippenberg et al., 2004; Williams \& O’Reilly, 1998).

Increased social categorization on the basis of demographic attributes is associated with negative stereotypes and negative attitudes between work unit members of different demographic subgroups (Tajfel, 1978; Tajfel \& Turner, 1986; Tekleab \& Quigley, 2013). Subsequently, in line with SCT and SIT, the increased negative attitudes and stereotypes within highly demographically diverse work units is expected to result in increased relationship conflict and negative socialization outcomes (Ashforth \& Mael, 1989; Guillaume et al., 2017; Tajfel, 1978; Tajfel \& Turner, 1986; Tekleab \& Quigley, 2013). Thus, the more negative relationship between team-oriented culture and relationship conflict in work groups with high racial heterogeneity compared to work groups with high diversity in other demographic attributes (i.e., age and gender) may in large part be attributed due to the increased and particularly high positive association between racial diversity and relationship conflict to begin with compared to other demographic diversity attributes. This may leave an even greater opportunity for team-oriented culture to reduce relationship conflict and social categorization processes in highly racially diverse work groups compared to groups that are diverse in other attributes.

Consistent with the theoretical frameworks of SCT and SIT, the finding that teamoriented culture may attenuate the relationship between some diversity variables and relationship conflict may be due to a reduction in between-group social categorization and 
comparison processes. In a team-oriented culture, members of work units may be supported in identifying themselves on the basis of their team, rather than as members of demographic groups (Chuang et al., 2004; Tajfel, 1978; Tajfel \& Turner, 1986; Tekleab \& Quigley, 2013). Thus, team-oreinted culture may account for the decreased negative association with relationship conflict in heterogenous work units through the promotion of a single collective readily- acessible interdependent work unit identity (Guillaume et al., 2017; Mohammed \& Angell, 2004).

Regarding how outcome-oriented culture is related to relationship conflict and task conflict, our analysis finds that outcome-oriented culture is reliably and positively associated with relationship conflict and task conflict. Thus, the current findings provide additional support for understanding whether outcome-oriented culture may incite and/or exacerbate relationship conflict and task conflict within groups. More specifically, in regard to the association between outcome-oriented culture and relationship conflict, the current findings indicate that outcome-oriented culture may engender and increase the detrimental positive associations between gender, racial, age, and organizational tenure heterogeneity and relationship conflict.

With respect to gender, racial, age, and organizational tenure heterogeneity, the results show increased levels of reported work group outcome-oriented culture within samples was reliably associated with positive increases in the relationship between demographic diversity and relationship conflict. Specifically, at higher levels of outcomeoriented culture, the associations between demographic diversity and relationship conflict were more positive than at lower levels of outcome-oriented culture for gender, racial, age, and organizational tenure diversity. . Similarly, regarding task conflict, the results also show 
that samples with work groups that reported higher levels of outcome-oriented culture had stronger positive relationships between sample demographic diversity in gender, race, age, and organizational tenure and task conflict. In addition, these current findings indicate that increasing the amount of outcome-oriented culture may substantially have especially detrimental consequences for intragroup conflict in work groups with high gender heterogeneity and work groups with high racial heterogeneity, as higher levels of outcomeoriented culture were associated with particularly strong positive increases between demographic diversity and relationship conflict for gender and racial diversity. Thus, increasing the level outcome-oriented culture may particularly be detrimental to the conflict occurring within highly gender and racially diverse groups by increasing the occurrence of adverse relationship conflict.

The finding that outcome-oriented culture is reliably positively associated with detrimental relationship conflict is in line with previous findings examining the effects of work unit culture on intragroup conflict in work teams (Chuang et al., 2004; Dwyer \& Chadwick, 2003; Galinsky et al., 2015; Mohammed \& Angell, 2004). In addition, the finding that the association between gender diversity and relationship conflict was more positive with work units with higher levels of outcome-oriented culture compared to work units with lower levels of outcome-oriented culture is also in line with previous work (Chuang et al., 2004; Mohammed \& Angell, 2004; Schaeffner et al., 2015).

The increased positive association between demographic diversity and relationship conflict within work units with high levels of outcome-oriented culture has largely been attributed to the theoretical frameworks of SIT and SCT that suggest that a wide variability of surface-level demographic differences in highly heterogeneous work units have 
significantly more positive associations between outcome-oriented culture and relationship conflict compared to more homogenous work units in surface-level demographic attributes (Tajfel, 1978; Tajfel \& Turner, 1986; Tekleab \& Quigley, 2013). Since outcome-oriented and individualistic cultures are characterized by promoting and prioritizing individual achievement and results over collaboration and work group cohesion which, they may passively promote the comparisons individuals tend to classify and differentiate themselves from others on the basis of surface-level demographic differences such as differences in race and gender instead of promoting the identification of a shared collective interdependent work unit identity for work group members (Mohammed \& Angell, 2004; Schaeffner et al., 2015). Work groups with high outcome-oriented cultures may, thus, foster increased social categorization and between-group comparisons based on surface-level demographic differences (e.g. gender and race) that may engender greater levels of relationship conflict through the increased stereotyping and development of hostile attitudes of out-group members (Tajfel \& Turner, 1986; Tekleab \& Quigley, 2013).

One of the primary implications for managers to optimize the development of teamoriented cultures within their work unit supported by evidence in existing research suggests that the development and implementation of a strong collective team identification that includes each of the team members within a work unit is an effective method to help to attenuate the negative effects of demographic diversity on intragroup conflict, team processes, and outcomes in work teams (Homan et al., 2007; Thatcher \& Patel, 2011). Findings in other studies have indicated that a higher level of team-oriented culture can be effectively increased within work units while also mitigating team identification to detrimental aspects of outcome-oriented culture associated with increased associations 
between diversity and intragroup conflict. Specifically, promoting a single collective group identity emphasizing inclusion for all group members, fostering pro-diversity beliefs, and encourage collaborative and open relationships in diverse work groups have each been found to be positively associated with increased group identification with a shared collective teamoriented culture and negatively associated with the categorization of demographic subgroups (Chuang, Church, \& Zikic, 2004; Galinsky et al., 2015; Homan et al., 2007).

With respect to the association between task conflict and relationship conflict, the results of the current meta-analysis replicate the findings of previous meta-analytic investigations examining the co-occurrence of task and relationship intragroup conflict (e.g., De Dreu and Weingart, 2003; DeWitt, Greer. \& Jehn, 2012) as the results indicate that task conflict was significantly and reliably associated with relationship conflict. In regard to the impact of team-oriented culture on conflict co-occurrence, the results of the WLS regression analysis indicated that team-oriented culture significantly moderated and attenuated the detrimental positive association between task and relationship conflict, such that increased team-oriented culture was linked with reduced conflict co-occurrence. The results of the subgroup categorical analysis examining conflict co-occurrence at high and low levels of teamoriented culture indicated that the reduced and less positive conflict-occurrence for samples with high team-oriented culture compared to samples with low-team orientation was not reliable, as the $95 \%$ confidence intervals overlapped, although the corrected correlation estimate between relationship conflict and task conflict was visibly more negative among samples with high team-oriented culture compared to samples with low team-oriented culture. Given the results of the WLS regression analysis and the visibly decreased and mitigated association between task and relationship conflict in samples with high team- 
oriented culture compared to samples with low team-orientation, the findings suggest that greater levels of team-oriented culture may further benefit intragroup conflict by potentially mitigating the detrimental co-occurrence of task and relationship conflict.

In regard to the impact of outcome-oriented culture on conflict co-occurrence, the results of the WLS regression analysis indicated that outcome-oriented culture significantly moderated and increased the detrimental positive association between task and relationship conflict, such that increased outcome-oriented culture was associated with increased conflict co-occurrence. The results of the sub-group categorical analysis comparing conflict cooccurrence at high and low levels of outcome-oriented culture indicated that samples with high levels of outcome-oriented culture had visibly more positive conflict co-occurrence corrected correlation estimates compared to samples with low levels of outcome-oriented culture, although the results indicated samples with high outcome-oriented culture did not have reliably more positive conflict co-occurrence than samples with low outcome-oriented culture, as the $95 \%$ confidence intervals overlapped. Given the results of the WLS regression analyses and the visibly more positive associations between task and relationship conflict among samples with high levels of outcome-oriented culture comparted to samples with low

levels of outcome-oriented culture, the results indicate that greater levels of outcome-oriented culture may be associated with positive increases in the detrimental association between task and relationship conflict.

\section{Theoretical Implications}

The results of the current meta-analysis suggest that the association between demographic diversity and intragroup conflict can be assessed using a contingent approach depending on the level of team-oriented culture and outcome-oriented culture within work 
units. These insights offer original and contemporary contributions to how team-oriented and outcome-oriented culture types may potentially mitigate or engender detrimental relationship conflict in teams working in highly demographically heterogeneous organizations and demographically heterogeneous teams. One implication of these findings may be that promoting a strong team-oriented culture, and also lowering the level of outcome-oriented culture, may reduce the occurrence of detrimental intragroup conflict occurring within highly demographically diverse work groups, which in turn, may increase proximal group outcomes such as satisfaction and viability that are negatively associated with intragroup conflict (Chuang, Church, \& Zikic, 2004; Galinsky et al., 2015).

Previous research has found that organizational tenure diversity can be quite beneficial for gathering information and collective group knowledge (Lyons \& Kuron, 2014). Specifically, organizational tenure diversity has been found to be positively associated with technical communication, training outcomes, problem-solving quality, and group knowledge sharing within teams (Lyons \& Kuron, 2014; Williams \& O’Reilly, 1998; Zenger \& Lawrence; 1989). However, despite the potential benefits of organizational tenure diversity within work groups, the results of the current meta-analysis confirm previous research that points to tenure diversity being associated with increases in group power conflicts, relationship conflict, and voluntary group member withdrawal (Williams \& O'Reilly, 1998). The results also shed light on the contextual moderator of team-oriented culture that may buffer or mitigate the positive relationship associated between organizational tenure diversity within work units and relationship conflict, and as a result, sheds light on one potentially powerful moderator that may mitigate intragroup conflict in highly tenure diverse work units. This reduction in relationship conflict, may, in turn, also promote the potential benefits of 
knowledge sharing, information processing, and training outcomes in highly tenure diverse teams (Galinsky et al., 2015; Lyons \& Kuron, 2014; Williams \& O’Reilly, 1998; Zenger \& Lawrence; 1989). Thus, the results of the current meta-analytic investigation indicate that team-oriented culture may promote the benefits and mitigate the pitfalls of organizational tenure diversity by promoting reduced intragroup conflict.

Regarding racial demographic diversity within work units, the results of the current meta-analysis confirm the findings of previous workgroup diversity meta-analytic investigations (e.g., Williams \& O'Reilly, 1998) that have found that racial diversity is more and particularly positively associated with intragroup conflict compared to deep-level diversity attributes such as organizational tenure and functional background (Galinsky et al., 2015; Guillaume et al., 2017; Williams \& O'Reilly, 1998). The results also indicate that the especially strong effect of team-oriented culture on relationship conflict in racially diverse teams compared to other demographic attributes may partially be attributed to the saliency of race as a highly salient surface-level demographic attribute that is readily cognitively accessible to all members within work units, which promotes particularly greater levels of social categorization processes between work unit members into different racial subgroups (Galinsky et al., 2015; Guillaume et al., 2017; Schaeffner et al., 2015).

In addition, the findings of the current meta-analysis also shed light on the specific mechanisms in contextual situations may buffer or mitigate relationship conflict in highly gender heterogeneous and highly racially heterogeneous work units as team-oriented culture was found to be more negatively associated with the relationships between racial and gender demographic diversity with relationship conflict compared to the relationships between diversity in the other demographic attributes (i.e., age and organizational tenure diversity) 
with relationship conflict. One potential mechanism why team-oriented culture may especially mitigate the relationships between racial and gender diversity with relationship conflict compared to other demographic attributes may be due to changes in the social identity of individual group members. Specifically, team-oriented culture may mitigate the occurrence of detrimental social categorization processing that often take place in highly racially diverse work units and highly gender diverse work units by promoting the categorization of a single work group identity for all members that may likely replace strong natural social categorization mechanisms that may have normally divided racially diverse and gender diverse team members into different perceived racial and gender subgroups (Chuang, Church, \& Zikic, 2004; Galinsky et al., 2015; Guillaume et al., 2017; Schaeffner et al., 2015).

With respect to age heterogeneity, the findings of the current meta-analysis generally corroborate the results of previous demographic diversity and intragroup conflict research that has found that age heterogeneity within work units is negatively associated with affective group outcomes including group member satisfaction and team viability (e.g., Lyons \& Kuron, 2014; Zenger \& Lawrence; 1989). Specifically, in general, the more similar work unit members are in age on aggregate, the more likely they are to hold similar attitudes, interests, and beliefs, and thus the more likely they are to communicate with, share knowledge with, and not have relationship conflict with one another (Lyons \& Kuron, 2014; Zenger \& Lawrence; 1989). However, the effect of team-oriented culture and outcomeoriented culture were found to not to have a significant effect on the association between age diversity and relationship conflict, promoting the implication that further research is needed to identify other potential contextual moderators of age diversity within work units and 
relationship conflict. Thus, future research would likely benefit from further investigating other potential moderators that mitigate may mitigate the positive association between age heterogeneity and relationship conflict.

With respect to the association of gender diversity and intragroup conflict, the results of the current meta-analysis confirm the findings of previous meta-analytic investigations that indicated a significant positive association between gender heterogeneity and relationship conflict (e.g., Galinsky et al., 2015; Thatcher \& Patel, 2011; Williams \& O'Reilly, 1998). Further, a key contribution of the current meta-analysis was the identification and examination of team-oriented culture as a contextual moderator that may mitigate the potential detrimental positive association between gender heterogeneity and relationship conflict by reducing the propensity of highly gender diverse groups to utilize detrimental social categorizations the negative stereotypes associated with them (Thatcher \& Patel, 2011).

Previous research has indicated one reason gender is positively associated with intragroup conflict in groups can be attributed to social categorization processes engendered by negative and competing gender stereotypes about the competence and likeability of men and women (e.g., Spencer, Steele, \& Quinn, 1999; Tomkiewicz \& Bass, 2008). For example, stereotypes about women being typically more emotionally expressive than men, and generally less logically competent, have been described as a primary source of intragroup conflict occurring between men and women in highly gender diverse work units (Guillaume et al., 2017; Heilman, 2012; Jehn, Northcraft, \& Neale, 1999; Leonard, Levine, \& Joshi, 2004). Such stereotypes and the associated increase in intragroup conflict that occurs based on gender categorizations may also likely have substantial consequences for achieving 
gender parity in numerically male-dominated fields, as previous research has suggested that as groups become more heterogeneous and conflict increases, women may be especially likely to leave these groups, resulting in the groups returning to being relatively gender homogenous (Heilman, 2012; Tomkiewicz \& Bass, 2008). Thus, competing gender stereotypes about the competence and likeability of men and women have tangible may likely have detrimental implications for intragroup conflict as well as women's success in management and leadership positions in the fields like science, technology, engineering, and mathematics (STEM; Beasley \& Fischer, 2012; Heilman, 2012; Tomkiewicz \& Bass, 2008).

\section{Limitations and Future Research}

The current study findings contain important and novel insights into the potential effects of organizational culture on the associations between demographic heterogeneity and intragroup conflict. A limitation in this meta-analytic investigation is the limited number of studies in the primary analyses. Future research is needed to address this concern, and reduce the sampling error potentially present in these analyses (Borenstein et al., 2011). However,

our analyses have a large number of groups to analyze. The smallest group analysis in Table 2 of the four primary culture and conflict associations was based on $N=1909$ groups, a sample size that many would consider large in published individual empirical studies.

In future work, it will also be useful to examine other potential moderators of the diversity conflict relationship, such as the organizational level of the groups in the sample, length of the group project, and so forth (De Dreu, 2006; De Witt, Greer, \& Jehn, 2012). More specifically, one direction for future research may be to examine the association between demographic diversity and task and relationship conflict with the contextual moderator of group organizational level, since previous research has demonstrated the level 
of groups within TMT (top management teams) may significantly impact the amount of task conflict and relationship conflict within (De Witt, Greer, \& Jehn, 2012). However, other findings examining the effect of diversity in work units have indicated that the organizational level of groups was not significantly related to the association between demographic diversity intragroup conflict (e.g. Li and Hambrick; 2005). Thus, future research is needed for studies to indicate the organizational level of the teams included within samples in order to better determine the potential role of organizational level as a contextual moderator between demographic diversity and intragroup conflict.

Given the restrictions on the current data availability in the workgroup diversity research detailing team tenure, an additional limitation of the current meta-analysis was that we were unable to formally test for any effects of time as a contextual moderator. Research has shown that the length of time groups spend together may reduce the relationship between surface-level demographic attributes and relationship and task conflict, making group tenure a potentially relevant moderator (e.g., Mohammed \& Angell, 2004). Specifically, tension and conflict resulting from salient demographic differences such as gender, age, and race have been found to abate over time while differences in knowledge, views, and preferences instead were found to become increasingly salient as teams interact over a period of months or years (Thatcher \& Patel, 2011). However, the overall impact of time on the association between demographic diversity and relationship conflict is widely uncertain as the findings of previous research examining the impact of time on the association between diversity and relationship conflict have found that team tenure had no impact on team conflict or processes (Li \& Hambrick, 2005) while other studies have found that teams working together for longer periods of time have significantly less relationship conflict than newer teams 
(Barkema \& Shvyrkov, 2007). Thus, a key issue to address for future workplace diversity research will be the development of future controlled experimental studies that examine the longitudinal/temporal effects on the association between demographic diversity and conflict within groups over time (Christian, Porter, \& Moffitt, 2006; Ensari \& Miller, 2006; Thatcher \& Patel, 2011; Webber \& Donahue, 2001).

As there was a very limited number of published studies with experimental and quasiexperimental data, another limitation of the current meta-analysis was that it included only cross-sectional correlational data and could not determine the casual direction of the associations between diversity and conflict. Specifically, a controlled experimental longitudinal study assessing the effects of demographic diversity and work unit culture on intragroup conflict over time would be able to assess the causal directionality of the associations between demographic diversity and intragroup conflict over time as well as whether the positive associations between demographic diversity in gender, race, age, and organizational tenure and relationship conflict decrease over time (e.g. Barkema \& Shvyrkov 2007; Mohammed \& Angell, 2004), increase over time, or are relatively stable over time (e.g. Li \& Hambrick; 2005). Thus, an additional avenue for future research is to increase efforts towards conducting similar controlled longitudinal and experimental and quasiexperimental work on diversity, culture, and interpersonal conflict in order better assess the causal directionality of the associations between diversity, culture, and conflict.

In terms of the direction of the relationship between culture and conflict, it is possible that greater rates of task and relationship conflict encourage groups to increase their actual or perceived levels of outcome-oriented culture, while lower rates of task and relationship conflict promote groups to perceive and/or implement stronger team-oriented cultures. 
However, since culture is characterized as deeply rooted in predominate assumptions, values, and beliefs, and is considered to be relatively stable over time (O'Reilly, Chatman, \& Caldwell, 1991; Schein, 1985), the possibility that culture causally influences conflict appears to be high; teams are likely to enter into an already established work unit culture that may impact the level of intragroup conflict occurring within work groups, rather than work groups affecting the predominant organizational culture. However, future research would benefit from conducting experimental and quasi-experimental studies that randomly assign diverse groups to unique cultural conditions to help clarify the direction of the causality of the associations between culture and conflict.

Relatedly, the causal direction of the relationship between diversity and conflict is not clear (De Wit, Greer, \& Jehn, 2011; Viechtbauer, 2007). It may be, for example, that groups with high levels of relationship conflict alter the retention and attrition of group members so that they become increasingly diverse. While this alternative explanation does not, perhaps, seem as logical as the inverse relationship, future research still needs to probe the direction of this relationship.

Although the four diversity variables included in the current meta-analytic investigation were selected due to their widespread recognition as the most prominent and diversity attributes in the literature (e.g., Guillaume et al., 2017; Williams \& O’Reilly, 1998), future work is needed to examine other types of diversity that may impact work group conflict. Previous findings examining the impact of deep-level diversity on of intragroup conflict have indicated that greater levels of deep-level diversity may have different associations with relationship conflict and task conflict compared to diversity in surface-level attributes (Galinsky et al., 2015; Guillaume et al., 2017). In particular, findings on the 
association between the deep-level diversity attribute of sexual orientation heterogeneity and intragroup conflict have indicated that increased levels of sexual orientation was only modestly positively correlated with relationship conflict and task conflict ( Liao, Chuang, \& Joshi, 2008). Previous research examining the impact of political orientation heterogeneity on workgroup conflict outcomes have also found that political orientation diversity within workgroups was modestly positively correlated with task and relationship conflict (Mazur, 2010). Similarly, research examining the impact of deep-level attributes on intragroup conflict have supported the theoretical framework suggested by social identity theory indicating that deep-level demographic differences between work group members (e.g., value differences, political orientation, etc.) may be more modestly correlated with task and relationship conflict within groups compared to surface-level demographic differences (e.g., race, gender). Future research may especially benefit from examining other types of deeplevel diversity attributes such as political orientation, sexual orientation, or values to help further address this gap (Guillaume et al., 2017; Liao, Chuang, \& Joshi, 2008; Olkin, 2002). Although study information regarding the average length of team duration was recorded and coded whenever possible in the current meta-analysis, an additional limitation of the current investigation was that team duration was not examined as a moderator variable. This is due to the fact that most of the qualified studies did not include information about the average team duration. A limited body of work examining the impact of time on the relationship between demographic diversity and intragroup conflict has indicated that time may modestly impact the relationship between demographic heterogeneity within groups and relationship conflict (e.g., Mohammed \& Angell, 2004), indicating potential marginal decreases between the association of demographic diversity and relationship conflict over 
time. However, other findings have indicated that time did not significantly the strength or direction of the association between surface-level diversity and relationship conflict (e.g., Thatcher \& Patel, 2011). Thus, future research should seek to further investigate this relationship.

Similarly to team duration, an additional limitation of the current investigation was that team size was not included as a moderator variable. Although study information regarding the average team size was recorded and coded for each study whenever included, the current meta-analysis did not include the average team size as a moderator variable since team size was not included as a primary theoretical moderator variable of interest.

Additionally, the results of existing research conducted examining the impact of team size on the relationship between demographic heterogeneity and intragroup conflict (e.g., Lyons \& Kuron, 2014; Thatcher \& Patel, 2011; Williams \& O’Reilly, 1998) have generically indicated that team-size does not significantly impact the strength or direction of the association between demographic diversity and intragroup conflict. However, future research may seek to help shed light on the impact of team size in the demographic diversity and intragroup conflict relationships by examining team size as a moderator.

In order to analyze the results of the impact of team-oriented culture and outcomeoriented culture on relationship conflict and task conflict at the same unit of analysis, the current meta-analysis examined team-oriented culture and outcome-oriented culture at the work unit level of analysis only, and did not include measures of culture at the branch or organizational level of analysis. Since work unit culture is nested within multiple additional levels of culture, and these different levels of culture may interact with another, future research should seek to further examine the impact of team-oriented culture and outcome- 
oriented culture at the organizational and branch levels of analysis in order to examine and compare the independent effects of culture on task and relationship conflict at higher levels of analysis in addition to work unit level culture (Hartnell et al., 2011). Future research should further examine how the multiple nested levels of team-oriented culture and outcomeoriented culture may interact with each other and impact the association between culture and intragroup conflict.

The current investigation included the two most prominent and theoretically relevant culture dimensions: team-oriented culture and outcome-oriented culture. However, other culture dimensions, such as Hierarchy and Adaptability from the competing values framework, may also serve as culture types that may be related to task and relationship conflict, or may also impact the association between heterogeneity in demographic attributes and intragroup conflict (Hartnell et al., 2011; Williams \& Durray, 2006) Specifically, the hierarchy dimension of culture may potentially further increase the positive association between work unit demographic heterogeneity in gender, race, and organizational tenure with relationship conflict and task conflict, since strong hierarchy cultures are characterized by having a low tolerance for individual considerations that may reduce the amount of interpersonal conflict in highly demographically diverse teams (e.g., flexible work schedules for working mothers, etc.) (Dwyer \& Chadwick, 2003; Gelfand, Leslie, \& Keller, 2008).

Adaptable cultures may also be expected to lower the positive association between work unit demographic heterogeneity and relationship conflict and task conflict by allowing and encouraging open collaboration between diverse team members, and allowing for more autonomy and individual consideration for the needs of diverse individuals (Hartnell et al., 2011; Williams \& Durray, 2006). However, it may be instead that the lack of formal 
instructions and guidelines for work group interactions associated with highly adaptable cultures may increase the amount of task and relationship conflicts in highly demographically heterogeneous workgroups; the clear formal structure and order associated with highly hierarchical cultures, meanwhile, may mollify the amount of intragroup conflict occurring within highly demographically heterogeneous work groups (Hartnell et al., 2011). Future research may thus benefit from the examination of other culture dimensions with their association to task and relationship conflict and the impact they have on the association between demographic heterogeneity and task and relationship conflict.

An additional limitation of the current meta-analysis was that the limited amount of samples that included data on more than one of the four demographic diversity attributes (sample heterogeneity in: gender, race, age and organizational tenure) that prevented the analyzes of more than one of the four demographic attributes simultaneously together and only allowed for demographic diversity attributes to be examined independently. Thus, future research should seek to publish additional studies investigating the impact of team-oriented and outcome-oriented culture on task and relationship conflict that include sample demographic information on heterogeneity in multiple types of demographic attributes (i.e., gender and race) that may interact together to distinctly impact task and relationship conflict within work groups.

A final limitation of the current investigation was that industry type was not formally included and tested as a potential contextual moderator in the analysis. Specifically, the relationship between demographic diversity and intragroup conflict may be significantly moderated by the overall numerical demographic parity of the workforce in each respective industry. For example, previous results have found that highly gender heterogeneous work 
groups within industries that are predominately numerically male-dominated in the U.S. workforce reported greater intragroup conflict and lower group member satisfaction compared to highly gender heterogeneous work groups employed in industries that with a relatively equal proportion of men and women in the workforce (Amason, Liu, \& Fu, 2010; Guillaume et al., 2017; Nielsen, 2017). Future research should seek to further investigate this relationship.

\section{Conclusions}

The purpose of the current meta-analysis was to examine the impact of surface-level demographic diversity (i.e., gender, race, and age heterogeneity) and deep-level diversity (i.e., organizational tenure heterogeneity) on intragroup conflict (i.e., task conflict and relationship conflict) as moderated by differences between studies in terms of average group culture (i.e., team-oriented culture and outcome-oriented culture). The results provide invaluable insights shedding light on how different organizational culture types may mitigate interpersonal conflict in heterogeneous teams in the workplace and optimize intrapersonal effectiveness in an increasingly demographically heterogeneous workplace. Specifically, the findings from the current meta-analysis provide strong support that fostering greater levels of team-oriented culture and lower levels of outcome-oriented culture within work groups may

likely play crucial contextual roles in helping to alleviate the detrimental association between demographic diversity on intragroup conflict. 


\section{REFERENCES}

*Articles used in the meta-analysis are marked with an asterisk.

Albert, S., \& Whetten, D. (1985). Organizational identity. In L. L. Cummings \& B. M. Staw, (Eds.), Research in organizational behavior, 7, 263-295. Greenwich, CT: JAI Press.

Amason, A. C. (1996). Distinguishing the effects of functional and dysfunctional conflict on strategic decision-making: resolving a paradox for top management teams, Academy of Management, 39(1), 123-148.

Amason, A. C., Liu, J. \& Fu, P. (2010). TMT demography, conflict, and (effective) decision making: the key role of value congruence, Academy of Management Proceedings, 2010(1), 1-6.

Amason, A.C. \& Schweiger, D. M. (1994). Resolving the paradox of conflict, strategic decision making, and organizational performance, International Journal of Conflict Management, 5(3), 239-253.

Arthur, W., Bennett, W., \& Huffcutt, A. I. (2001). Conducting meta-analysis using SAS. Mahwah, NJ: Erlbaum.

*Ayub, N., \& Jehn, K. A. (2010). The moderating influence of nationalism on the relationship between national diversity and conflict. Negotiation and Conflict Management Research, 3(3), 249-275.

Baird, K., Harrison, G. \& Reeve, R. (2007). Success of activity management practices: The influence of organizational and cultural factors. Accounting \& Finance, 47(1), 47-67.

Beal, D. J., Corey, D. M., \& Dunlap, W. P. (2002). On the bias of Huffcutt and Arthur's (1995) procedure for identifying outliers in the meta-analysis of correlations. Journal of Applied Psychology, 87(3), 583-589.

Beasley, M. A., \& Fischer, M. J. (2012). Why they leave: The impact of stereotype threat on the attrition of women and minorities from science, math and engineering majors. Social Psychology of Education, 15(4), 427-448.

*Beersma, B., \& De Dreu, C. K. W. (2002). Integrative and distributive negotiation in small groups: Effects of task structure, decision rule, and social motive. Organizational Behavior and Human Decision Processes, 87, 227-252.

*Bisseling, D., \& Sobral, F. (2011). A cross-cultural comparison of intragroup conflict in the Netherlands and Brazil. International Journal of Conflict Management, 22(2), 151-169. 
Blaine, B. E. (2013). Understanding race, racial stereotypes, and racism. In B. E. Blaine (Ed.) Understanding the psychology of diversity (pp. 87-112, 2 ${ }^{\text {nd }}$ ed.). Thousand Oaks, CA: Sage Publications, Inc.

Borenstein, M., Hedges, L. V., Higgins, J. P., \& Rothstein, H. R. (2011). Introduction to meta-analysis. John Wiley \& Sons.

*Boros, S., Meslec, N., Curşeu, P. L., \& Emons, W. (2010). Struggles for cooperation: conflict resolution strategies in multicultural groups. Journal of managerial psychology, 25(5), 539-554

Bowleg, L. (2008). When black + lesbian + woman $\neq$ black lesbian woman: The methodological challenges of qualitative and quantitative intersectionality research.

Sex Roles, 59(5-6), 312-325.

*Bowles, T. (2009). A comparison of two measures of communication and the communication style of university students. E-Journal of Applied Psychology, 5(1), 53-66.

Bradley, B. H., Postlethwaite, B. E., Klotz, A. C., Hamdani, M. R., \& Brown, K. G. (2012). Reaping the benefits of task conflict in teams: The critical role of team psychological safety climate. Journal of Applied Psychology, 97(1), 151-158.

Brewer, M. B. (1979). In-group bias in the minimal intergroup situation: A cognitive motivational analysis. Psychological Bulletin, 86, 307-324.

Bunderson, J. S., \& Sutcliffe, K. M. (2002). Comparing alternative conceptualizations of functional diversity in management teams: Process and performance effects. Academy of management journal, 45(5), 875-893.

Byrne, D. (1971). The Attraction Paradigm. Academic Press, New York, NY.

Caldwell, D., Chatman, J., \& O'Reilly, C. (1990). Building organizational commitment: A multi-firm study. Journal of Occupational Psychology, 63, 245-261.

Caldwell, D., \& O'Reilly, C. (1990). Measuring person-job fit using a profile comparison process. Journal of Applied Psychology, 75, 648-657.

Charaf, K., \& Bescos, P. L. (2013). The role of organizational and cultural factors in the adoption of activity-based costing: The case of Moroccan firms. Accounting and Management Information Systems 12(1), 4-21.

Chan, D. (1998). Functional relations among constructs in the same content domain at different levels of analysis: A typology of composition models. Journal of Applied Psychology, 83, 234-246. 
Chatman, J. (1988). Matching people and organizations: Selection and socialization in public accounting firms. Unpublished doctoral dissertation, Walter A. Haas School of Business, University of California, Berkeley.

Chatman, J. (1989). Improving interactional organizational research: A model of person organization fit. Academy of Management Review, 14, 333-34.

*Chatman, J. A., \& Barsade, S. G. (1995). Personality, organizational culture, and cooperation: Evidence from a business simulation. Administrative Science Quarterly, $40(3), 423-443$.

*Chatman, J. A., Polzer, J. T., Barsade, S.G. \& Neale, M.A. (1998). Being different yet feeling similar: the influence of demographic composition and organizational culture on work process and outcomes. Administrative Science Quarterly, 43, 749-80.

*Chatman, J. A., \& Spataro, S. E. (2005). Using self-categorization theory to understand relational demography-based variations in people's responsiveness to organizational culture. Academy of Management Journal, 48(2), 321-331.

Christian, J., Porter, L. W., \& Moffitt, G. (2006). Workplace diversity and group relations: An overview. Group Processes \& Intergroup Relations, 9(4), 459-466.

Chen, G., Kirkman, B. L., Kanfer, R., Allen, D., \& Rosen, B. (2007). A multilevel study of leadership, empowerment, and performance in teams. Journal of Applied Psychology, 92, 331-346.

Chrobot-Mason, D., \& Thomas, K. M. (2002). Minority employees in majority organizations: The intersection of individual and organizational racial identity in the workplace. Human Resource Development Review, 1, 323-344.

Chuang, T., Church, R., \& Zikic, J. (2004). Organizational culture, group diversity and intra-group conflict. Team Performance Management: An International Journal, 10(1), 26- 34.

Cohen, J. (1988). Statistical power analysis for the behavioral sciences. Mahwah, NJ: Erlbaum Colquitt, J. A., Conlon, D. E., Wesson, M. J., \& Porter, C. (2001), Justice at the millennium: a meta-analytic review of 25 years of organizational justice research, Journal of Applied Psychology, 86(1), 425-445.

Colquitt, J. A., Noe, R. A., \& Jackson, C. L. (2002), Justice in teams: antecedents and consequences of procedural justice climate, Personnel Psychology, 55(1). 83-109. 
Cox, T. H., \& Blake, S. (1991). Managing cultural diversity: Implications for organizational competitiveness. The Executive, 45-56.

Cropanzano, R., \& Greenberg, J. (1997). Progress in organizational Justice: Tunneling through the Maze, John Wiley, New York, NY.

Dayan, M., Ozer, M., \& Almazrouei, H. (2017). The role of functional and demographic diversity on new product creativity and the moderating impact of project uncertainty. Industrial Marketing Management, 61, 144-154.

De Dreu, C. K. (2002). Team innovation and team effectiveness: the importance of minority dissent and reflexivity, European Journal of Work and Organizational Psychology, 11(3), 285-298.

De Dreu, C. K. (2006). When too little or too much hurts: Evidence for a curvilinear relationship between task conflict and innovation in teams, Journal of Management, 32(1), 83-107.

De Dreu, C. K., \& Weingart, L. R. (2003). Task versus relationship conflict, team performance, and team member satisfaction: a meta-analysis, Journal of Applied Psychology, 88(4), 741-749.

De Wit, F. R. C., Greer, L. L., \& Jehn, K. A. (2012). The paradox of intragroup conflict: A meta-analysis. Journal of Applied Psychology, 97(2), 360-390.

*DeChurch, L. A., \& Marks, M. A. (2001). Maximizing the benefits of task conflict: The role of conflict management. International Journal of Conflict Management, 12, 422.

DeChurch, L. A., Mesmer-Magnus, J. R., \& Doty, D. (2013). Moving beyond relationship and task conflict: Toward a process-state perspective, Journal of Applied Psychology, 98(4), 559-578.

*De Dreu, C. K. W., \& Van Vianen, A. E. M. (2001). Managing relationship conflict and the effectiveness of organizational teams. Journal of Organizational Behavior, 22, 309-328.

De Dreu, C. K. W., \& Weingart, L. R. (2003b). Task versus relationship conflict, team effectiveness, and team member satisfaction: A meta-analysis. Journal of Applied Psychology, 88, 741-749.

Denison, D. R. (1984). Bringing corporate culture to the bottom line. Organizational Dynamics, 13(2), 5-22.

*Desivilya, H. S., \& Yagil, D. (2005). The role of emotions in conflict management: The case of work teams. The International Journal of Conflict Management, 16, 55- 69. 
Dwyer, Richard, \& Chadwick, K. (2003). Gender Diversity in Management and Firm Performance: The Influence of Growth Orientation and Organizational Culture, Journal of Business Research, 56, 1009-1019.

Eisenhardt, K. M., Kahwajy, J. L., \& Bourgeois, L. J. (1997). How management teams can have a good fight. Harvard business review, 75, 77-86.

Erdogan, B., Liden, R. C., \& Kraimer, M. L. (2006). Justice and leader-member exchange: The moderating role of organizational culture. Academy of Management Journal, 49, 395406.

Flink, C. M. (2015). Multidimensional conflict and organizational performance. The American Review of Public Administration, 45(2), 182-200.

Fortune. (2017). The Best Workplaces for Diversity 2017. Retrieved from http://fortune.com/best-workplaces-for-diversity/

Fu, J. H. Y., Morris, M. W., Lee, S. L., Chao, M., Chiu, C. Y., \& Hong, Y. Y. (2007). Epistemic motives and cultural conformity: Need for closure, culture, and context as determinants of conflict judgments. Journal of Personality and Social Psychology, 92, 191-207.

Galinsky, A. D., Todd, A. R., Homan, A. C., Phillips, K. W., Apfelbaum, E. P., Sasaki, S. J. \& Maddux, W. W. (2015). Maximizing the gains and minimizing the pains of diversity: A policy perspective. Perspectives on Psychological Science, 10(6), 742-748.

Gelfand, M. J., Leslie, L. M., \& Keller, K. (2008). On the etiology of organizational conflict cultures. Research in Organizational Behavior, 28, 137-166.

*Gelfand, M. J., Leslie, L. M., Keller, K., \& de Dreu, C. (2012). Conflict cultures in organizations: How leaders shape conflict cultures and their organizational-level consequences. Journal of Applied Psychology, 97(6), 1131-1147.

Gelfand, M. J., Raver, J. L., Nishii, L., Leslie, L. M., Lun, J., Lim, B. C., \& Yamaguchi, S. (2011). Differences between tight and loose cultures: A 33-nation study. Science, 332, 1100-1104.

*Glisson, C., \& James, L. R. (2002). The cross-level effects of culture and climate in human service teams. Journal of Organizational Behavior: The International Journal of Industrial, Occupational and Organizational Psychology and Behavior, 23(6), 767-794.

Gilson, L. L., Lim, H. S., Luciano, M. M., \& Choi, J. N. (2013). Unpacking the crosslevel effects of tenure diversity, explicit knowledge, and knowledge sharing on 
individual creativity. Journal of Occupational and Organizational Psychology, 86(2), 203-222.

Gould, J., \& Sardeshmukh, S. (2017). Tackling gender diversity at senior organizational levels: A road map for women's advancement. In Academy of Management Proceedings Academy of Management, 17(1), 13091.

Gregory, B. T., Harris, S. G., Armenakis, A. A., \& Shook, C. L. (2009). Organizational culture and effectiveness: A study of values, attitudes, and organizational outcomes.

Journal of Business Research, 62(7), 673-679.

Guillaume, Y. R., Dawson, J. F., Woods, S. A., Sacramento, C. A., \& West, M. A. (2017). Getting diversity at work to work: What we know and what we still don't know. Journal of occupational and organizational psychology, 86(2), 123-141.

Gupta, A., Leong, F. T. L., \& Szymanski, D. M. (2011). The "model minority myth": internalized racialism of positive stereotypes as correlates of psychological distress, and attitudes toward help-seeking. Asian American Journal of Psychology, 2(2), 101-114.

Harrison, D. A., Price, K. H., Gavin, J. H., \& Florey, A. T. (2002). Time, teams, and task performance: Changing effects of surface-and deep-level diversity on group functioning. Academy of management journal, 45(5), 1029-1045.

Hartnell, C. A., Ou, Y. A., \& Kinicki, A. (2011). Organizational culture and organizational effectiveness: A meta-analytic investigation of the competing values framework's theoretical suppositions. Journal of Applied Psychology, 96, 677-694.

Hedges, L. V., \& Olkin, I. (1985). Statistical methods for meta-analysis. Orlando, FL: Academic Press.

Heilman, M. E. (2012). Gender stereotypes and workplace bias. Research in Organizational Behavior, 32, 113-135

Hicks, D. A. (2002). Spiritual and religious diversity in the workplace: Implications for leadership. The leadership quarterly, 13(4), 379-396.

Ho, C., \& Jackson, J. W. (2001). Attitudes toward asian americans: Theory and measurement. Journal of Applied Social Psychology, 31(8), 1553-1581.

Hofstede, G. (1998), Attitudes, values and organizational culture: disentangling the concepts, Organization Studies, 19, 477-492. 
Hofstede, G. (2001). Culture's consequences: Comparing, values, behaviors, institutions, and organizations across nations (2nd ed.). Thousand Oaks, CA: Sage.

Hofstede, G., Neuijen, B., Ohayv, D., \& Sanders, G. (1990). Measuring organizational cultures: A qualitative and quantitative study across twenty cases. Administrative Science Quarterly, 35, 286-316.

Holck, L., Muhr, S. L., \& Villeseche, F. (2016). Identity, diversity and diversity management: On theoretical connections, assumptions and implications for practice. Equality, Diversity and Inclusion: An International Journal, 35(1), 48- 64.

Homan, A. C., van Knippenberg, D., Van Kleef, G. A., \& De Dreu, C. K. (2007). Interacting dimensions of diversity: Cross-categorization and the functioning of diverse work groups. Group Dynamics: Theory, Research, and Practice, 11, 79- 94.

*Huang, J. C. (2010). Unbundling task conflict and relationship conflict: The moderating role of team goal orientation and conflict management. International Journal of Conflict Management, 21(3), 334-355.

Huffcutt, A. I., \& Arthur, W. (1995). Development of a new outlier statistic for metaanalytic data. Journal of Applied Psychology, 80(2), 327-334.

Hunter, J. E., \& Schmidt, F. L. (2004). Methods of meta-analysis: Correcting error and bias in research findings. Thousand Oaks, CA: Sage.

Hunter, J. E., \& Schmidt, F. L. (2000). Fixed effects vs. random effects meta-analysis models: Implications for cumulative research knowledge. International Journal of Selection and Assessment, 8(4), 275-292.

Hunter, J. E., Schmidt, F. L., \& Jackson, G. B. (1982). Meta-analysis: Cumulating research findings across studies (4). United States: Sage Publications, Inc.

Huffcutt, A. I., \& Arthur, W. (1995). Development of a new outlier statistic for metaanalytic data. Journal of Applied Psychology, 80(2), 327.

*Jehn, K. A. (1994). Enhancing effectiveness: An investigation of advantages and disadvantages of value-based intragroup conflict. International Journal of Conflict Management, 5(3), 223-238.

*Jehn, K. A. (1995). A multimethod examination of the benefits and detriments of intragroup conflict. Administrative Science Quarterly, 40, 256-282.

Jehn, K. A. (1997). A qualitative analysis of conflict types and dimensions in organizational groups. Administrative Science Quarterly, 42, 530-557. 
*Jehn, K. A., Chadwick, C., \& Thatcher, S. M. (1997). To agree or not to agree: The effects of value congruence, individual demographic dissimilarity, and conflict on workgroup outcomes. International journal of conflict management, 8(4), 287305.

Jehn, K. A., \& Chatman, J. A. (2000). The influence of proportional and perceptual conflict composition on team performance. International Journal of Conflict Management, 11(1), 56-73.

*Jehn, K. A., \& Mannix, E. A. (2001). The dynamic nature of conflict: A longitudinal study of intragroup conflict and group performance. Academy of management journal, 44(2), 238-251.

Jehn, K. A., Northcraft, G. B., \& Neale, M. A. (1999). Why differences make a difference: a field study of diversity, conflict and performance in workgroups. Administrative Science Quarterly, 44(4), 741-763.

Jehn, K. A., Rispens, S. \& Thatcher, S. M. (2010). The effects of conflict asymmetry on work group and individual outcomes, Academy of Management, 53(3), 596-616.

Johnson, C. E., Wood, R., \& Blinkhorn, S. F. (1988). Spurious and spuriouser: The use of ipastive personality tests. Journal of Occupational Psychology, 61, 153-162.

*Jordan, P. J., \& Troth, A. C. (2004). Managing emotions during team problem solving: Emotional intelligence and conflict resolution. Human Performance, 17, 195-218.

Judge, T. A. \& Bono, J. E. (2001). Relationship of core self-evaluations traits-selfesteem, generalized self-efficacy, locus of control, and emotional stability - with job satisfaction and job performance: a meta-analysis, Journal of Applied Psychology, $86(1), 80-92$.

Kellow, J. T., \& Jones, B. D. (2008). The effects of stereotypes on the achievement gap: Reexamining the academic performance of african american high school students. Journal of Black Psychology, 34(1), 94-120.

Kim, K., \& Von Glinow, M. A. (2017). Contextual determinants in disclosing one's stigmatized identity during expatriation: The case of lesbian and gay self-initiated expatriates. Journal of Global Mobility, 5(3), 317-338.

Kinicki, A. J., McKee-Ryan, F. M., Schriesheim, C. A., \& Carson, K. P. (2002). Assessing the construct validity of the job descriptive index: A review and meta- analysis. Journal of Applied Psychology, 87, 14-32.

Kisamore, J. L., \& Brannick, M. T. (2008). An illustration of the consequences of metaanalysis model choice. Organizational Research Methods, 11, 35-53. 
Kleinman, G., Siegel, P., \& Eckstein, C. (2002). Teams as a learning forum for accounting professionals. The Journal of Management Development, 21(5), 427- 460.

Koch, P. T., Koch, B. J., Menon, T., \& Shenkar, O. (2016). In cross-national teams, cultural differences can be an advantage. LSE Business Review, 71-89.

Kozlowski, S. W. J., \& Klein, K. J. (2000). A multilevel approach in theory and research in organization: Contextual, temporal and emergent processes. In K. J. Klein \& S. W. J. Kozlowski (Eds.), Multilevel theory, research, and methods in organizations: Foundations, extensions, and new directions (pp. 3-90). San Francisco, CA: JosseyBass.

Lambert, J. (2016). Cultural diversity as a mechanism for innovation: Workplace diversity and the absorptive capacity framework. Journal of Organizational Culture, Communications and Conflict, 20(1), 68.

Leonard, J. S., Levine, D. I., \& Joshi, A. (2004). Do birds of a feather shop together? The effects on performance of employees' similarity with one another and with customers. Journal of Organizational Behavior, 25(6), 731-754.

Levine, J. M., \& Moreland, R. L. (1999). Knowledge transmission in work groups: Helping newcomers to succeed. Shared cognition in organizations: The management of knowledge, 267-296.

Leys, C., Ley, C., Klein, O., Bernard, P., \& Licata, L. (2013). Detecting outliers: Do not use standard deviation around the mean, use absolute deviation around the median. Journal of Experimental Social Psychology, 49(4), 764-766.

Liao, H., Chuang, A., \& Joshi, A. (2008). Perceived deep-level dissimilarity: Personality antecedents and impact on overall job attitude, helping, work withdrawal, and turnover. Organizational Behavior and Human Decision Processes, 106(2), 106124.

Lind, E. A., \& Early, C. P. (1992). Procedural justice and culture, International Journal of Psychology, 37(1), 227-242.

*Liu, J., Fu, P., \& Liu, S. (2009). Conflicts in top management teams and team/firm outcomes: The moderating effects of conflict-handling approaches. International Journal of Conflict Management, 20, 228-250.

Loughry, M. L., \& Amason, A. C. (2014). Why won't task conflict cooperate? Deciphering stubborn results. International Journal of Conflict Management, 25(4), 333-358. 
*Lovelace, K., Shapiro, D. L., \& Weingart, L. R. (2001). Maximizing cross-functional new product teams' innovativeness and constraint adherence: A conflict communications perspective. Academy of Management Journal, 44, 779-793.

Lyons, S., \& Kuron, L. (2014). Generational differences in the workplace: A review of the evidence and directions for future research. Journal of Organizational Behavior, 35(1), 139-157.

Malmi, T. (1997). Towards explaining activity-based costing failure: Accounting and control in a decentralized organization, Management Accounting Research, 8 , 459-480.

*McMillan, A., Chen, H., Richard, O. C., \& Bhuian, S. N. (2012). A mediation model of task conflict: Linking organizational culture, subordinate values, and subordinate outcomes. International Journal of Conflict Management, 23(3), 307-332.

Meng, X. L., Rosenthal, R., \& Rubin, D. B. (1992). Comparing correlated correlation coefficients. Psychological Bulletin, 111, 172-175.

Miao, M. C., Tien, C. T., Chang, H. T., \& Ko, Y. Y. (2010). The effect of dysfunctional conflict on learning performance: the role of cognitive style, Social Behavior and Personality, 38(2), 69-186.

Milliken, F. J., \& Martins, L. L. (1996). Searching for common threads: Understanding the multiple effects of diversity in organizational groups. Academy of Management Review, 21, 402-433.

*Mohammed, S., \& Angell, L. C. (2004). Surface-and deep-level diversity in workgroups: Examining the moderating effects of team orientation and team process on relationship conflict. Journal of Organizational Behavior: The International Journal of Industrial, Occupational and Organizational Psychology and Behavior, 25(8), 1015-1039.

Mooney, A. C., Holahan, P. J., \& Amason, A. C. (2007). Don't take it personally: Exploring cognitive conflict as a mediator of affective conflict. Journal of management studies, 44(5), 733-758.

Moorman, R. H. (1991), Relationship between organizational justice and organizational citizenship behaviors: Do fairness perceptions influence employee citizenship? Journal of Applied Psychology, 76, 845-55.

*Nguyen, R. V. (2007). Conflict in functionally diverse teams (Doctoral dissertation, ProQuest Information \& Learning). 
*Nibler, R., \& Harris, K. L. (2003). The effects of culture and cohesiveness on intragroup conflict and effectiveness. Journal of Social Psychology, 143, 613-631.

Nielsen, M. W., (2017). Gender diversity leads to better sciences. Proceedings of the National Academy of Sciences, 114(8), 1740-1742.

Nosek, B. A., Smyth, F. L., Hansen, J. J., Devos, T., Lindner, N. M., Ranganath, K. A., \& Banaji, M. R. (2007). Pervasiveness and correlates of implicit attitudes and stereotypes. European Review of Social Psychology, 18, 36-88.

Nunnally, J. C. (1978). Psychometric theory. New York: McGraw-Hill.

O’Neill, T. A., Allen, N. J., \& Hastings, S. E. (2013). Examining the 'pros' and 'cons' of team conflict: a team-level meta-analysis of task, relationship, and process conflict, Human Performance, 26(3), 236-260.

O'Reilly, C. A. (1977). Personality-job fit: Implications for individual attitudes and performance. Organizational Behavior and Human Performance, 18, 36-46.

O'Reilly, C. A. (1989). Corporations, culture, and commitment: Motivation and social control in organizations. California Management Review, 31(4), 9-25.

O’Reilly, C. A., Chatman, J., \& Caldwell, D. F. (1991). People and organizational culture: a profile comparison approach to assessing person- organization fit. Academy of Management, 34, 487-516.

Olkin, R. (2002). Could you hold the door for me? Including disability in diversity. Cultural Diversity and Ethnic Minority Psychology, 8(2), 130.

*Park, H., Ribière, V., \& Schulte Jr, W. D. (2004). Critical attributes of organizational culture that promote knowledge management technology implementation success. Journal of Knowledge management, 8(3), 106-117.

*Patrick, R. R. (1997). Teams and conflict management style: The moderating effect of conflict management style on the relationship between the type of conflict and team effectiveness in continuous work teams (Doctoral dissertation, ProQuest Information \& Learning).

Pelled, L. H. (1996). Demographic diversity, conflict, and work group outcomes: an intervening process theory, Organization Science, 7, 615-631.

Pinjani, P., \& Palvia, P. (2013). Trust and knowledge sharing in diverse global virtual teams. Information \& Management, 50(4), 144-153. 
Price, K. H., Harrison, D. A., \& Gavin, J. H. (2006). Withholding inputs in team contexts: member composition, interaction processes, evaluation structure, and social loafing. Journal of Applied Psychology, 91(6), 1375-1384.

Rababah, A. (2015). The relationship between cultural factors and balanced scorecard implementation. International Review of Management and Business Research, 4(4), 1208-1218.

Ragins, B. R., Singh, R., \& Cornwell, J. M. (2007). Making the invisible visible: Fear and disclosure of sexual orientation at work. Journal of Applied Psychology, 92, 1103-1118.

Richard, O. C., Kirby, S. L., \& Chadwick, K. (2013). The impact of racial and gender diversity in management on financial performance: How participative strategy making features can unleash a diversity advantage. The International Journal of Human Resource Management, 24(13), 2571-2582.

Roberson, Q. M., \& Park, H. J. (2007). Examining the link between diversity and firm performance: The effects of diversity reputation and leader racial diversity. Group \& Organization Management, 32(5), 548-568.

*Rousseau, D. M. (1990). Normative beliefs in fund-raising organizations: Linking culture to organizational performance and individual responses. Group \& Organization Studies, 15, 448-460.

Schaeffner, M., Huettermann, H., Gebert, D., Boerner, S., Kearney, E., \& Song, L. J. (2015). Swim or sink together: The potential of collective team identification and team member alignment for separating task and relationship conflicts. Group \& Organization Management, 40(4), 467-499.

Schein, E. (1985). Organizational Culture and Leadership. Jossey-Bass, San Francisco, CA: Jossey-Bass.

Schein, E. H. (1992). Organizational culture and leadership: A dynamic view. San Francisco, CA: Jossey-Bass.

Schein, E. H. (2003). DEC is dead, long live DEC: The lasting legacy of digital equipment corporation. San Francisco, CA: Berrett-Koehler Publishers.

*Schlaerth, A. (2014). The moderational role of organizational culture and psychological climate in the relationship between authentic leadership and constructive conflict behaviors (Doctoral dissertation, ProQuest Dissertations \& Theses Global).

Schneider, B. (1987). The people make the place. Personnel Psychology, 40, 437-453. 
Shaw, J. B. (2004). The development and analysis of a measure of group faultlines. Organizational Research Methods, 7(1), 66-100.

Shih, M., Pittinsky, T. L., \& Ambady, N. (1999). Stereotype susceptibility: Identity salience and shifts in quantitative performance. Psychological Science, 10(1), 80- 83.

Shore, L. M., Randel, A. E., Chung, B. G., Dean, M. A., Holcombe Ehrhart, K., \& Singh, G. (2011). Inclusion and diversity in work groups: A review and model for future research. Journal of Management, 37(4), 1262-1289.

*Simons, T., Pelled, L. H., \& Smith, K. A. (1999). Making use of difference: Diversity, debate, and decision comprehensiveness in top management teams. Academy of Management Journal, 42, 662-673.

*Simons, T. L., \& Peterson, R. S. (2000). Task conflict and relationship conflict in top management teams: The pivotal role of intragroup trust. Journal of Applied Psychology, 85(1), 102-111.

*Simosi, M., \& Xenikou, A. (2010). The role of organizational culture in the relationship between leadership and organizational commitment: an empirical study in a Greek organization. The International Journal of Human Resource Management, 21(10), 1598-1616.

Simpson, E. H. (1949). Measurement of diversity. Nature, 163, 688.

Siy, J. O., \& Cheryan, S. (2013). When compliments fail to flatter: American individualism and responses to positive stereotypes. Journal of Personality and Social Psychology, 104(1), 87-102.

*Somech, A., Desivilya, H. S., \& Lidogoster, H. (2009). Team conflict management and team effectiveness: The effects of task interdependence and team identification. Journal of Organizational Behavior, 30, 359-378.

Sparrowe, R. T., \& Liden, R. C. (1997). Process and structure in leader member exchange. Academy of Management Review, 22, 522-552.

Spector, P. E. (1987). Method variance as an artifact in self-reported affect and perceptions at work: Myth or significant problem? Journal of Applied Psychology, 72, 438-443.

Spector, P. E. (2006). Method variance in organizational research. Organizational Research Methods, 9, 221-232.

Spencer, S. J., Steele, C. M., \& Quinn, D. M. (1999). Stereotype threat and women's math performance. Journal of Experimental Social Psychology, 35(1), 4-28. 
Tajfel, H. (1978). Differentiation between Social Groups. Academic Press, Oxford.

Tajfel, H. \& Turner, J. (1986). The social identity of intergroup behavior, in Worchel, S., \& Austin, W. Psychology and Intergroup Relations. Nelson-Hall, Chicago, IL, 7- 24.

Tekleab, A. G., Karaca, A., Quigley, N. R., \& Tsang, E. W. (2016). Re-examining the functional diversity-performance relationship: The roles of behavioral integration, team cohesion, and team learning. Journal of Business Research, 69(9), 35003507.

Tekleab, A. G. \& Quigley, N. R. (2013). Team deep-level diversity, relationship conflict, and team members' affective reactions: a cross-level investigation, Journal of Business Research, 67(3), 394-402.

*Tekleab, A. G., Quigley, N. R., \& Tesluk, P. E. (2009). A longitudinal study of team conflict, conflict management, cohesion, and team effectiveness. Group \& Organization Management, 34, 170-205.

Thakrar, M. (2017). How to lead the push for diversity in the workplace. Retrieved from https://www.forbes.com/sites/forbescoachescouncil/2017/06/09/how-to-lead-thepush-for-diversity-in-the-workplace/\#3d0527d2415b

Thatcher, S. M. B., \& Patel, P. C. (2011). Demographic faultlines: A meta-analysis of the literature. Journal of Applied Psychology, 96(6), 1119-1139.

*Tjosvold, D., Law, K. S., \& Sun, H. F. (2006). Effectiveness of Chinese teams: The role of conflict types and conflict management approaches. Management and Organization Review, 2, 231-252.

Tomkiewicz, J., \& Bass, K. (2008). Differences between male students' and female students' perception of professors. College Student Journal, 42(2), 422-430.

U.S. Department of Labor. (2017). Current Employment Statistics. Washington, DC: U.S. Bureau of Labor Statistics.

Vaara, E., Sarala, R., Stahl, G. K., \& Björkman, I. (2012). The impact of organizational and national cultural differences on social conflict and knowledge transfer in international acquisitions, Journal of Management Studies, 49(1), 1-27.

Vacha-Haase, T. (1998). Reliability generalization: Exploring variance in measurement error affecting score reliability across studies. Educational and Psychological Measurement, 58, 6-20. 
Van Der Vegt, G. S., Bunderson, J. S., \& Oosterhof, A. (2006). Expertness diversity and interpersonal helping in teams: Why those who need the most help end up getting the least. Academy of Management Journal, 49(5), 877-893.

van Knippenberg, D., Dawson, J. F., West, M. A., \& Homan, A. C. (2011). Diversity faultlines, shared objectives, and top management team performance. Human Relations, 64, 307-336.

van Knippenberg, D., De Dreu, C. K. W., \& Homan, A. C. (2004). Work group diversity and group performance: An integrative model and research agenda. Journal of Applied Psychology, 89, 1008-1022.

Viechtbauer, W. (2007). Accounting for heterogeneity via random-effects models and moderator analyses in meta-analysis. Journal of Psychology, 215, 104-121.

*Virgil-King, D. M. C. (1999). Team conflict, integrative conflict management strategies, and team effectiveness: A field study (Doctoral dissertation, UMI Microform).

Viswesvaran, C., Schmidt, F. L., \& Ones, D. S. (2002). The moderating influence of job performance dimensions on convergence of supervisory and peer ratings of job performance: Unconfounding construct-level convergence and rating difficulty. Journal of Applied Psychology, 87(2), 345-354.

*Wagner, J. A. (1995). Studies of individualism-collectivism: Effects on cooperation in groups. Academy of Management Journal, 38(1), 152-173.

Wang, G., Jing, R., \& Klossek, A. (2007). Antecedents and management of conflict: resolution styles of Chinese top managers in multiple rounds of cognitive and affective conflict, International Journal of Conflict Management, 18(1), 74-97.

Webber, S. S., \& Donahue, L. M. (2001). Impact of highly and less job-related diversity on work group cohesion and performance: A meta-analysis. Journal of management, 27(2), 141-162.

*West, B. J., Patera, J. L., \& Carsten, M. K. (2009). Team level positivity: Investigating positive psychological capacities and team level outcomes. Journal of Organizational Behavior, 30, 249-267.

Williams, E. A., \& Duray, R. (2006). Teamwork orientation, group cohesiveness, and student learning: A study of the use of teams in online distance education. Journal of Management Education, 30(4), 592-616.

Williams, K. Y., \& O'Reilly, C., A. (1998). Demography and diversity in organizations: a review of 40 years of research. Research in Organizational Behavior, 20, 77-140. 
Wooley, A., Aggar, I., \& Malone, T. (2015). Collective intelligence and group performance. Current Directions in Psychology Science, 24(6), 420-424.

*Yousofpourfard, H. (2012). Cultural intelligence: A new approach to manage teamwork in culturally diverse teams (Doctoral dissertation, ProQuest Information \& Learning).

Zenger, T. R., \& Lawrence, B. S. (1989). Organizational demography: The differential effects of age and tenure distributions on technical communication. Academy of Management journal, 32(2), 353-376. 
Table 1

Study, Sample Characteristics, and Effect Size Information

\begin{tabular}{|c|c|c|c|c|c|c|c|c|c|}
\hline $\begin{array}{l}\text { Studies Included in } \\
\text { Meta-Analysis }\end{array}$ & $N$ & $\begin{array}{l}\text { Team- } \\
\text { Oriented } \\
\text { Culture }\end{array}$ & $\begin{array}{l}\text { Relationship } \\
\text { Conflict }\end{array}$ & $\begin{array}{l}\text { Outcome- } \\
\text { Oriented } \\
\text { Culture }\end{array}$ & $\begin{array}{c}\text { Task } \\
\text { Conflict }\end{array}$ & Gender & Race & Age & Tenure \\
\hline $\begin{array}{l}\text { DeChurch \& Marks, } \\
\text { (2001) }\end{array}$ & 96 & $\mathrm{X}$ & & $\mathrm{X}$ & $\mathrm{X}$ & $\mathrm{X}$ & $\mathrm{X}$ & $\mathrm{X}$ & \\
\hline Yousof. (2012) & 41 & $\mathrm{X}$ & $\mathrm{X}$ & $\mathrm{X}$ & $\mathrm{X}$ & $\mathrm{X}$ & & $\mathrm{X}$ & \\
\hline $\begin{array}{l}\text { Jehn, Chadwick, \& } \\
\text { Thatcher, (1997) }\end{array}$ & 88 & $\mathrm{X}$ & $\mathrm{X}$ & $\mathrm{X}$ & $\mathrm{X}$ & $\mathrm{X}$ & & $\mathrm{X}$ & \\
\hline $\begin{array}{l}\text { Chatman, Polzer, } \\
\text { Barsade, \& Neale, } \\
\text { (1998) }\end{array}$ & 20 & $\mathrm{X}$ & $\mathrm{X}$ & $\mathrm{X}$ & $\mathrm{X}$ & $\mathrm{X}$ & $\mathrm{X}$ & & \\
\hline $\begin{array}{l}\text { West, Patera, \& } \\
\text { Carsten, (2009) }\end{array}$ & 101 & $\mathrm{X}$ & $\mathrm{X}$ & $\mathrm{X}$ & & $\mathrm{X}$ & $\mathrm{X}$ & & \\
\hline Wagner, (1995) & 99 & $\mathrm{X}$ & $\mathrm{X}$ & $\mathrm{X}$ & & $\mathrm{X}$ & $\mathrm{X}$ & $\mathrm{X}$ & \\
\hline Boros, Meslec, Curşeu, \& & 125 & $\mathrm{X}$ & $\mathrm{X}$ & $\mathrm{X}$ & & $\mathrm{X}$ & & & \\
\hline $\begin{array}{l}\text { Emons, (2010) Jordan \& } \operatorname{Trc} \\
\text { (2004) }\end{array}$ & $\begin{array}{l}\text { roth, } \\
108\end{array}$ & $\mathrm{X}$ & $\mathrm{X}$ & $\mathrm{X}$ & $\mathrm{X}$ & $\mathrm{X}$ & & & \\
\hline $\begin{array}{l}\text { Tekleab, Quigley, \& } \\
\text { Tesluk, (2009) }\end{array}$ & 53 & $\mathrm{X}$ & $\mathrm{X}$ & & $\mathrm{X}$ & $\mathrm{X}$ & & $\mathrm{X}$ & \\
\hline $\begin{array}{l}\text { Glisson \& James, } \\
(2002)\end{array}$ & 33 & $\mathrm{X}$ & $\mathrm{X}$ & $\mathrm{X}$ & & $\mathrm{X}$ & $\mathrm{X}$ & $X$ & $\mathrm{X}$ \\
\hline Yousofpourfard, (2012) Hua & lahig6 & $\mathrm{X}$ & $\mathrm{X}$ & $\mathrm{X}$ & $\mathrm{X}$ & $\mathrm{X}$ & & $\mathrm{X}$ & $\mathrm{X}$ \\
\hline$(2010)$ & 120 & $\mathrm{X}$ & $\mathrm{X}$ & $\mathrm{X}$ & $\mathrm{X}$ & $\mathrm{X}$ & & $\mathrm{X}$ & \\
\hline $\begin{array}{l}\text { Somech, Desivilya, \& } \\
\text { Lidogoster, (2009) Jehn \& }\end{array}$ & 77 & $\mathrm{X}$ & $\mathrm{X}$ & & $\mathrm{X}$ & $\mathrm{X}$ & & $\mathrm{X}$ & $\mathrm{X}$ \\
\hline Mannix, (2001) Bisseling \& & 51 & $X$ & $\mathrm{X}$ & $\mathrm{X}$ & $\mathrm{X}$ & $\mathrm{X}$ & & & \\
\hline $\begin{array}{l}\text { Sobral, } \\
\text { (2011) }\end{array}$ & 58 & $\mathrm{X}$ & $\mathrm{X}$ & $\mathrm{X}$ & $\mathrm{X}$ & & & & $X$ \\
\hline Jehn, (1995) & 93 & & $\mathrm{X}$ & $\mathrm{X}$ & $\mathrm{X}$ & $\mathrm{X}$ & & $\mathrm{X}$ & $\mathrm{X}$ \\
\hline Liu, Fu, \& Liu, (2009) & 123 & $\mathrm{X}$ & $\mathrm{X}$ & $\mathrm{X}$ & $\mathrm{X}$ & $\mathrm{X}$ & & $\mathrm{X}$ & \\
\hline Patrick, (1997) & 57 & $\mathrm{X}$ & $\mathrm{X}$ & $\mathrm{X}$ & $\mathrm{X}$ & $\mathrm{X}$ & & $\mathrm{X}$ & $\mathrm{X}$ \\
\hline Simons, Pelled, \& & 57 & & & $\mathrm{X}$ & $\mathrm{X}$ & & & $\mathrm{X}$ & $\mathrm{X}$ \\
\hline $\begin{array}{l}\text { Smith, (1999) Desivilya \& } \\
\text { Yagil, } \\
(2005)\end{array}$ & 69 & $X$ & $\mathrm{X}$ & $\mathrm{X}$ & $\mathrm{X}$ & $\mathrm{X}$ & & $X$ & $\mathrm{X}$ \\
\hline $\begin{array}{l}\text { Mohammed \& Angell, } \\
\text { (2004) }\end{array}$ & 57 & $\mathrm{X}$ & $\mathrm{X}$ & & & $\mathrm{X}$ & $\mathrm{X}$ & & \\
\hline Lovelace, Shapiro, \& & 43 & $\mathrm{X}$ & & $\mathrm{X}$ & $\mathrm{X}$ & $\mathrm{X}$ & $\mathrm{X}$ & & $\mathrm{X}$ \\
\hline Weingart, (2001) Ayub \& Je & ehn, & & & & & & & & \\
\hline$(2010)$ & 29 & & $\mathrm{X}$ & $\mathrm{X}$ & $\mathrm{X}$ & $\mathrm{X}$ & & $\mathrm{X}$ & \\
\hline Jehn, (1994) & 88 & $\mathrm{X}$ & $\mathrm{X}$ & & $\mathrm{X}$ & $\mathrm{X}$ & & & \\
\hline Virgil-King, (1999) & 65 & $\mathrm{X}$ & $\mathrm{X}$ & & $\mathrm{X}$ & $\mathrm{X}$ & & $\mathrm{X}$ & \\
\hline $\begin{array}{l}\text { McMillan, Chen, } \\
\text { Richard, \& Bhuian, } \\
\text { (2012) }\end{array}$ & 200 & $\mathrm{X}$ & $\mathrm{X}$ & $\mathrm{X}$ & $\mathrm{X}$ & $\mathrm{X}$ & $\mathrm{X}$ & $\mathrm{X}$ & $\mathrm{X}$ \\
\hline Bowles, (2009) Beersma \& & Dé & $\mathrm{X}$ & $\mathrm{X}$ & $\mathrm{X}$ & $\mathrm{X}$ & $\mathrm{X}$ & & $\mathrm{X}$ & \\
\hline $\begin{array}{l}\text { Dreu, } \\
(2002)\end{array}$ & 91 & $\mathrm{X}$ & $\mathrm{X}$ & $\mathrm{X}$ & $\mathrm{X}$ & & & & \\
\hline $\begin{array}{l}\text { Gelfand, Leslie, Keller, \& D } \\
\text { Dreu, (2012) Chatman \& }\end{array}$ & De31 & $\mathrm{X}$ & $\mathrm{X}$ & $\mathrm{X}$ & $\mathrm{X}$ & $\mathrm{X}$ & $\mathrm{X}$ & & $\mathrm{X}$ \\
\hline $\begin{array}{l}\text { Spataro, } \\
(2005)\end{array}$ & 128 & $X$ & $\mathrm{X}$ & $\mathrm{X}$ & & $\mathrm{X}$ & $\mathrm{X}$ & $X$ & $X$ \\
\hline $\begin{array}{l}\text { De Dreu, \& Van } \\
\text { Vianen, (2001) }\end{array}$ & 27 & $\mathrm{X}$ & $\mathrm{X}$ & $\mathrm{X}$ & & $\mathrm{X}$ & & & \\
\hline Nguyen, (2007) & 41 & & $\mathrm{X}$ & $\mathrm{X}$ & $\mathrm{X}$ & & & & \\
\hline
\end{tabular}




\begin{tabular}{|c|c|c|c|c|c|c|c|c|c|}
\hline $\begin{array}{l}\text { Tjosvold, Law, \& Sun, } \\
(2006)\end{array}$ & 186 & $\mathrm{X}$ & $\mathrm{X}$ & $\mathrm{X}$ & $X$ & $\mathrm{X}$ & & & \\
\hline $\begin{array}{l}\text { Chatman \& Barsade, } \\
\text { (1995) }\end{array}$ & 14 & $\mathrm{X}$ & $\mathrm{X}$ & $\mathrm{X}$ & $\mathrm{X}$ & $\mathrm{X}$ & $\mathrm{X}$ & & \\
\hline Rousseau, (1990) & 32 & $\mathrm{X}$ & $\mathrm{X}$ & $\mathrm{X}$ & & & & & \\
\hline $\begin{array}{l}\text { Park, Ribiere, \& } \\
\text { Schulte, (2004) }\end{array}$ & 26 & $\mathrm{X}$ & & $\mathrm{X}$ & $\mathrm{X}$ & & & & \\
\hline Schlaerth, (2014) & 55 & $\mathrm{X}$ & $\mathrm{X}$ & & & $\mathrm{X}$ & $\mathrm{X}$ & $\mathrm{X}$ & $\mathrm{X}$ \\
\hline Nibler \& Harris, (2003) & 100 & $\mathrm{X}$ & $\mathrm{X}$ & $\mathrm{X}$ & $\mathrm{X}$ & & & & \\
\hline $\begin{array}{l}\text { Simons \& Peterson, } \\
(2000)\end{array}$ & 70 & $\mathrm{X}$ & $\mathrm{X}$ & $\mathrm{X}$ & $\mathrm{X}$ & $\mathrm{X}$ & $\mathrm{X}$ & & \\
\hline Huang, (2010) & 120 & $\mathrm{X}$ & $\mathrm{X}$ & $\mathrm{X}$ & $\mathrm{X}$ & $\mathrm{X}$ & & $\mathrm{X}$ & \\
\hline
\end{tabular}


Table 2

Meta-Analysis Results for Team-Oriented Culture and Outcome-Oriented Culture with Intragroup Conflict Types

\begin{tabular}{|c|c|c|c|c|c|c|c|c|c|c|c|c|c|}
\hline Predictor & Conflict Type & $k$ & $N$ & $r$ & $\rho$ & $S D \rho$ & $\%$ SEV & $\begin{array}{c}80 \% \\
\text { credibility } \\
\text { interval }\end{array}$ & $\begin{array}{c}95 \% \\
\text { confidence } \\
\text { interval }\end{array}$ & CMA 5 & $\%$ & CMA $10 \%$ & $\%$ \\
\hline Team-Oriented Culture & Relationship Conflict & 31 & 2,616 & -0.25 & -0.29 & 0.21 & $24.2 \%$ & $-0.56,-0.02$ & $-0.38,-0.21$ & -0.29 & $0.15 \%$ & -0.41 & $-39.62 \%$ \\
\hline Team-Oriented Culture & Task Conflict & 25 & 2,102 & -0.11 & -0.13 & 0.30 & $15.67 \%$ & $-0.51,0.25$ & $-0.26,-0.01$ & -0.32 & $141.42 \%$ & -0.36 & $168.14 \%$ \\
\hline Outcome-Oriented Culture & Relationship Conflict & 29 & 2,336 & 0.15 & 0.18 & 0.39 & $10.62 \%$ & $-0.32,0.67$ & $0.03,0.33$ & 0.23 & $30.17 \%$ & 0.21 & $-18.68 \%$ \\
\hline Outcome-Oriented Culture & Task Conflict & 24 & 1,909 & 0.15 & 0.18 & 0.33 & $13.91 \%$ & $-0.24,0.60$ & $0.04,0.32$ & 0.17 & $7.08 \%$ & 0.07 & $61.11 \%$ \\
\hline
\end{tabular}

Note. $k=$ number of effect sizes; $N=$ total sample size; $r=$ sample size weighted mean of the observed correlations; $\rho=$ estimated true-score correlation; $S D \rho$ $=$ estimated standard deviation of $\rho ; \% \mathrm{SEV}=$ percentage of variance due to sampling error; artifact distribution corrections are carried out using the methods described in Hunter and Schmidt (2004). Confidence intervals were computed using the methods reported in Viswesvaran, Schmidt, and Ones (2002), also described in Schmidt \& Hunter (2015). Cumulative meta-analysis is run as a test of publication bias. Two alternate estimates are reported: the effect from the studies with the (1) $5 \%$ and (2) 10\% largest sample sizes. To aid in interpretation, \% difference between overall estimate and CMA estimates are reported as additional indicators. 
Table 3

WLS Regression Analyses with Sample Demographic Diversity and Culture as Predictor Variables and Relationship Conflict as Criterion Variable

\begin{tabular}{|c|c|c|c|c|c|c|c|c|}
\hline Predictor & $B$ & $S E B$ & $\beta$ & $t$ & $p$ & $\begin{array}{c}95 \% \text { confidence } \\
\text { interval }\end{array}$ & $R^{2}$ & $k$ \\
\hline Gender Diversity & .51 & .17 & .30 & 7.23 & .00 & $0.23,0.79$ & .05 & 18 \\
\hline Team-Oriented Culture & -.59 & .23 & -.29 & -4.42 & .00 & $-0.97,-0.21$ & & \\
\hline Gender X Team-Oriented Culture & -.73 & .13 & -.56 & -6.12 & .00 & $-0.94,-0.52$ & & \\
\hline Gender Diversity & .56 & .26 & .46 & 3.96 & .00 & $0.13,0.99$ & .07 & 19 \\
\hline Outcome-Oriented Culture & .36 & .16 & .10 & 2.76 & .03 & $0.10,0.62$ & & \\
\hline Gender X Outcome-Oriented Culture & .73 & .32 & .56 & 3.19 & .02 & $0.20,1.26$ & & \\
\hline Racial Diversity & 1.49 & .19 & .81 & 12.90 & .00 & $1.18,1.80$ & .35 & 11 \\
\hline Team-Oriented Culture & -.59 & .16 & -.45 & -3.71 & .01 & $-0.85,-0.33$ & & \\
\hline Race X Team-Oriented Culture & -.58 & .15 & -.44 & -3.13 & .02 & $-0.83,-0.33$ & & \\
\hline Racial Diversity & 1.12 & .30 & .70 & 10.39 & .00 & $0.63,1.61$ & .07 & 10 \\
\hline Outcome-Oriented Culture & .81 & .16 & .61 & 4.94 & .00 & $0.55,1.07$ & & \\
\hline Race X Outcome-Oriented Culture & .67 & .18 & .47 & 4.58 & .00 & $0.37,0.97$ & & \\
\hline Age Diversity & .21 & .11 & .58 & 2.45 & .03 & $0.03,0.39$ & .52 & 14 \\
\hline Team-Oriented Culture & -.71 & .23 & -.65 & -5.59 & .00 & $-1.09,-0.33$ & & \\
\hline Age X Team-Oriented Culture & -.30 & .16 & -.31 & -2.58 & .03 & $-0.57,-0.04$ & & \\
\hline Age Diversity & .06 & .21 & .76 & 4.56 & .00 & $-0.29,0.41$ & .20 & 16 \\
\hline Outcome-Oriented Culture & .54 & .16 & .16 & 6.65 & .00 & $0.28,0.80$ & & \\
\hline Age X Outcome-Oriented Culture & .39 & .17 & .21 & 2.91 & .03 & $0.11,0.67$ & & \\
\hline Organizational Tenure Diversity & .72 & .27 & .49 & 6.46 & .01 & $0.28,1.16$ & .65 & 12 \\
\hline Team-Oriented Culture & -.19 & .26 & -.13 & -0.63 & .53 & $-0.62,0.24$ & & \\
\hline Organizational Tenure X Team-Oriented Culture & -.69 & .32 & -.62 & -12.20 & .00 & $-1.22,-0.16$ & & \\
\hline Organizational Tenure Diversity & .55 & .13 & .58 & 8.54 & .00 & $0.34,0.76$ & .61 & 10 \\
\hline Outcome-Oriented Culture & .28 & .26 & .25 & 4.69 & .00 & $-0.15,0.71$ & & \\
\hline Organizational Tenure X Outcome-Oriented Culture & .43 & .20 & .36 & 2.58 & .04 & $0.10,0.76$ & & \\
\hline
\end{tabular}

Note. $\quad k=$ number of effect sizes; $B=$ unstandardized regression coefficient, $S E B=$ standard error of unstandardized coefficient, $\beta=$ standardized regression coefficient. 
Table 4

WLS Regression Analyses with Team-Oriented Culture and Outcome-Oriented Culture Predictor Variables and Conflict Cooccurrence as the Criterion Variable

\begin{tabular}{|c|c|c|c|c|c|c|c|c|}
\hline Predictor & $B$ & $S E B$ & $\beta$ & $t$ & $p$ & $\begin{array}{l}95 \% \text { confidence } \\
\text { interval }\end{array}$ & $R^{2}$ & $k$ \\
\hline $\begin{array}{l}\text { Constant } \\
\text { Team-Oriented Culture }\end{array}$ & $\begin{array}{l}.50 \\
-.22\end{array}$ & $\begin{array}{l}.02 \\
.03\end{array}$ & $\begin{array}{r}.00 \\
-.19\end{array}$ & $\begin{array}{c}25.16 \\
5.43\end{array}$ & $\begin{array}{l}.00 \\
.00\end{array}$ & $\begin{array}{c}0.47,0.53 \\
-0.27,-0.17\end{array}$ & .04 & 23 \\
\hline $\begin{array}{l}\text { Constant } \\
\text { Outcome-Oriented Culture }\end{array}$ & $\begin{array}{l}.93 \\
.63\end{array}$ & $\begin{array}{l}.03 \\
.05\end{array}$ & $\begin{array}{l}.00 \\
.27\end{array}$ & $\begin{array}{l}33.09 \\
11.90\end{array}$ & $\begin{array}{l}.00 \\
.00\end{array}$ & $\begin{array}{l}0.88,0.98 \\
0.55,0.71\end{array}$ & .08 & 19 \\
\hline
\end{tabular}

Note. $k=$ number of effect sizes; $B=$ unstandardized regression coefficient, $S E B=$ standard error of unstandardized coefficient, $\beta=$ standardized regression coefficient. 
Table 5

Categorical Subgroup Analysis Results of the Associations between Team-Oriented Culture and Outcome-Oriented Culture with Conflict Co-Occurrence

\begin{tabular}{|c|c|c|c|c|c|c|c|c|c|c|c|c|c|}
\hline Culture Predictor & Culture Level & $k$ & $N$ & $r$ & $\rho$ & $S D \rho$ & $\% \mathrm{SEV}$ & $\begin{array}{c}80 \% \\
\text { credibility } \\
\text { interval }\end{array}$ & $\begin{array}{c}95 \% \\
\text { confidence } \\
\text { interval }\end{array}$ & CMA 5 & $\%$ & CMA $10 \%$ & $\%$ \\
\hline $\begin{array}{l}\text { Overall } \\
\text { Conflict } \\
\text { Co-Occurrence }\end{array}$ & Overall & 25 & 2,161 & 0.52 & 0.61 & 0.28 & $9.76 \%$ & $0.25,0.97$ & $0.50,0.73$ & 0.71 & $-16.59 \%$ & 0.73 & $-19.59 \%$ \\
\hline \multirow[t]{2}{*}{$\begin{array}{l}\text { Team- } \\
\text { Oriented Culture }\end{array}$} & $\begin{array}{l}\text { High Team-Oriented } \\
\text { Culture }\end{array}$ & 12 & 1,054 & 0.49 & 0.58 & 0.21 & $17.01 \%$ & $0.31,0.85$ & $0.45,0.71$ & 0.60 & $-3.18 \%$ & 0.66 & $-13.51 \%$ \\
\hline & $\begin{array}{l}\text { Low Team-Oriented } \\
\text { Culture }\end{array}$ & 11 & 864 & 0.58 & 0.68 & 0.20 & $15.74 \%$ & $0.42,0.94$ & $0.55,0.81$ & 0.65 & $4.28 \%$ & 0.73 & $-6.98 \%$ \\
\hline \multirow[t]{2}{*}{$\begin{array}{l}\text { Outcome-Oriented } \\
\text { Culture }\end{array}$} & $\begin{array}{l}\text { High Outcome-Oriented } \\
\text { Culture }\end{array}$ & 10 & 782 & 0.62 & 0.72 & 0.19 & $15.25 \%$ & $0.47,0.97$ & $0.59,0.85$ & 0.71 & $2.08 \%$ & 0.93 & $-28.89 \%$ \\
\hline & $\begin{array}{l}\text { Low Outcome-Oriented } \\
\text { Culture }\end{array}$ & 9 & 743 & 0.51 & 0.61 & 0.14 & $32.86 \%$ & $0.42,0.77$ & $0.50,0.72$ & 0.59 & $1.40 \%$ & 0.66 & $-9.91 \%$ \\
\hline
\end{tabular}

Note. $k=$ number of effect sizes; $N=$ total sample size; $r=$ sample size weighted mean of the observed correlations; $\rho=$ estimated true-score correlation; $S D \rho$ $=$ estimated standard deviation of $\rho ; \% \mathrm{SEV}=$ percentage of variance due to sampling error; artifact distribution corrections are carried out using the methods described in Hunter and Schmidt (2004). Confidence intervals were computed using the methods reported in Viswesvaran, Schmidt, and Ones (2002); also described in Schmidt \& Hunter (2015). Cumulative meta-analysis is run as a test of publication bias. Two alternate estimates are reported: the effect from the studies with the (1) 5\% and (2) 10\% largest sample sizes. To aid in interpretation, \% difference between overall estimate and CMA estimates are reported as additional indicators. 
Table 6

WLS Regression Analyses with Sample Demographic Diversity and Culture as Predictor Variables and Task Conflict as the Criterion Variable

\begin{tabular}{|c|c|c|c|c|c|c|c|c|}
\hline Predictor & $B$ & $S E B$ & $\beta$ & $t$ & $p$ & $\begin{array}{c}95 \% \text { confidence } \\
\text { interval }\end{array}$ & $R^{2}$ & $k$ \\
\hline $\begin{array}{l}\text { Gender Diversity } \\
\text { Team-Oriented Culture } \\
\text { Gender X Team-Oriented Culture }\end{array}$ & $\begin{array}{l}.24 \\
-.47 \\
-.61\end{array}$ & $\begin{array}{l}.08 \\
.16 \\
.21\end{array}$ & $\begin{array}{l}.21 \\
-.34 \\
-.43\end{array}$ & $\begin{array}{c}3.81 \\
-6.64 \\
-4.24\end{array}$ & $\begin{array}{l}.03 \\
.00 \\
.00\end{array}$ & $\begin{array}{rr}0.11, & 0.37 \\
-0.73, & -0.21 \\
-0.96, & -0.26\end{array}$ & .12 & 18 \\
\hline $\begin{array}{l}\text { Gender Diversity } \\
\text { Outcome-Oriented Culture } \\
\text { Gender X Outcome-Oriented Culture }\end{array}$ & $\begin{array}{l}.95 \\
.58 \\
.55\end{array}$ & $\begin{array}{l}.36 \\
.14 \\
.20\end{array}$ & $\begin{array}{l}.77 \\
.59 \\
.51\end{array}$ & $\begin{array}{l}2.60 \\
4.16 \\
2.73\end{array}$ & $\begin{array}{l}.02 \\
.00 \\
.02\end{array}$ & $\begin{array}{l}0.36,1.54 \\
0.35,0.81 \\
0.22,0.88\end{array}$ & .13 & 19 \\
\hline $\begin{array}{l}\text { Racial Diversity } \\
\text { Team-Oriented Culture } \\
\text { Race X Team-Oriented Culture }\end{array}$ & $\begin{array}{r}1.57 \\
-.72 \\
-1.65\end{array}$ & $\begin{array}{l}.91 \\
.05 \\
.45\end{array}$ & $\begin{array}{l}1.67 \\
-.95 \\
-.84\end{array}$ & $\begin{array}{l}2.93 \\
-13.75 \\
-4.71\end{array}$ & $\begin{array}{l}.04 \\
.00 \\
.00\end{array}$ & $\begin{array}{r}0.07,3.07 \\
-0.80,-0.64 \\
-2.39,-0.91\end{array}$ & .76 & 11 \\
\hline $\begin{array}{l}\text { Racial Diversity } \\
\text { Outcome-Oriented Culture } \\
\text { Race X Outcome-Oriented Culture }\end{array}$ & $\begin{array}{r}1.27 \\
.87 \\
1.45\end{array}$ & $\begin{array}{l}.25 \\
.24 \\
.52\end{array}$ & $\begin{array}{l}.89 \\
.89 \\
.87\end{array}$ & $\begin{array}{l}5.04 \\
3.60 \\
4.67\end{array}$ & $\begin{array}{l}.00 \\
.00 \\
.00\end{array}$ & $\begin{array}{l}0.86,1.68 \\
0.48,1.26 \\
0.59,2.31\end{array}$ & .22 & 10 \\
\hline $\begin{array}{l}\text { Age Diversity } \\
\text { Outcome-Oriented Culture } \\
\text { Age X Outcome-Oriented Culture }\end{array}$ & $\begin{array}{l}.07 \\
.90 \\
.71\end{array}$ & $\begin{array}{l}.23 \\
.14 \\
.30\end{array}$ & $\begin{array}{l}.88 \\
.89 \\
.65\end{array}$ & $\begin{array}{l}2.19 \\
6.32 \\
2.84\end{array}$ & $\begin{array}{l}.06 \\
.00 \\
.02\end{array}$ & $\begin{array}{l}-0.31,0.45 \\
0.67,1.13 \\
0.22,1.20\end{array}$ & .21 & 16 \\
\hline $\begin{array}{l}\text { Organizational Tenure Diversity } \\
\text { Team-Oriented Culture } \\
\text { Organizational Tenure X Team-Oriented Culture }\end{array}$ & $\begin{array}{r}.79 \\
-1.02 \\
-1.13\end{array}$ & $\begin{array}{l}.23 \\
.38 \\
.46\end{array}$ & $\begin{array}{l}.74 \\
-.81 \\
-.91\end{array}$ & $\begin{array}{l}3.13 \\
-5.61 \\
-5.21\end{array}$ & $\begin{array}{l}.00 \\
.00 \\
.00\end{array}$ & $\begin{array}{l}0.41,1.17 \\
-1.65,-0.39 \\
-1.89,-0.37\end{array}$ & .82 & 11 \\
\hline $\begin{array}{l}\text { Organizational Tenure Diversity } \\
\text { Outcome-Oriented Culture } \\
\text { Organizational Tenure X Outcome-Oriented Culture }\end{array}$ & $\begin{array}{l}.08 \\
.42 \\
.71\end{array}$ & $\begin{array}{l}.13 \\
.19 \\
.24\end{array}$ & $\begin{array}{l}.07 \\
.41 \\
.56\end{array}$ & $\begin{array}{l}3.13 \\
2.84 \\
4.48\end{array}$ & $\begin{array}{l}.01 \\
.03 \\
.00\end{array}$ & $\begin{array}{r}-0.13,0.29 \\
0.11,0.73 \\
0.32,1.10\end{array}$ & .87 & 10 \\
\hline
\end{tabular}

Note. $k=$ number of effect sizes; $B=$ unstandardized regression coefficient, $S E B=$ standard error of unstandardized coefficient, $\beta=$ standardized regression coefficient. 
Table 7

Cumulative Meta-Analyses Iteration Results Reported between Team-Oriented Culture and Relationship Conflict

\begin{tabular}{|c|c|c|c|}
\hline$\#$ & $N$ & $r$ & $\rho$ \\
\hline 1 & 200 & -0.12 & -0.14 \\
\hline 2 & 386 & -0.22 & -0.26 \\
\hline 3 & 517 & -0.35 & -0.41 \\
\hline 4 & 645 & -0.26 & -0.31 \\
\hline 5 & 771 & -0.25 & -0.29 \\
\hline 6 & 896 & -0.23 & -0.27 \\
\hline 7 & 1019 & -0.20 & -0.24 \\
\hline 8 & 1139 & -0.23 & -0.27 \\
\hline 9 & 1259 & -0.24 & -0.29 \\
\hline 10 & 1367 & -0.23 & -0.27 \\
\hline 11 & 1468 & -0.24 & -0.28 \\
\hline 12 & 1567 & -0.22 & -0.26 \\
\hline 13 & 1663 & -0.22 & -0.26 \\
\hline 14 & 1751 & -0.22 & -0.26 \\
\hline 15 & 1839 & -0.23 & -0.26 \\
\hline 16 & 1916 & -0.23 & -0.27 \\
\hline 17 & 1986 & -0.24 & -0.28 \\
\hline 18 & 2055 & -0.23 & -0.27 \\
\hline 19 & 2120 & -0.24 & -0.28 \\
\hline 20 & 2177 & -0.25 & -0.29 \\
\hline 21 & 2234 & -0.25 & -0.29 \\
\hline 22 & 2290 & -0.24 & -0.29 \\
\hline 23 & 2345 & -0.25 & -0.29 \\
\hline 24 & 2398 & -0.25 & -0.30 \\
\hline 25 & 2449 & -0.25 & -0.29 \\
\hline 26 & 2490 & -0.25 & -0.29 \\
\hline 27 & 2523 & -0.25 & -0.29 \\
\hline 28 & 2555 & -0.25 & -0.29 \\
\hline 29 & 2582 & -0.25 & -0.29 \\
\hline 30 & 2602 & -0.25 & -0.29 \\
\hline 31 & 2616 & -0.25 & -0.29 \\
\hline
\end{tabular}

Note. Cumulative meta-analysis iterations are reported for each iteration in the distribution in descending order of sample size for each of the 31 independent studies with the estimates of $r$ and $\rho$ for each iteration to allow for the analysis of potential positive drift and aid in visual interpretation. $N=$ total sample size; $r=$ sample size weighted mean of the observed correlations; $\rho=$ estimated true-score correlation; \# = cumulative meta-analysis iteration number. 
Table 8

Cumulative Meta-Analysis Iteration Results Reported between Team-Oriented Culture and Task Conflict

\begin{tabular}{|c|c|c|c|}
\hline$\#$ & $N$ & $r$ & $\rho$ \\
\hline 1 & 200 & -0.25 & -0.30 \\
\hline 2 & 386 & -0.23 & -0.27 \\
\hline 3 & 517 & -0.30 & -0.36 \\
\hline 4 & 646 & -0.28 & -0.33 \\
\hline 5 & 772 & -0.27 & -0.32 \\
\hline 6 & 895 & -0.23 & -0.27 \\
\hline 7 & 1015 & -0.22 & -0.26 \\
\hline 8 & 1123 & -0.20 & -0.24 \\
\hline 9 & 1214 & -0.15 & -0.18 \\
\hline 10 & 1302 & -0.14 & -0.16 \\
\hline 11 & 1390 & -0.14 & -0.16 \\
\hline 12 & 1467 & -0.13 & -0.15 \\
\hline 13 & 1544 & -0.14 & -0.17 \\
\hline 14 & 1614 & -0.15 & -0.18 \\
\hline 15 & 1683 & -0.15 & -0.18 \\
\hline 16 & 1741 & -0.13 & -0.15 \\
\hline 17 & 1798 & -0.14 & -0.17 \\
\hline 18 & 1854 & -0.13 & -0.15 \\
\hline 19 & 1907 & -0.13 & -0.16 \\
\hline 20 & 1958 & -0.14 & -0.16 \\
\hline 21 & 2001 & -0.13 & -0.15 \\
\hline 22 & 2042 & -0.12 & -0.15 \\
\hline 23 & 2068 & -0.11 & -0.14 \\
\hline 24 & 2088 & -0.11 & -0.13 \\
\hline 25 & 2102 & -0.11 & -0.13 \\
\hline
\end{tabular}

Note. Cumulative meta-analysis iterations are reported for each iteration in the distribution in descending order of sample size for each of the 25 independent studies with the estimates of $r$ and $\rho$ for each iteration to allow for the analysis of potential positive drift and aid in visual interpretation. $N=$ total sample size; $r=$ sample size weighted mean of the observed correlations; $\rho=$ estimated true-score correlation; \# = cumulative meta-analysis iteration number. 
Table 9

Cumulative Meta-Analysis Iteration Results Reported Between Outcome-Oriented Culture and Relationship Conflict

\begin{tabular}{cccc}
\hline$\#$ & $N$ & $r$ & $\rho$ \\
\hline 1 & 200 & -0.03 & -0.04 \\
2 & 331 & 0.27 & 0.32 \\
3 & 459 & 0.17 & 0.21 \\
4 & 585 & 0.20 & 0.24 \\
5 & 710 & 0.19 & 0.23 \\
6 & 833 & 0.14 & 0.17 \\
7 & 953 & 0.20 & 0.24 \\
8 & 1073 & 0.11 & 0.14 \\
9 & 1174 & 0.09 & 0.11 \\
10 & 1273 & 0.08 & 0.10 \\
11 & 1369 & 0.08 & 0.10 \\
12 & 1462 & 0.11 & 0.13 \\
13 & 1553 & 0.13 & 0.16 \\
14 & 1641 & 0.11 & 0.14 \\
15 & 1729 & 0.13 & 0.16 \\
16 & 1799 & 0.12 & 0.15 \\
17 & 1868 & 0.14 & 0.17 \\
18 & 1933 & 0.14 & 0.18 \\
19 & 1991 & 0.15 & 0.18 \\
20 & 2048 & 0.14 & 0.17 \\
21 & 2099 & 0.14 & 0.17 \\
22 & 2140 & 0.14 & 0.18 \\
23 & 2181 & 0.13 & 0.16 \\
\hline
\end{tabular}

Note. Cumulative meta-analysis iterations are reported for each iteration in the distribution in descending order of sample size for each of the 23 independent studies with the estimates of $r$ and $\rho$ for each iteration to allow for the analysis of potential positive drift and aid in visual interpretation. $N=$ total sample size; $r=$ sample size weighted mean of the observed correlations; $\rho=$ estimated true-score correlation; \# = cumulative meta-analysis iteration number 
Table 10

Cumulative Meta-Analysis Iteration Results of the Co-Occurrence of Task Conflict and Relationship Conflict

\begin{tabular}{|c|c|c|c|}
\hline \# & $N$ & $r$ & $\rho$ \\
\hline 1 & 200 & 0.56 & 0.66 \\
\hline 2 & 386 & 0.59 & 0.69 \\
\hline 3 & 517 & 0.62 & 0.73 \\
\hline 4 & 643 & 0.66 & 0.77 \\
\hline 5 & 766 & 0.61 & 0.71 \\
\hline 6 & 886 & 0.60 & 0.71 \\
\hline 7 & 1006 & 0.60 & 0.70 \\
\hline 8 & 1114 & 0.62 & 0.73 \\
\hline 9 & 1207 & 0.56 & 0.66 \\
\hline 10 & 1298 & 0.56 & 0.65 \\
\hline 11 & 1386 & 0.55 & 0.65 \\
\hline 12 & 1474 & 0.53 & 0.63 \\
\hline 13 & 1551 & 0.50 & 0.59 \\
\hline 14 & 1621 & 0.51 & 0.59 \\
\hline 15 & 1690 & 0.51 & 0.60 \\
\hline 16 & 1755 & 0.52 & 0.61 \\
\hline 17 & 1813 & 0.52 & 0.61 \\
\hline 18 & 1870 & 0.52 & 0.61 \\
\hline 19 & 1926 & 0.51 & 0.60 \\
\hline 20 & 1979 & 0.51 & 0.60 \\
\hline 21 & 2030 & 0.52 & 0.61 \\
\hline 22 & 2071 & 0.52 & 0.61 \\
\hline 23 & 2112 & 0.53 & 0.62 \\
\hline 24 & 2141 & 0.53 & 0.62 \\
\hline 25 & 2161 & 0.52 & 0.61 \\
\hline
\end{tabular}

Note. Cumulative meta-analysis iterations are reported for each iteration in the distribution in descending order of sample size for each of the 25 independent studies with the estimates of $r$ and $\rho$ for each iteration to allow for the analysis of potential positive drift and aid in visual interpretation. $N=$ total sample size; $r=$ sample size weighted mean of the observed correlations; $\rho=$ estimated true-score correlation; \# = cumulative meta-analysis iteration number 


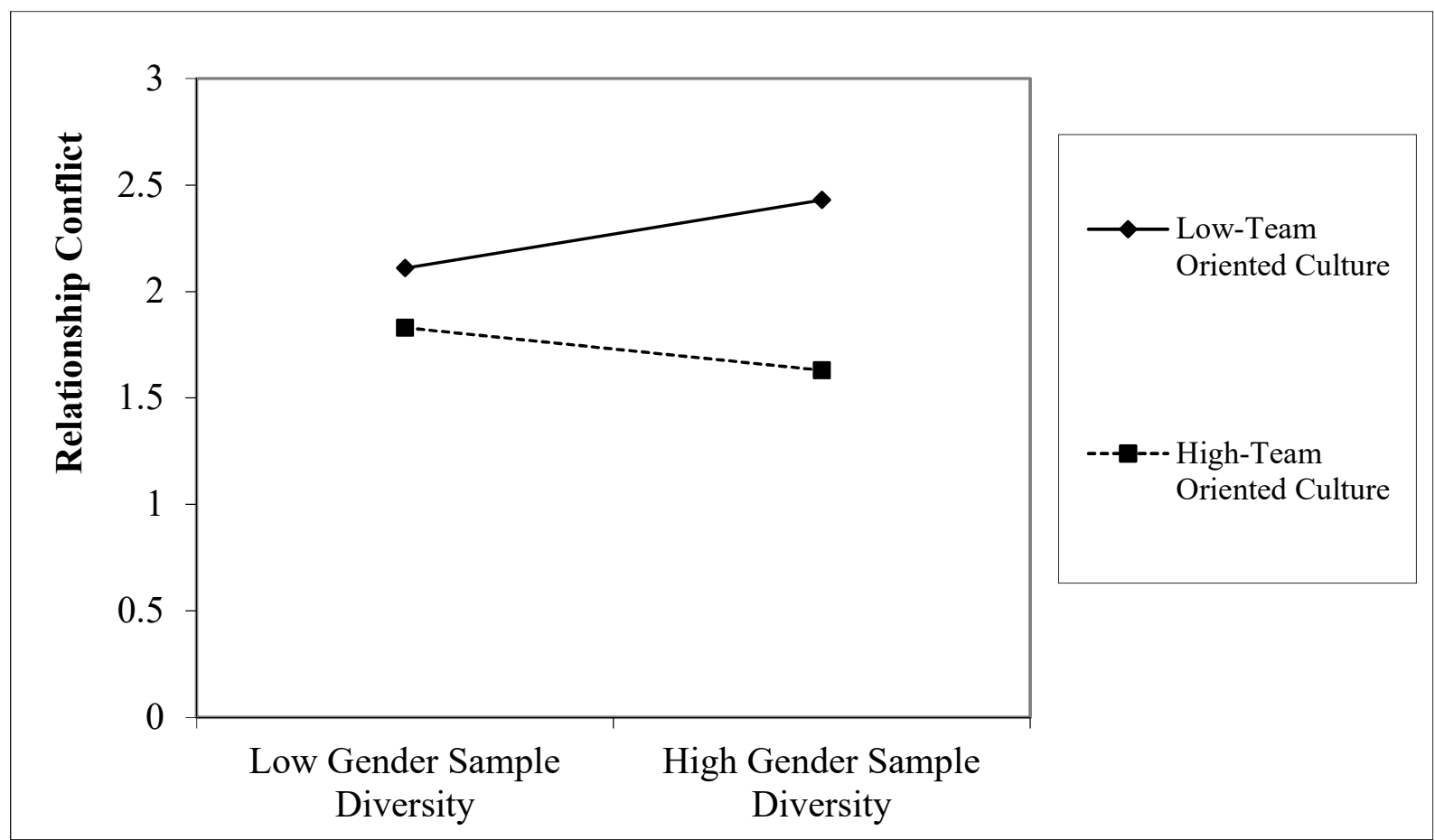

Figure 1. Interaction between team-oriented culture and sample gender diversity on relationship conflict. 


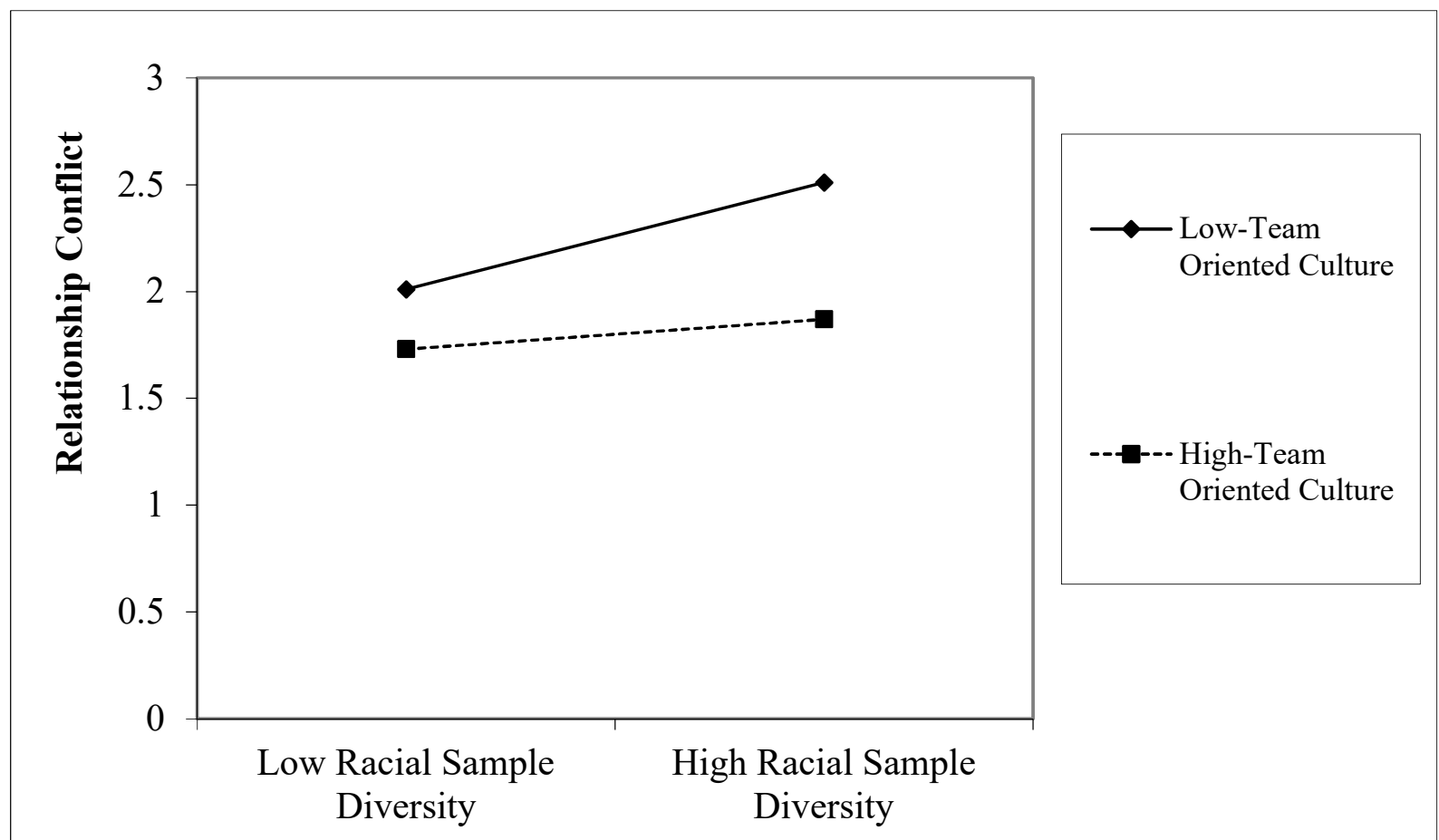

Figure 2. Interaction between team-oriented culture and sample racial diversity on relationship conflict. 


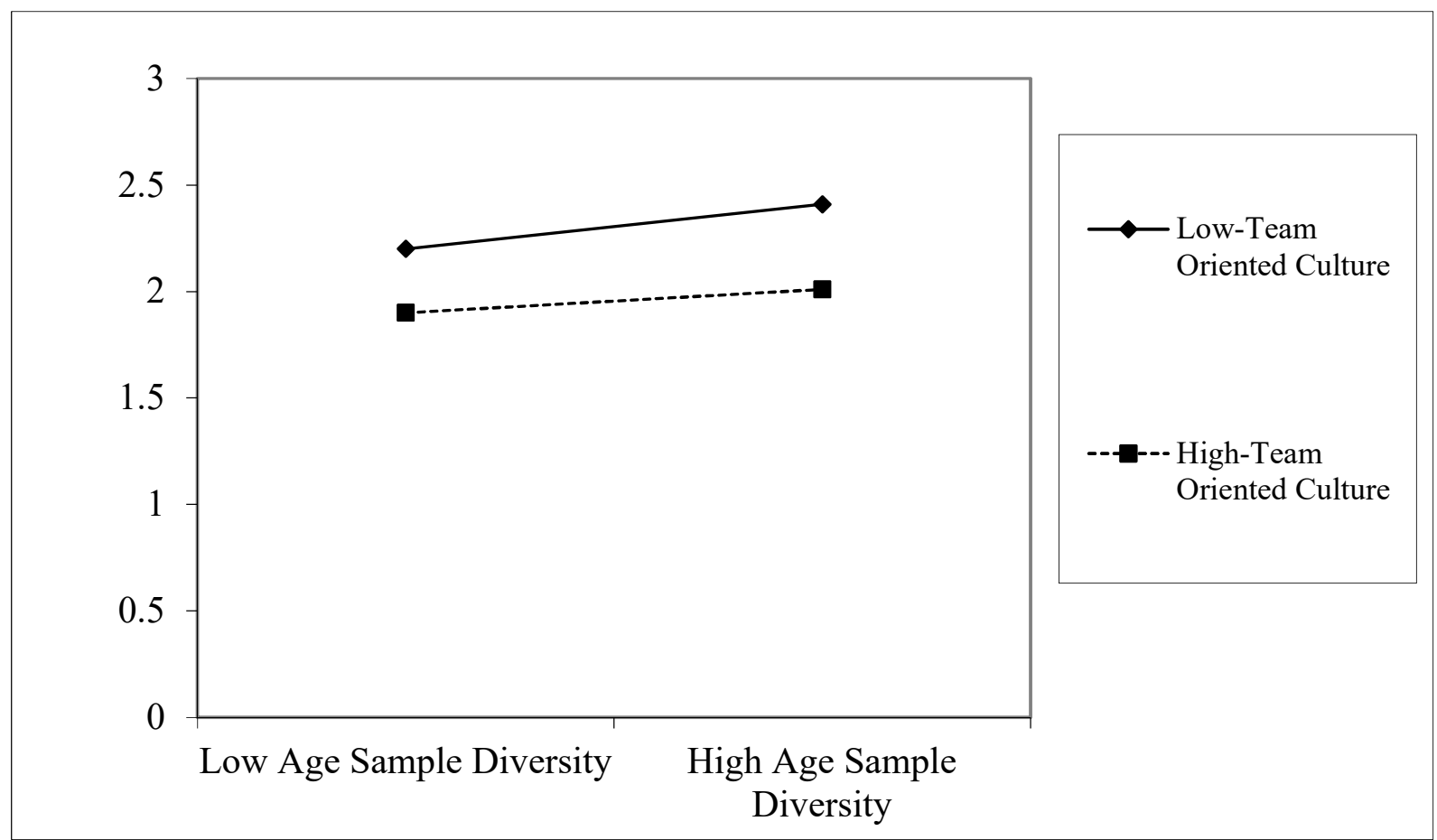

Figure 3. Interaction between team-oriented culture and sample age diversity on relationship conflict. 


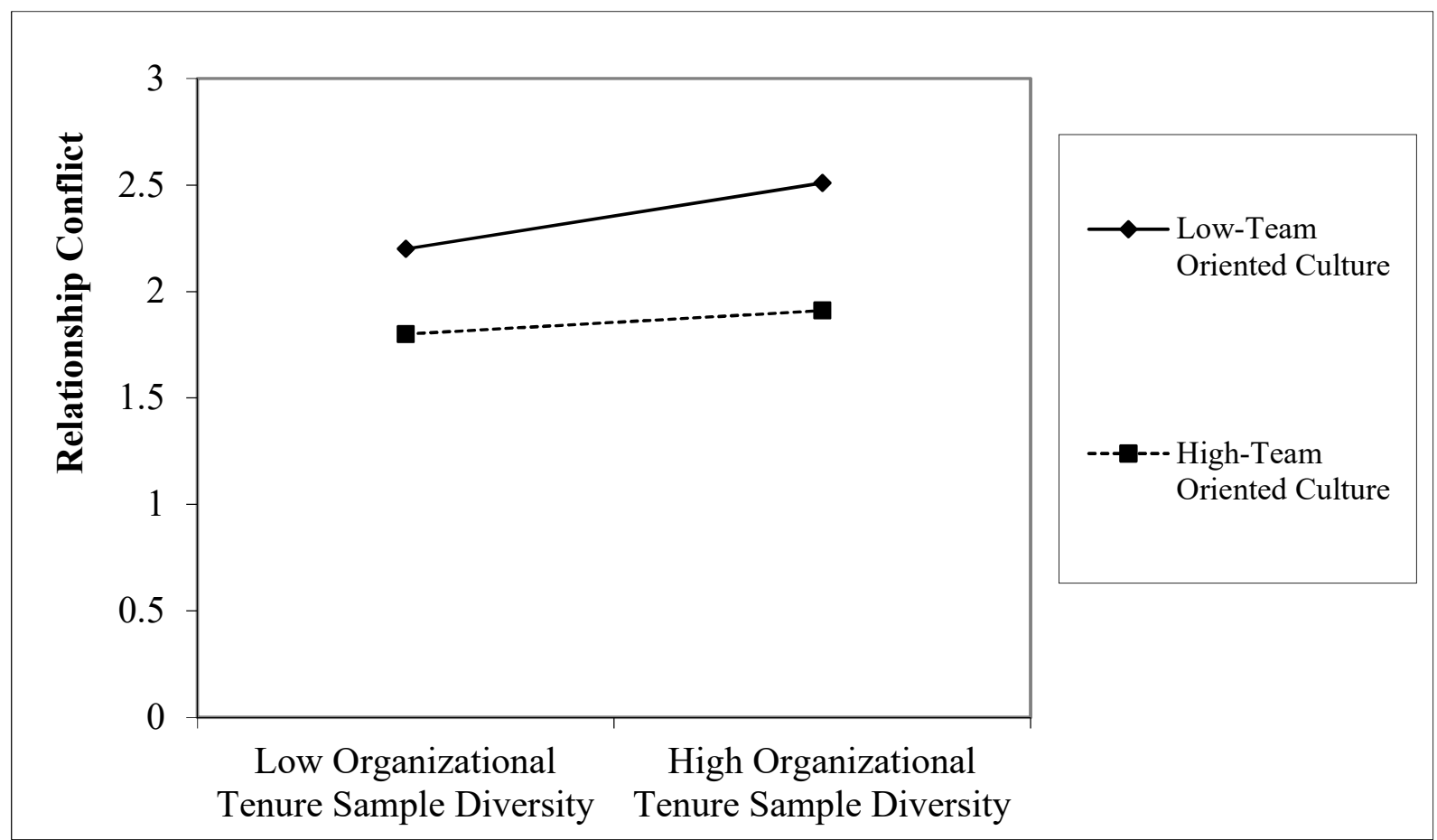

Figure 4. Interaction between team-oriented culture and sample organizational tenure diversity on relationship conflict. 
VITA

\section{RYAN JACOBSON}

\section{EDUCATION}

Present

Doctoral Candidate, Industrial and Organizational Psychology, Florida International University, Miami, FL

2016

M.S., Industrial and Organizational Psychology, Florida International University, Miami, FL 2016

2013

Bachelor of Social Work, Psychology Minor, University of Missouri, St. Louis, MO, 2013

\section{ACADEMIC PUBLICATIONS AND PRESENTATIONS IN DISCIPLINE}

Eaton, A. A., Saunders, J., Jacobson, R., \& West, K. (accepted for publication). How gender and race stereotypes impact the advancement of scholars in STEM: Professors' biased evaluations of physics and biology post-doctoral candidates. Sex Roles.

Jacobson, R. K., \& Eaton, A. A. (2017). How organizational policies influence bystander likelihood of reporting moderate and severe sexual harassment at work. Employee Responsibilities and Rights Journal, 1-26.https://doi.org/10.1007/s10672-017-9309-1

Jacobson, R. K., \& Viswesvaran, C. (2017). A reliability generalization study of the political skill inventory. Sage Open, 7(3). doi: https://doi.org/10.1177/2158244017706714.

Jacobson, R., \& Eaton, A. A. (2017, April). How organizational policies influence the likelihood of reporting coworker perpetrated sexual harassment. Poster presented at the annual conference of the Society for Industrial and Organizational Psychology, Orlando, FL.

Paustian-Underdahl, S., Manderville, A., Eaton, A.A., Jacobson, R., \& Quiroz, V. (2016, April). Investigating pregnancy disclosures at work via discontinuous change modeling. Symposium presented at the annual conference of the Society for Industrial and Organizational Psychology, Anaheim, CA.

Jacobson, R., Eaton, A. A., \& Zimmerman, A. (2016, April). How organizational policies influence the likelihood of reporting sexual harassment. Poster presented at the annual convention of the Society for Industrial and Organizational Psychology, in Anaheim, CA.

Jacobson, R., \& Eaton, A. A. (2015, November). How organizational policies influence the reporting likelihood of sexual harassment. Oral presentation given at the 16th annual Women, Sexuality, and Gender Student Association Conference, FIU, Miami, FL. 
Jacobson, R., \& Eaton, A. A. (2014, November). The effect of stereotypes on the success of women and minorities in STEM. Oral presentation given at the 15th annual Women, Sexuality, and Gender Student Association Conference, FIU, Miami, FL.

Cox, J., Jacobson, R. K., Pensoneau, D., Morton, J., \& Casad, B. J. (2014, April) Mapping Emotion to Cardiovascular Threat and Challenge during Motivated Performance. Presented at Inaugural Society of Affective Sciences Conference in April 26, 2014 at Washington D.C., MD. 